\title{
Die Eposdebatte um 180o und ihre gattungstheoretischen Problemstellungen
}

Bis hierhin hat sich bereits abgezeichnet, dass die rigiden Kategorien und Zugriffe der regelbasierten Gattungstheorie den Veränderungen im Kunstsystem an der Epochenschwelle nicht mehr gerecht werden und dass dieser Geltungsverlust gerade am Gegenstand des Epos besonders augenfällig thematisiert und reflektiert wird. Darauf vermögen die bereits ab Mitte des 18. Jahrhunderts einsetzende Fragmentarisierung der Gattung sowie die um 180o fast explosionsartige Ausbreitung gattungspoetologischer Abhandlungen zum Epos ${ }^{1} \mathrm{zu}$ verweisen. Zudem hat sich gezeigt, dass Goethe den epistemologischen Wandel - der Fragmentierung des Wissens, der Pluralisierung der Wissenssysteme und der Beschleunigung der medialen Wissensverbreitung - bereits in dieser frühen Phase des Klassizismus nicht nur seismographisch wahrnimmt und kritisch beleuchtet, sondern auch produktiv $\mathrm{zu}$ machen versucht. Die These eines wandelbaren Klassizismus mit einer unsicheren epistemologischen Verfasstheit scheint sich also zu bestätigen und soll nun entlang der Eposdebatte weiterverfolgt werden.

Im Weiteren wird es deshalb darum gehen, Goethes explorative Epistemologie als alternativen Zugang zum allgemeinen Gattungsdenken der Epochenschwelle und Goethes spezifische Auseinandersetzung mit dem Epos als selbstreflexive Suche nach neuen Beobachtungs- und Beschreibungsmöglichkeiten von literarischen Formen aufzuzeigen. In der Inbezugsetzung der gleichwohl vom klassizistischen Gattungsbegriff wie auch vom Epos traditionell geforderten Eigenschaften der Einheit, Totalität und Abgeschlossenheit einerseits und einer auf Offenheit, Beweglichkeit und Vielfältigkeit ausgerichteten Wissensorganisationen andererseits wird der Anspruch auf normative Formbestimmung - und damit auch die Vorstellung eines in sich ruhenden, abgeschlossenen Kunstwerks - nämlich gerade grundlegend unterlaufen. Bereits im Briefwechsel zwischen Goethe und Schiller, der das Epische immer wieder aus einer anderen Perspektive betrachtet und seine gefährdete Form sowohl im Vergleich mit dem Roman wie auch dem Dramatischen zu fassen versucht, können explorative Erkenntniswege, wie sie Der Versuch als Vermittler methodologisch stark gemacht hat, aufgespürt

1 Vgl. S. XI in diesem Buch.

(C) MIRIAM EGLOFF, 2022 | DOI:10.30965/9783846767054_005

This is an open access chapter distributed under the terms of the CC BY-NC-ND 4.o license. Eg loff - 9783846767054 
werden. Anstatt als normative Konservierungsstrategie lässt sich unter diesem Gesichtspunkt auch die übergreifende Debatte um das epischen Erzählen in der frühen Moderne im Sinne Foucaults ${ }^{2}$ als offener, breit gestreuter und heterogener Diskurs eines lose verbundenen, interagierenden Kollektivs betrachten, zu dem neben Schiller und Goethe auch Friedrich August Wolf, Wilhelm von Humboldt, August Wilhelm und Friedrich Schlegel, Johann Gottfried Herder, Johann Heinrich Voß, Christoph Martin Wieland sowie Christian Friedrich von Blanckenburg gezählt werden können.

Die verschiedenen, auf unterschiedlichen ästhetisch-philosophischen Denkrichtungen beruhenden Äußerungen über das Epos, seine Merkmale und Möglichkeiten will das folgende Kapitel deshalb nicht gegeneinander ausspielen, sondern als jeweils eigenständige, gleichwertige Beiträge nebeneinanderstellen. Diese Perspektivierung ermöglicht es einerseits, darauf hinzuführen, wie die einzelnen Beiträge trotz methodischer und programmatischer Differenzen gemeinsam auf die schwierige Genese einer kulturellen Moderne verweisen. Und zum anderen kann so eine hohe diskursive Energie nachgewiesen werden, die sich die Diskursteilnehmer, allen voran Goethe, auch bewusst zunutze machen.

\subsection{Gattungspoetologie als Gegenwartskritik: Zwischen Epos und Roman}

Der von Goethe und Schiller gemeinsam erarbeitete Aufsatz Über epische und dramatische Dichtung ist wohl der meist zitierte gattungspoetologische Text zum Epos und gilt überhaupt als Schlüsseltext des Klassizismus. Die darin äußerst pointiert zusammengefassten Eigenschaften des Epischen erörtern die beiden Dichter über den Zeitraum von 1795 und 1797 in ihrem Briefwechsel und diese Gesprächs-Konstellation wird hier, wie oben bereits angedeutet, als bedeutsam für die darin umrissene Eposkonzeption angesehen. Im dialogischen Hin und Her des Briefwechsels kommt die mit

2 Der hier wiedergegebene Diskursbegriff orientiert sich an Foucault, Michel: Die Ordnung des Diskurses, mit einem Essay von Ralf Konersmann. Frankfurt a. M.: Fischer 2007. Nach Foucault wird im Diskurs alles reguliert, was zu einem bestimmten Zeitpunkt zu einem bestimmten Thema gesagt bzw. geschrieben werden kann. Der Diskurs etabliert aber auch, was gerade nicht sag- oder schreibbar ist bzw. wer gerade nichts zu sagen oder schreiben hat, und produziert so Wissen - im Sinne von Bewusstseinsinhalten, mit deren Hilfe das Individuum die Wirklichkeit seiner Umgebung gestaltet und deutet - und Machtstrukturen. Diskurse sind also Denksysteme, die Wirklichkeit konstituieren, indem sie durch bestimmte regelhafte Praktiken die Wahrnehmung prägen. 
dem Experimentalfeld strukturelle verwandte Erweiterungsbewegung zum Ausdruck, die sowohl den produktiven Motor der Eposdebatte markiert als auch in der Re-Konzeption des Epischen selbst als grundlegend erscheinen wird. Die Darstellung des Gattungsgesprächs als Sammeln und Vergleichen von vielfältigen, heterogenen Kriterien zeigt, wie sich die Gattungsdefinition die schließlich nichts Anderes ist als eine Gestalt-Bestimmung - bereits zu diesem Zeitpunkt einem direkten Zugriff entzieht. Darauf macht auch Goethe selbst aufmerksam, wenn er die im Briefwechsel erarbeiteten Erkenntnisse schließlich zusammenfasst, den Aufsatz zur Redaktion an Schiller schickt und im dazugehörigen Begleitbrief feststellt, dass ihm beim Versuch, diejenigen Kriterien ausfindig zu machen und zu benennen, die die epische Gattung definieren, vor allem aufgefallen ist, dass „wir Moderne und die Genres so sehr zu vermischen geneigt sind, ja dass wir gar nicht einmal im Stand sind sie von einander zu unterscheiden“3.

Zunächst fällt an dieser Stelle die deutliche Selbstverortung in der Moderne und die damit verbundene Selbstkritik auf, zudem scheint im hier interessierenden Zusammenhang auch die enge Verknüpfung von Zeitbewusstsein und Kulturpessimismus bemerkenswert. Im Kern der Problemdiagnose steht nämlich das Unvermögen, nicht mehr zwischen der Zeit und den Formen der Kunst unterscheiden zu können - in dieser Moderne stellt sich die Kunst als eine amorphe Masse dar, in der gar keine einzelnen Gestalten, keine fassbaren Formen mehr ausgemacht werden können: Eine derartig gestaltlose Kunst taugt auch nicht zur Kulturleistung. Von welch elementarer Bedeutung eine sicht- oder greifbare Form für Goethe spätestens seit seiner Italien-Reise ist, hat bereits die desperate Bemerkung über seine „Rückweisung aus dem formreichen Italien ins gestaltlose Deutschland ${ }^{4}$ angezeigt. Auch in der kleinen Schrift Einfache Nachahmung der Natur, Manier, Styl von 1788 „ruht der Stil“ hier als Begriff der Form - „auf den tiefsten Grundfesten der Erkenntnis, auf dem Wesen der Dinge, insofern uns erlaubt ist, es in sichtbaren und greiflichen Gestalten zu erkennen“. ${ }^{5}$ Damit greift Goethe eine Problematik der Morphologie auf, die sich ihm offenbar gerade auch in Bezug auf die Frage nach dem Epischen als grundsätzlich aufdrängt: Erkenntnis erfordert Fassbarkeit. So gilt also auch für die Kunst, was Goethe in der Morphologie für die Natur festgehalten hat: Sie wird fassbar und dadurch überhaupt erst sinnhaft und kulturfähig, insofern „sie die Reihe der Gestalten übersieht und die verschiedenen charakteristischen Formen nebeneinanderzu stellen und nachzuahmen weiß

3 Goethe an Schiller, 23.12.1797, BW. S. 535.

4 HA 13. S. 101; vgl. S. 80 in diesem Buch.

5 Goethe, Johann Wolfgang: Kunsttheoretische Schriften und Uebersetzungen, Bd. 19. S. 79. 
dann wird der Stil der höchste Grad wohin sie gelangen kann; der Grad, wo sie sich den höchsten menschlichen Bemühungen gleichstellen darf" ${ }^{6}$

Dass Gattungsgrenzen und -gesetze nicht mehr fassbar oder differenzierbar sind, sich also jeglicher Erkenntnis entziehen und damit eine klare, eindeutige Bestimmung des Epischen von vornherein als prekäres Experiment erscheint, diagnostiziert Goethe als problematische Zeiterscheinung: $\mathrm{Zu}$ sehr sind die „heutigen“ Künstler nur darauf bedacht, dem Streben des Publikums nach „völlig wahr[em]“ und „vollkommen Gegenwärtigen“ nachzugeben, anstatt Kunstwerke „innerhalb ihre[r] reinen Bedingungen“ - sprich in einer klaren Gestalt -hervorzubringen. ${ }^{7}$ Dabei ist gerade eine eindeutige, stabile Formgebung die wichtigste, schwierigste und gleichwohl schönste Aufgabe des wahren Künstlers, wie in der Einleitung in die Propyläen festgehalten wird:

Eines der vorzüglichsten Kennzeichen des Verfalles der Kunst ist die Vermischung der verschiedenen Arten derselben. Die Künste selbst sowie ihre Arten sind untereinander verwandt, sie haben eine gewisse Neigung, sich zu vereinigen, ja sich ineinander zu verlieren; aber eben darin besteht die Pflicht, das Verdienst, die Würde des echten Künstlers, dass er das Kunstfach, in welchem er arbeitet, von andern abzusondern, jede Kunst und Kunstart auf sich selbst zu stellen und sie aufs möglichste zu isolieren wisse. ${ }^{8}$

Für Goethe hebt die Beherrschung des Stoffs durch bewusste Differenzierung und Gestaltung gerade den wahren Künstler als Kunstschaffenden ab vom bloßen Kunstliebhaber: „Was dem Dilettanten eigentlich abgeht, ist Architektonik im höchsten Sinne, diejenige ausübende Kraft, welche erschafft, bildet, konstituiert“, „anstatt ihn zu beherrschen“, „gibt [er] sich [...] dem Stoff dahin". ${ }^{9}$ Und auch für Schiller, dessen Formbegriff Oschmann als bisweilen ziemlich gewalthafte Kampfrhetorik gegen alles Anarchische und Kontingente aufgezeigt hat, ${ }^{10}$ steht die Form wohl frei und rein, aber nie zufällig über allem und ist gleichsam alles, nämlich Zweck und Mittel zugleich. Das richtet sich klar gegen die eklektischen Programme der frühen Romantik, die gerade die freie Vermischung der Formen propagieren und vom Roman sogar explizit einfordern: „Die Vermischung und Verflechtung sehr heterogener Bestandteile und selbst aller Mythologien ist eine nothwendige Aufgabe des Romans“,

\footnotetext{
6 Ebd.

$7 \quad$ Goethe an Schiller, 23.12.1797, BW. S. 535.

8 Goethe: Kunsttheoretische Schriften und Uebersetzungen. Berliner Ausgabe, Bd. 19. S. 185 .

$9 \quad$ FA I, 18. S. 785 .

10 Vgl. Oschmann, Dirk: Zwischen Theorie und Performanz. Schillers Begriff der „Form“. In: Deutsche Zeitschrift für Philologie 2 (2017). S. 187-204.
} 
schreibt etwa Friedrich Schlegel in der Neuen Mythologie und an anderer Stelle: „[...] ich kann mir einen Roman kaum anders denken, als gemischt aus Erzählung, Gesang und anderen Formen. ${ }^{11}$

\subsubsection{Episches und Dramatisches}

Eine Vermischung der Formen bzw. der Gattungen wird von Goethe und Schiller, zumindest in den theoretischen Auseinandersetzungen, radikal abgelehnt, wie die obige Stelle aus den Propyläen deutlich macht. Durch das Vernachlässigen der Form und das Hingeben an den Inhalt - wie es sich darin zeigt, dass man heute auch den besten Roman noch im Theater aufgeführt sehen wolle, daraus aber nur schlechte Dramen entstünden - rücke die gesamte Dichtung in die Nähe des Dramas und dessen Drang zum Realistischen und Gegenwärtigen. ${ }^{12}$ Das Gegenwärtige erfährt damit eine deutlich negativ Aufladung. Insofern wird die realistische Repräsentation der Gegenwart und der mit ihr verbundenen räumlichen, zeitlichen und sozialen Begebenheiten, die im Roman der Aufklärung noch so positiv bewertet wurde und wesentlich zur Nobilitierung der Gattung beigetragen hatte, ${ }^{13}$ schon erstaunlich bald wieder hintertrieben.

An der Feststellung über die allgemeine Dramatisierung der Dichtung wird zudem deutlich, dass die Unterschiede zwischen den Gattungen nicht mehr in ihrer jeweiligen Äußerlichkeit verortet werden können - die konkrete, äußere Gestalt erscheint nun mehr als eine mögliche Ausprägung, denn als die einzig wahre Erscheinungsform. Es bedarf also feinerer, tiefer liegender Differenzierungskriterien ${ }^{14}$ und dafür werden nun die innerlichen Eigengesetzlichkeiten in den Blick genommen. Die Relativierung der äußeren Form als bloße Representation einer eigentlich inneren, immanenten Prädisposition ${ }^{15}$ stellt Gestalt und Inhalt in ein verändertes Entsprechungsverhältnis ${ }^{16}$, das einerseits an Lessings mediale und materiale Ausdifferenzierung der Künste anschließt und das darin angelegte Programm der Autonomieästhetik auf dem Feld der Dichtung fortsetzt ${ }^{17}$ und andererseits von der an der

11 KFSA, II, 16. S. 354 und 336.

12 Vgl. Goethe an Schiller, 23.12.1797, BW. S. 535 .

13 Vgl. S. 26 in diesem Buch.

14 Vgl. Oschmann, Dirk: Gattungstheorie um 180o. In: Zymner, Rüdiger (Hrsg.): Handbuch Gattungstheorie. Stuttgart: Metzler 2010. S. 206-209, hier S. 207.

15 Dazu vgl. Burdorf, Dieter: Poetik der Form. Begriffs- und Problemgeschichte. Stuttgart: Metzler 2001. S. $119 \mathrm{ff}$.

16 Vgl. Willems, Gottfried: Das Konzept der literarischen Gattung. Untersuchungen zur klassischen deutschen Gattungstheorie insbesondere zur Ästhetik. Tübingen: Vischer 1981. S. 212-242.

17 Vgl. Oschmann: Gattungstheorie um 180o. S. 206-209, hier S. 207. 
Beobachtung der lebendigen Natur gewonnen Vorstellung gradueller anstatt kategorischer Unterschiede profitiert. ${ }^{18}$ Gleichzeitig wird aber im Gegensatz zur romantischen Freisetzung der formalen Sprach- und Stilelemente auch immer noch an der Überzeugung festgehalten, dass eine eindeutige, reine und dem Gegenstand adäquate äußere Gestalt von größter Bedeutung ist. So kritisiert Goethe an den damals besonders populären Brief-Romanen etwa ihre Tendenz zu einer realistischen und gegenwärtigen Darstellung. Aufgrund dieser "völlig dramatischen“ Anlage befindet er das Einfügen von Dialogen, also von äußerlich gattungsfremden Form-Elementen, aber gerade für legitim: „[D]ie Romane in Briefen [sind] völlig dramatisch, man kann deswegen recht förmliche Dialoge [...] einschalten; erzählende Romane mit Dialogen untermischt würden dagegen zu tadeln seyn [sic]. ${ }^{“ 9}$ Vom Kern des Epischen als klar erzählender Gattung wird der Brief-Roman dadurch jedoch entschieden abgerückt, ebenso vom gattungsübergreifenden Ideal der Formenreinheit. Es zeigt sich hier deutlich, dass einerseits eine Engführung von Roman und Drama stattfindet, die entscheidend auf dem Bewusstsein von der inneren Form beruht und dass der Roman andererseits aufgrund seiner formalen Disparität - innerlich dramatisch, äußerlich episch - und pluralistischen Erscheinungsformen als kunstferne, potenziell dilettantische Unterhaltungsgattung des Erzählens vom Epos abgesetzt wird.

Inwiefern den Bemühungen um das Dramatische tatsächlich eine implizite Roman-Diskussion eingeschrieben wird, soll ein weiterer Blick in den Briefwechsel ${ }^{20}$ veranschaulichen. Das Zentrum dieser Korrespondenz ist bekanntlich Goethes zweiter Roman Wilhelm Meisters Lehrjahre und Schillers Kritik desselben. Darin wird aber auch deutlich, dass die Auseinandersetzung mit dem Epischen unterschwellig schon früh den Diskurs mitbestimmt bzw. besonders von Goethe forciert wird. Schiller liest und begleitet den Roman sowie die Unterhaltungen und hat aufgrund seiner Werther-Lektüre hohe Erwartungen, die er dann aber nicht erfüllt sieht. Für das 4. Buch wünschte er sich,

\footnotetext{
18 Vgl. S. 95 f. in diesem Buch.

19 Goethe an Schiller, 23.12.1797, BW. S. 535.

20 Zum Briefwechsel insgesamt vgl. die Beiträge in Barner, Wilfried; Lämmert, Eberhard et al. (Hrsg.): Unser Commercium: Goethes und Schillers Literaturpolitik. Vorträge des Symposiums vom 6. bis 9. September 1982 aus Anlass des Goethe-Jahres [in Marbach]. Stuttgart: Cotta 1984; von Wiese, Benno: Goethe und Schiller im wechselseitigen Vorurteil. In: Ders. (Hrsg.): Von Lessing bis Grabbe. Studien zur deutschen Klassik und Romantik. Düsseldorf: Bagel 1968. S. 108-137.
} 
in Rücksicht auf die Verkettung des ganzen, und der Mannichfaltigkeit wegen, die sonst in einem so hohen Grade behauptet worden ist, dass diese Materie nicht so unmittelbar hinter einander vorgetragen sondern wenn es angienge [sic] durch einige bedeutende ZwischenUmstände hätte unterbrochen werden / können. ${ }^{21}$

Schiller zielt hier mit seiner Kritik nachdrücklich auf eine unzulässige Beschleunigung des Erzähltempos, die nicht nur die Vielfalt, die zum Schönen gereichen würde, empfindlich beschränkt, sondern die grundsätzlich gestaltbildenden Kräfte des Anknüpfens, des Erzählens geradezu aushebelt. Er legt den Fokus damit auf die gleichwohl typische wie problematische Zeitökonomie des Romans, dessen erhöhte Geschwindigkeit das ästhetische Ideal maximaler Bedeutungsfülle auf so drastische Art und Weise beschränkt, dass die Anforderungen der hohen - sprich poetischen - Kunst schlicht nicht erfüllt werden können.

Das Darstellungsmittel der erzählten Zeit und der dargestellte Inhalt stehen im Roman in einem unschönen Missverhältnis - die Handlung schreitet ebenso wie das gegenwärtige Leben schneller voran, als dass ihre Einzelheiten nachvollziehbar würden. „Gegenwart wird nach den revolutionären Veränderungen von 1789 als bloße Tagesaktualität und politischer Streit der Meinungen [denunziert]“, hält Lehmann diesbezüglich fest. Und „wo es um Kunst geht und ästhetische Erziehung," sei, so Schiller in den Horen, „das beschränkte Interesse der Gegenwart“ sowie der ,jetzige Weltlauf“ als Bezugsgrösse auszuschließen. ${ }^{22}$ In dieser Beziehung erscheint Schiller dann gerade auch das 5. Meister-Buch besonders mangelhaft, das er in einem Zustand der „Trunkenheit“ gelesen habe. Dieses habe ihn „so Schlag auf Schlag ergriffen und in seinem Wirbel unfreywillig [sic] mit fortgenommen“, dass er an dessen Ende erst wieder zu „einer ruhigen Besinnung“ habe finden können und sich sehr darüber wundert, wie Goethe „ein so hinreißendes Interesse zu bewirken

21 Schiller an Goethe, 22.2.1795, BW. S. 61.

22 Lehmann, Johannes F.: Ist die Romantik modern oder vormodern? Folgerungen. In: Graevenitz, Gerhart von; Hinderer, Walter et al. (Hrsg.): Romantik Kontrovers. Ein Debattenparcours zum zwanzigjährigen Jubiläum der Stiftung für Romatikforschung (= Stiftung für Romantikforschung, Bd. 58). 2015. S. 149-157, hier S. 153. „Die Gegenwart ist zu schnell, zu provisorisch, ihr ständiger Wechsel führt in blindes Chaos" so Oesterle in: „Es ist an der Zeit!“ Zur kulturellen Konstruktionsveränderung von Zeit gegen 1800. S. 91-121, hier S. 98. Und auch bei Becker heißt es: „In der Beschleunigungswahrnehmung entleert sich Geschichte zu einer blinden Abfolge ständiger Wechsel“, Becker, Ernst Wolfgang: Zeit der Revolution! - Revolution der Zeit? Zeiterfahrungen in Deutschland in der Ära der Revolutionen 1787-1848/49 (= Kritische Studien zur Geschichtswissenschaft, Bd. 129). Göttingen: Vandenhoeck \& Ruprecht 1999. S. 199. 
wusste“. ${ }^{23}$ Bezeichnenderweise äußert sich Goethe gerade im siebten Kapitel von Wilhelm Meisters Lehrjahren zum Unterschied zwischen Roman und Drama und nimmt dabei ebenfalls das Tempo in den Blick:

Im Roman sollen vorzüglich Gesinnungen und Begebenheiten vorgestellt werden; im Drama Charaktere und Taten. Der Roman muss langsam gehen, und die Gesinnungen der Hauptfigur müssen, es sei auf welche Weise es wolle, das Vordringen des Ganzen zur Entwicklung aufhalten. Das Drama soll eilen, und der Charakter der Hauptfigur muss sich nach dem Ende drängen und nur aufgehalten werden. [Hervorhebungen M.E. $]^{24}$

Goethe ist sich also prinzipiell einig mit Schiller in Bezug auf die unterschiedlichen Gangarten der beiden Gattungen, schließt sich jedoch nicht an dessen Verdikt über den Roman und die darin zentral gestellte Zeichen-Akzeleration an, sondern beharrt vielmehr auf der Langsamkeit jeglichen Erzählens. Wenn Schiller den Roman ästhetisch disqualifiziert, ${ }^{25}$ dann nimmt er damit die ideologisch voreingenommene Hierarchisierung von Roman und Epos vorweg, die sich durch die gesamte Epikdebatte der Moderne ziehen wird. Darüber hinaus scheint darin nicht nur seine Forderung nach einer "strengen Separation“ der Kunst von der „wirklichen Welt ${ }^{\text {“2 }}$ auf, sondern auch seine Enttäuschung über die zunehmende Aufspaltung der Literatur in triviale, massentaugliche Textsorten auf der einen Seite und formbewusst-anspruchsvolle auf der anderen. ${ }^{27}$

In seiner Abhandlung Über naive und sentimentalische Dichtung von 1795 unternimmt Schiller dann eine eingehende kunstkritische Betrachtung der Gattung, in der er sich ebenfalls stark auf Goethes Meister-Roman bezieht. Der Roman könne gar keinen Anspruch erheben, ein "schönes Werk“ zu sein, heißt es da, stimme er doch weder mit der Natur noch dem Ideal überein. Es gibt Schiller zufolge zwar Romane, die „wahre, obgleich überspannte Empfindung, ein[en] leichte[n] Humor und ein[en] aufgeweckte[n], feine[n] Verstand“" aufweisen würden, es fehle ihnen aber entweder an der "gehörigen Nüchternheit des Verstandes“ oder aber „an ästhetischer Würde“, mit poetischer Literatur habe das nichts zu tun. Der Roman bleibe jedoch beliebt in „unserer und aller

\footnotetext{
23 Schiller an Goethe, 15.6.1795, BW. S. 87.

24 HA 7. S. 308.

25 Vgl. Christians, Heiko: Der Traum vom Epos. Romankritik und politische Poetik in Deutschland (1750-2000). Freiburg i. B.: Rombach 2004. S. 141.

26 Schiller an Herder, 4.11.1795. In: Schillers Briefe, mit Einleitung und Kommentar hrsg. v. Erwin Streitfeld und Viktor Žmegač. Königstein: Athenäum 1983. S. 296.

27 Vgl. Vosskamp, Wilhelm: Klassik als Epoche. Zur Typologie und Funktion der Weimarer Klassik. In: Herzog; Koselleck (Hrsg.): Epochenschwelle und Epochenbewusstsein. S. $493-514$, hier S. 497 .
} 
Zeiten [...], wo man ästhetische Werke bloß schreibt, um zu gefallen, und bloß liest, um sich ein Vergnügen zu machen. ${ }^{28}$ Popularität und Produktivität der Gattung werden hier als Indizienbeweise für den Eintritt in ein kunstloses Zeitalter gedeutet - eine Konnotation, die sich bekanntlich noch bei Hegel und Nietzsche wiederfinden wird. In den Briefen über die ästhetische Erziehung wird Schiller deshalb apodiktisch fordern, dass der Dichter nie Zögling seiner Zeit sein darf. ${ }^{29}$ Mit seiner Roman-Beurteilung richtet sich Schiller sowohl gegen die zeitgenössische Leserschaft und deren Lektürepraxis wie auch gegen den dilettantischen Dichter, der zeitgemäße literarische Texte zu Unterhaltungszwecken schreibt. Er nennt den „Romanschreiber" einen „prosaischen Erzähler“, der nur ein „Halbbruder" des Dichters sei, weil der Roman „die Erde noch so sehr berührt" ${ }^{30}$ und somit gar nicht poetisch durchgeformt werden kann. ${ }^{31}$ Diese konsequent ablehnende Haltung gegenüber dem Roman, aber auch gegen seine Verfasser und Leser kommt dann gleichfalls im Briefwechsel mit Goethe zum Ausdruck, wenn Schiller am Meister-Roman dessen Hang zum Dramatischen kritisiert: „Es sieht zuweilen aus, als schrieben sie für den Schauspieler, da Sie doch nur von dem Schauspieler schreiben wollen.“32 Schiller spricht dem Roman das Prädikat der wahren, kulturtragenden, hier eben mit dem Epischen gleichgesetzten Kunst kategorisch ab: Darin sei zu wenig „poetische[r] Ernst“, viel zu frei dagegen die „Grazie der Bewegung“. ${ }^{33}$ Diese Argumentation mag auf den ersten Blick irritieren, zitiert Schiller hier doch gerade sein eigenes Schönheitsideal der sublimierten Bewegung, ${ }^{34}$ welches er für seine alternative Gattungstrias der Empfindungsweisen produktiv macht, indem er Idylle, Satire und Elegie aufgrund ihrer unterschiedlichen, distinktiven Dynamiken differenziert: Die Idylle ist bestimmt durch Ruhe, die Satire durch Bewegung und die Elegie durch den Wechsel von Bewegung

28 Schiller: Über naive und sentimentalische Dichtung. In: Ders.: Sämtliche Werke, hrsg. v. Gerhard Fricke und Herbert G. Göpfert, Bd. 5. München: Hanser 1962. S. 740.

29 Vgl. Schiller: Über die ästhetische Erziehung des Menschen in einer Reihe von Briefen. In: Ebd. S. 593 .

30 Ebd.

31 Vgl. Oschmann: Zwischen Theorie und Performanz. Schillers Begriff der „Form“. S. 187.

32 Schiller an Goethe, 15.6.1795, BW. S. 88.

33 Schiller an Goethe, 8.6.1796, BW. S. 224. Schiller orientiert sich hier am Freiheitsbegriff von Kant. Freiheit heißt da, frei zu sein von äußeren Zwängen oder Fremdbestimmung, nur der eigenen, inneren Begebenheiten folgend, vgl. Schiller: Kallias oder über die Schönheit. In: Ders.: Sämtliche Werke, Bd. 5. S. 40o: „Schönheit ist [also nichts anderes, als] Freiheit in der Erscheinung“.

Vgl. Schiller: Über Anmut und Würde. In: Ebd. S. 434 ff. 
und Ruhe. ${ }^{35}$ Es soll hier deshalb dezidiert darauf hingewiesen werden, dass Schiller die positiv-ludistische Bewegungsästhetik, aufgrund der ihm später der Status eines Spielers zugesprochen wird, ${ }^{36}$ exklusiv am Gegenstand des Dramatischen und im direkten Kontext mit den „theatralischen Zwecken“37 seiner Tragödienproduktion entwirft.

Während „das Drama wirklich durch einen so schlechten Hang des Zeitalters in Schutz genommen wird“38, sieht Schiller die Kunst des Erzählens, die in ihrem Kern auf Zeit angewiesen ist, umso radikaler davon bedroht. Deshalb fordert er von den erzählenden Formen, und allen voran vom Roman, gerade eine absolute Resistenz gegenüber dem zunehmend auch in die Kunst eindringenden Prinzip der Dynamisierung. Insofern verbindet Schiller seine Roman-Kritik im Kern mit der Diagnose eines allgemeinen Kunstzerfalls, gegen dessen sich primär als ökonomisches Missverhältnis äußernde Dekadenzerscheinungen - einseitige Ausrichtung auf Unterhaltung, übertriebene Spannung und gehetzte Neugier - er energisch plädiert. Es sind deshalb genau diese mit dem oben bemängelten Drang zum Realistischen und Gegenwärtigen in Verbindung stehenden Elemente des Dramatischen, die Schiller an Goethes Roman entschieden negativ beurteilt:

Ich glaube zu bemerken, dass eine gewisse Condescendenz gegen die schwache Seite des Publicums [sic] Sie verleitet hat, einen mehr theatralischen Zweck und durch mehr theatralische Mittel, als bey einem Roman nöthig [sic] und billig ist, zu verfolgen. / Wenn je eine poetische Erzählung der Hülfe / des wunderbaren und überraschenden entbehren konnte, so ist es Ihr Roman; $[\ldots] .^{39}$

Diese Trivialisierung des Romans aufgrund seiner ästhetischen Zugehörigkeit zur Moderne und die damit einhergehende Engführung von Drama und Roman zugunsten eines entgegengestellten, poetisch anspruchsvollen Eposkonzepts markiert nicht nur die Infragestellung des äufklärerischen Roman-Begriffs, sondern stellt gerade einen zentralen Knotenpunkt innerhalb des diskursiven Netzwerks der goethezeitlichen Eposdebatte dar. So hält Wilhelm von Humboldt in seiner extensiven Abhandlung über Goethes Hermann und Dorothea etwa fest: „Ein scharfsinniger und geistvoller Kritiker

35 Vgl. Schiller: Über naive und sentimentalische Dichtung. S. 724. Zu diesem Zusammenhang siehe vor allem Oschmann, Dirk: Bewegliche Dichtung. Sprachtheorie und Poetik bei Lessing, Schiller und Kleist. München: Fink 2007. S. 167-169 und ders.: Zwischen Ästhetik und Mechanik. Frühromantische Visionen der Dynamisierung. S. 129-143, hier S. $34 \mathrm{f}$.

$3^{6}$ Alt; Lepper; Raulff (Hrsg.): Schiller, der Spieler. S. 9 .

37 Ebd.

38 Schiller an Goethe, 29.12.1797, BW. S. 546.

39 Schiller an Goethe, 8.7.1796, BW. S. 225. 
hat bemerkt, dass die Werke der Alten eine hohe und würdige Ruhe hervorbringen, da uns die der Neuem hingegen in einer unruhigen Spannung lassen. [Hervorhebungen M.E.] ${ }^{40}$ Diese wertende, am Begriff der Ruhe festgemachte Differenzierung von antiker und moderner Kunst verweist ebenso auf eine drängende Spannung als Dekadenzsymptom der gegenwärtigen Literatur wie Schillers kritische Haltung gegenüber dem Roman.

Und auch August Wilhelm Schlegel scheint der Roman mit seinem Hang zum Dramatischen auf problematische Weise mit einer trivialen, chaotischen Gegenwart sowie einer kunstfernen Gesellschaft verknüpft: Beide Gattungen, der Roman und das Drama, schilderten vornehmlich das Privatleben, wobei die im Roman dargestellte moderne Vorstellung von Liebe, der Erfüllung privaten Glücks als Lebensziel, zur Gefühlsduselei verkomme und so „die Hässlichkeit und Verworrenheit unserer gewöhnlichen Romanenwelt" zu verstellen suche. ${ }^{41}$ Bei der "Schlaffheit solcher Leser, die in einem Roman, gänzlich unbekümmert um sittliche Eigenthümlichkeit [sic], nur das gehörige Maß an gesetzlosem Ungestüm der Leidenschaft verlangen“" wundert es Schlegel allerdings nicht, dass "ein Werk wie Wilhelm Meister unbegriffen angestaunt wird, weil es die Vielseitigkeit der menschlichen Bestrebungen mit der höchsten Klarheit auseinander breitet, und daher der Liebe nur einen untergeordneten Platz einräumt". ${ }^{42}$ Obwohl im Grund miteinander einig, stellt Schlegel nun ausgerechnet denjenigen Roman als ein wahres, episches Kunstwerk heraus, an dem Schiller seine Missbilligung der Gattung zum Ausdruck bringt - Goethes Wilhelm Meister. Diese Paradoxie von Einigkeit in der kunsttheoretischen Argumentführung und Abweichung in der pragmatischen Werkbeurteilung zwischen Schiller und Schlegel kann als Hinweis darauf gelesen werden, dass sich die Zuschreibungen des Epischen und des Romanhaften zu Beginn der ästhetischen Moderne zu reinen Wertkategorien wandeln, die nicht mehr unbedingt mit der Gattungszugehörigkeit des Einzelwerks korrelieren müssen und dadurch zu universalen Parametern einer elitären Literatur- und Kulturkritik werden.

\subsubsection{Schwanken}

Für Schiller liegen die Probleme des Romans dann auch in einer grundsätzlichen Uneindeutigkeit und Vermischung formaler Elemente begründet, die

\footnotetext{
$40 \quad$ Humboldt, Wilhelm von: Ueber Göthes Herrmann und Dorothea (1799). S. 121.

41 Schlegel, August Wilhelm: Goethes Hermann und Dorothea. In: Ders. (Hrsg.): Sämtliche Werke, hrsg. v. Eduard Böcking, Bd. 11. Vermischte und kritische Schriften; 5 , Recensionen. Leipzig: Weidmann'sche Buchhandlung 1847. S. 183-221, hier S. 206. 
in den Propyläen als das „vorzüglichste Zeichen des Verfalls der Kunst“43 ausgewiesen werden:

Die Form des Meisters, wie überhaupt jede Romanform ist schlechterdings nicht poetisch, [...]. Weil es aber ein ächt poetischer Geist ist, der sich dieser Form bediente, [...], so entsteht ein sonderbares Schwanken zwischen einer prosaischen und poetischen Stimmung, für das ich keinen rechten Nahmen [sic] weiß. Ich möchte sagen, es fehlt dem Meister (dem Roman nehmlich) an einer gewissen poetischen Kühnheit, weil er, als Roman, es dem Verstande immer recht machen will - und es fehlt ihm wieder an einer eigentlichen Nüchternheit, (wofür er doch gewissermaassen [sic] die Foderung [sic] rege macht) weil er aus einem poetischen Geiste geflossen ist. [...] so ist es durchaus nöthig dafür zu sorgen, dass dasjenige was Ihr Geist in Ein Werk legen kann, immer auch die reinste Form ergreife, und nichts davon in einem unreinen Medium verloren gehe. Wer fühlt nicht alles das im Meister, was den Hermann so bezaubernd macht! Jenem fehlt nichts, gar nichts von Ihrem Geiste, er ergreift das Herz mit allen Kräften der Dichtkunst und gewährt einen immer sich erneuenden Genuss, und doch führt mich der Hermann (und zwar bloss durch seine rein poetische Form) in eine göttliche Dichterwelt, da mich der Meister aus der wirklichen Welt nicht ganz herauslässt. [...] Es ist offenbar zu viel von der Tragödie im Meister; ich meine das Ahndungsvolle, das Unbegreifliche, das subjectiv wunderbare, welches zwar mit der poetischen Tiefe und Dunkelheit aber nicht mit der Klarheit sich verträgt, die im Roman herrschen muss und in diesem auch so vorzüglich herrscht. [Hervorhebungen M.E. ${ }^{44}$

Das sonderbare Schwanken zwischen verschiedenen Formen und Stimmungen irritiert Schiller am Roman in allerhöchstem Maße, es scheint ihm gar das sichere Zeichen des Trivialen und der Kunstlosigkeit zu sein. Schiller vertritt damit zu diesem Zeitpunkt ein strenges Ideal der Formenreinheit, welches er selbst an anderen Stellen ${ }^{45}$ verwerfen wird. Bereits zwei Monate nach der scharfen Meister-Kritik wird Schiller Goethe gegenüber zwar konstatieren, dass die Vermischung der Gattungen nun mal unausweichlich sei unter den gegenwärtigen Bedingungen ${ }^{46}$ und im Jahr 1800 wird er diese Vermischung sogar zur programmatische Forderung erheben. In einem Brief an Goethe heißt es da nämlich: „man [muss] es wagen, bei einem neuen Stoff die Form neu zu

\footnotetext{
43 FA I, 16. S. 222.

44 Schiller an Goethe, 20.10.1797, BW. S. 502.

45 Schiller ist, wie Oschmann zeigt, in seiner Ästhetik sehr viel näher an frühromantischen Konzepten der Gattungsmischung, vgl. Oschmann: Bewegliche Dichtung. Sprachtheorie und Poetik bei Lessing, Schiller und Kleist. S. 149-200.

46 Schiller an Goethe, 29.12.1797, BW. S. 546: „Weil wir einmal die Bedingungen nicht zusammenbringen können, unter welchen eine jede der beiden Gattungen steht, so sind wir genöthigt, sie zu vermischen."
} 
erfinden, und sich den Gattungsbegriff immer beweglich erhalten. ${ }^{“ 47}$ Von den epistemischen und kreativen Möglichkeiten, die sich aus dieser Relativierung eröffnen, werden dann aber erst die späteren Dramen wie die Braut von Messina profitieren, die sich in der Verbindung von antiker Tragödienform mit modernen, zeitgenössischen Stoffen ${ }^{48}$ als experimentelle Gattungshybride erweisen. Wenn er das Schwanken wie oben als sonderbare Bewegung jenseits jeder Benennbarkeit denunziert, scheint Schiller im Zusammenhang mit der Diskussion über den Roman aber noch weit entfernt, sowohl von der positiven Formulierung eines autonomen, freien Kunstbegriffs wie in der Ästhetischen Erziehung als auch von der deutlich modernebejahenden Auffassung des ästhetischen Spiels mit den freigewordenen Formen als Synkretisierungskonzept. ${ }^{49}$

Während Schiller in der schwankenden Bewegung zwischen den Formen das Dekadenzmerkmal schlechthin verortet, wird das Schwanken für Goethe mehr und mehr zum zentralen Begriff seiner Morphologie, ${ }^{50}$ wie auch die bereits zitierte Stelle aus der Einleitung von 1817 nahelegt. ${ }^{11}$ In der Rezension zu D'Altons Darstellung der Skelette der Nagetiere aus dem Jahr 1824 begreift Goethe das „Schwanken von Form zu Unform, Unform zu Form“ als gefährliche, geradezu den Verstand raubende Bewegung. Daher erschient es ihm „fast besser [...] den Irrtum zu fixieren als im Wahren zu schwanken“.52 Das Schwanken ist demnach eine erodierende Bewegung, die jegliche Ordnung der Formen auflöst. Ihr übergangsloses Wechseln zwischen fassbarer Form und Nicht-Form ist bestenfalls irritierend, eigentlich aber gefährlich und steht insofern in Beziehung mit der gleichfalls als gefährlich taxierten Zentrifugalkraft der Morphologie. ${ }^{53}$ Zunächst geht die Vorstellung, dass der ständigen Hin- und Her-Bewegung eine auflösende und damit auch kunstgefährdende

Schiller an Goethe, 26.7.180o, BW. S. 927.

48 Vgl. dazu Oesterle, Günter: Friedrich Schiller: Die Braut von Messina. Radikaler Formrückgriff angesichts eines modernen kulturellen Synkretismus oder fatale Folgen kleiner Geheimnisse. In: Chiarini, Paolo; Hinderer, Walter et al. (Hrsg.): Schiller und die Antike. Würzburg: Königshausen \& Neumann 2008. S. 167-175, hier S. 168 f.

49 Vgl. Alt; Lepper; Ulrich (Hrsg.): Schiller, der Spieler, darin insb. Schneider: Das sentimentalische Spiel mit den Archiven des kulturellen Gedächtnisses. Schillers ludistische Ästhetik als Reflexion auf die Bedingungen künstlerischer Produktivität am Beginn der Moderne. S. 242-261, hier S. $251 \mathrm{ff}$.

$5^{\circ} \quad$ Vgl. Geulen: Aus dem Leben der Form. Goethes Morphologie der Nager. S. $65 \mathrm{f}$.

51 Vgl. S. 92 in diesem Buch.

$5^{2}$ Goethe: Die Skelette der Nagetiere, abgebildet und verglichen von D'Alton. Erste Abteilung: zehn Tafeln, zweite: acht Tafeln. Bonn 1823 u. 1824, zitiert nach Geulen: Aus dem Leben der Form. Goethes Morphologie der Nager. S. 24.

Vgl. S. 93 in diesem Buch. 
Kraft innewohnt, einig mit Schillers Ablehung des Amorphen als ästhetischer Ausdruck des kulturellen Zerfalls. Bei Goethe sind im Schwanken aber gleichzeitig alle Formen und Unformen enthalten, wenn auch in einem Zustand vor der Formwerdung. Aus dem unentwegt bewegten Grund haben sie sich noch nicht herausgelöst bzw. müssen sie erst noch gelöst werden. Das Schwanken fungiert damit als klarer Gegenbegriff zu dem der Gestalt, wie er weiter oben eingeführt wurde, ${ }^{54}$ aber es erscheint darin gemäß Geulen paradoxerweise gerade auch die Unbestimmbarkeit einer Form als Form. ${ }^{55} \mathrm{Im}$ Schwanken kann somit nicht nur eine Quelle der Beunruhigung ausgemacht werden, sondern gleichzeitig auch eine der Wahrheit, des Wissens, die den Unsicherheitsstatus dieses Wissens sichtbar macht. Dadurch wird die grundsätzliche Frage aufgeworfen, ob Ordnung und Gesetz von außen zu stiften oder immanent zu entdecken sind. ${ }^{56}$ Daraus ergibt sich eine konstitutive Verbindung zum Konzept der inneren Form, dem ähnlich wie der Unform der Status einer Form vor bzw. in der Form zugeschrieben wird und das den Geltungsverlust rein äußerlicher, normativer Ordnungsprinzipien zu kompensieren sucht.

Wie die bisherigen Ausführungen schließen lassen, greift Goethe die Idee des Schwankens bereits lange bevor er die Rezension zu den Nagetierskeletten schreibt als bewegliches, kreisendes Herantasten an vermeintlich feste Gegenstände auf. Gerade in den Bemühungen um das epische Erzählen zeigt sich nämlich deutlich, dass Goethe dem gleichwohl prekären wie erkenntnisfördernden Potenzial des Schwankens schon früh auf der Spur ist. 1796 scheinen die großen Erzählformen ganz grundsätzlich ein prekäres Unternehmen geworden zu sein. Nicht nur Goethes Arbeit am Meister-Roman bricht ab, auch im Briefwechsel mit Schiller kommen der Poetik und Zuständigkeit des Roman kaum noch Aufmerksamkeit zu. Angesicht dieser produktiven und kunsttheoretischen Schwierigkeiten wendet er sich, wie bereits in der Krise von 1790, wieder der Betrachtung der Natur zu, sodass die Morphologie von Pflanzen und Insekten im Sommer 1796 erneut in den Vordergrund rückt. ${ }^{57}$ Spätestens jetzt zeigt sich das Abwechseln zwischen kunst- und wissenschaftlicher Betätigung, theoretischer und kreativer Arbeit als ein übergreifendes Denkmuster Goethes, das Gegensätzlichkeit und Komplementarität bewusst

54 Vgl. S. $91 \mathrm{ff}$. in diesem Buch.

55 Vgl. Geulen: Aus dem Leben der Form. Goethes Morphologie der Nager. S. 66.

56 Vgl. ebd. S. 73.

57 Vgl. MA 4.2. S. 1021. 
fruchtbar macht ${ }^{58}$ und dessen Dynamik sich nun auch für die gattungspoetischen Probleme nutzbar machen lässt.

Unter dem Eindruck von Schillers unerbittlichem Rekurs gegen den modernen Roman beginnt Goethe sich in der Meister-Krise bezeichnenderweise wieder verstärkt für die antiken Formen des Erzählens, besonders das Epische und das Idyllische, zu interessieren und wendet sich erneut den Homerischen Epen sowie ihren zeitgenössischen Übersetzungen zu. So stehen die Jahre 1796/7 dann ganz im Zeichen des Epischen. In kurzer Zeit entstehen nun zuerst das Edyllion Alexis und Dora - bei welchem Goethe „eine bürgerliche Idylle im Sinn [hatte], weil ich doch so etwas auch muss gemacht haben"59 - und dann das idyllische Versepos Hermann und Dorothea. An Jacobi schreibt Goethe, wie er sich nach der Arbeit am Meister-Roman „mit allen meinen Kräften auf das epische geworfen [habe] und sehen [wolle], am Ende [seiner] Laufbahn, auch noch um diesen Eckstein herumzukommen". ${ }^{60}$ Neben dem homerischen Epos, das werden die Lektürekapitel weiter deutlich machen, lässt sich Goethe stark von der Poetologie der Idylle und insbesondere Voß' idyllischem Versepos Luise inspirieren: „Ich bin mir noch recht gut des reinen Enthusiasmus bewusst mit dem ich den Pfarrer von Grünau [Luises Vater] aufnahm [...]“, erinnert er sich, „[d]enn diese Freude ist am Ende doch productiv bey [sic] mir geworden, sie hat mich in diese Gattung gelockt, den Hermann erzeugt und wer weiß was noch daraus entstehen kann". ${ }^{61}$ Weitere Epos-Projekte wie die Jagd, Wilhelm Tell und auch die Achilleis werden als Vorhaben konzipiert - umgesetzt wird dann allerdings nur die Achilleis und auch diese nur teilweise.

Diese Hinwendung auf das Epos als Resignation und Flucht in die Antike zu interpretieren, wie das die traditionelle Forschung getan hat, greift jedoch wie oben angedeutet zu kurz, verleiht doch die durch die Schwierigkeiten mit dem Roman forcierte Novellen-, Epen- und Idyllen-Produktion dem Dichter gerade einen kreativen Schub. Beim Versuch, ein neues episches Erzählen zu generieren, befruchten sich die entgegengestellten Poetologien von Epos und Roman gegenseitig und führen insofern auf die Einsicht in eine grundsätzliche Wechselbeziehung zwischen alternativen poetologischen Prinzipien. Von einer derartigen Inbezugsetzung konträrer Charakteristiken sind allerdings

$5^{8}$ Vgl. Pfotenhauer, Helmut: Zur Funktion des novelistischen Augenblicks in Goethes Romanen. In: (Ders.): Sprachbilder: Untersuchungen zur Literatur seit dem achtzehnten Jahrhundert. Würzburg: Königshausen \& Neumann 20oo. S. 45-67, hier S. 54.

59 Goethe an Schiller Anfang Juni 1796, zitiert nach HA 2. S. 734.

6o Goethe an Jacobi, 17.10.1796, zitiert nach WA IV, 12. S. 234.

61 Goethe an Schiller, 28.2.1798, BW. S. 615 f. 
keine eindeutigen, fixierte Gattungen zu erwarten, wie sie die klassizistische Ästhetik einfordert, sondern vielmehr prekäre Formationen, die sich durch innere Spannungen auszeichnen. Darauf, wie produktiv diese Erkenntnis für Goethe aber wird, hat auch Florentine Biere in ihrer Darstellung der Novelle als poetologischem Experimentierraum für ein modernes Erzählen jenseits des Romans hingewiesen. ${ }^{62}$ Sie verortet in den Unterhaltungen ein bewusstes poetologisches Gegen-Programm zum großen Roman-Projekt der Lehrjahre, das verstärkt das Wunderbare und Widersprüchliche inszeniert. ${ }^{63}$ Anstatt um romanhaften Realismus und eine lückenlose Teleologie geht es in den Unterhaltungen viel mehr darum, die Möglichkeit einer gelungenen Unterhaltungsliteratur ${ }^{64}$ aufzuzeigen, die ihren eigenen ästhetischen Wert gerade durch die von Schiller diskreditierten Prinzipien des Neuen, der Unterhaltung und des Unbegreiflichen erhält. ${ }^{65}$

\subsubsection{Widerstand gegen den "schlechten Hang des Zeitalters“: Entschleunigung}

Vor diesem Hintergrund geht Goethe Ende 1797 daran, die im Briefwechsel mit Schiller gemeinsam über längere Zeit erörterten Eigenschaften des Epischen zu überarbeiten und in einem Aufsatz prägnant zusammenzufassen, an dessen Anfang er zu Schillers Vorwurf der unzulässigen Formenmischung explizit Stellung bezieht. Obwohl Goethe in dieser Passage den Künstler - und damit auch Schiller und sich selbst - ermahnt, „aus allen Kräfften [sic]“ diesen „kindischen, barbarischen, abgeschmackten Tendenzen“ der Vermischung zu widerstehen und die Kunstwerke rein zu halten, „wie es die Alten gethan [sic] haben“66, stellt er kurz darauf fest: „[A]ber wer kann sein Schiff von den Wellen sondern auf denen es schwimmt? Gegen Strom und Wind legt man nur kleine Strecken zurück." ${ }^{47}$ Goethe beklagt hier erneut den bereits vor dem Italien-Aufenthalt diagnostizierten Kulturverlust - mit dem Begriff des Barbarischen wird die moderne Kunst kategorisch aus der Kulturgeschichte

62 Vgl. Biere: Das andere Erzählen. Zur Poetik der Novelle 180o/19oo. S. 193-198.

63 Vgl. ebd. S. 193 f.

64 Vgl. Witte, Bernd: Das Opfer der Schlange. Zur Auseinandersetzung Goethes mit Schiller in den Unterhaltungen deutscher Ausgewanderten und im Märchen. In: Barner; Lämmert et al. (Hrsg.): Unser Commercium: Goethes und Schillers Literaturpolitik. Vorträge des Symposiums vom 6. bis 9. September 1982 aus Anlass des Goethe-Jahres. S. 461-484, hier S.482.

65 Vgl. Christians: Der Traum vom Epos. Romankritik und politische Poetik in Deutschland (1750-200o). S. $146 \mathrm{f}$.

66 Goethe an Schiller, 23.12.1797, BW. S. 536.

67 Goethe an Schiller, 23.12.1797, BW. S. 537. 
ausgeschlossen ${ }^{68}$ - einen zunehmenden, unaufhaltsamen Zerfall der Kunst, der sich in der Auflösung der Formen, der etablierten Gattungen äußert. Den primären Grund dafür macht er, anders als Schiller, weder in der sich von der wahren Kunst entfernten Gesellschaft noch im dilettantischen Künstler aus, sondern im „schlechten Hangs des Zeitalters" 69 und im gleichzeitigen Ausgeliefertsein daran. Es ist also das Schwanken der Zeit selbst, das auch in der Bewegungsmetapher des Wellengangs aktualisiert wird, dessen beunruhigende und unkontrollierbare Kraft die Gestalten bis zur Unkenntlichkeit verwischt. Hier liegt ein feiner aber entscheidender Unterschied zwischen Goethes Verständnis der Gattungsmischung als Konsequenz einer Dynamisierung der Zeit und der von Schiller spezifisch im Hinblick auf den modernen Roman angeprangerten Vermischung der poetischen Formen als Ausdruck eines gesellschaftlichen und künstlerischen Defizits. Goethes Wellengang-Vergleich enthält nämlich ein implizites Bekenntnis zur Historizität. Er fordert eben nicht eine absolute, klassizistische Verweigerungshaltung gegenüber den modernen Tendenzen der Dynamisierung - sprich dem Roman -, sondern vielmehr einen Moment des Innehaltens in dieser bewegten Zeit. Insofern beharrt Goethe darauf, die zwar generativen, aber auch anarchischen Kräfte der Moderne mit einem klassizistischen Formbegriff zu synthetisieren, anstatt zu vertilgen.

Die in der Meeres-Metaphorik anklingenden Prinzipien des Unkontrollierbaren und Unendlichen inszenieren zwar die einsetzende Moderne als ungestüme, alles mitreißende Bewegung, als unabsehbare Progression in eine horizont- und konturlose Zukunft, als dekadente Hetzerei in die Kulturlosigkeit. Wie Geulen in ihrer erkenntnisreichen Studie zur Morphologie aufzeigt, wird Goethe aber gerade das Schwanken zum übergeordneten Prinzip der Formwerdung erheben, in dem Form und Unform gleichberechtig nebeneinanderstehen. ${ }^{70}$ Dem Schwanken wird so eine Gesetzhaftigkeit zugesprochen - und sei es auch nur das Gesetz des steten Wandels -, die im Vermischen nicht aufgespürt werden kann. Goethes Bewusstsein dafür, dass das Schwanken der Zeit und die Veränderungen, die es mit sich bringt - seien sie noch so beunruhigend - auch erkenntnis- und kulturfördernde Impulse in sich trägt, manifestiert sich bereits in den 179oer Jahren. Die wechselseitige Beschäftigung mit Natur- und Kunstthemen, aber auch mit dem Epischen und dem Roman, erweisen sich nämlich schon zu diesem Zeitpunkt als ein

68 Vgl. zum Kulturbegriff Böhme; Matussek et al. (Hrsg.): Kulturwissenschaft Orientierung. Was sie kann, was sie will. S. $356-359$.

69 Schiller an Goethe, 29.12.1797, BW. S. 546.

70 Vgl. Geulen: Aus dem Leben der Form. Goethes Morphologie der Nager. S. 70-73. 
bewusst produktiv gemachtes Hin- und Herschwanken zwischen den Wissenssystemen oder eben auch den poetologischen Formen. Der verzeitlichte, prozessuale Formbegriff, den er später in der zweiten Morphologie-Einleitung als der Natur abgeschautes Verwandlungsgesetzt formulieren wird, beruht entscheidend auf dieser im Umfeld der Eposdebatte gewonnen Einsicht in die ambivalenten, sowohl bildenden wie auch gestaltauflösenden Kräfte der Zeit. Goethes Bild von den nur kleinen Strecken, die gegen die Gezeiten zu machen sind, wird so als eine reflexive, spezifisch moderne Haltung der bewusst widerständigen Entschleunigung lesbar, in der der Erfahrung, dass Fortschrittsdynamik und Subjektivierung eine beunruhigende Kehrseite haben, Rechnung getragen wird. Der ins Chaos führenden Zentrifugalkraft der fortschreitenden Zeit wird deshalb die kontrollierende, bändigende Macht der Entschleunigung entgegengesetzt. Insofern unterscheidet sich auch die Idee einer potenziell unendlichen, aber zeitlich kontrollierten und deshalb nachvollziehbaren Verwandlung positiv vom Prinzip einer wahllosen, unnachvollziehbaren Vermischung.

Dagegen werden Verzeitlichung und Beschleunigung von den Frühromantikern, die wie bereits gesehen gleichfalls um 1800 auf den Wechsel der Zeithorizonte und die davon indizierte Reflexivität der Gegenwart aufmerksam werden, gerade entschieden in die Kunst hineingetrieben..$^{71}$ So überantwortet Friedrich Schlegel sein Programm der neuen Mythologie explizit einer euphorisch angenommenen Beschleunigung der Zeit: „Und lasst uns denn, beim Licht und Leben! nicht länger zögern, sondern jeder nach seinem Sinn die grosse Entwickelung [sic] beschleunigen, zu der wir berufen sind. Seid der Größe des Zeitalters würdig. ${ }^{42}$ Die Prinzipien von Bewegung und Geschwindigkeit werden in der romantischen Theorie nicht zurückgebunden, sondern vielmehr in einen völlig entgrenzten Unendlichkeitsbegriff überführt, der wie Matuschek aufzeigt, als ein bewusstes sprachliches Mittel der Selbstermächtigung produktiv gemacht wird. ${ }^{73}$ Beobachtbar wird das etwa an den typisch apodiktischen Aussagen Schlegels, der den „Charakter der Mythologie“ als „[d]as absolute Setzen und das Setzen des Absoluten“74 bestimmt. Im Gegensatz zu Goethes Schwanken spürt Schlegel hier das rhetorische und epistemische Muster eines paradoxen Umschlags auf, dessen

71 Vgl. Oesterle: „Es ist an der Zeit!“ Zur kulturellen Konstruktionsveränderung von Zeit gegen 180o. S. 91-121, hier S. 91.

$72 \quad$ KFSA I, 2. S. 322.

73 Vgl. Matuschek: „Doch Homeride zu sein, auch nur als letzer, ist schön“. Zur Bedeutung der Mythologie bei Friedrich Schlegel. S. 115 ff. 
eingeschriebene Dynamik eben eine abrupte, plötzliche ist ${ }^{75}$ und insofern in engem Zusammenhang mit der romantischen Zeitlichkeitsvorstellung des flüchtigen Jetzt steht. ${ }^{76}$

Oberflächlich betrachtet bemühen sich derartige Feststellungen zwar um einen absoluten Definitionsanspruch, paradoxerweise verhindern sie aber gerade strategisch einen klaren Umriss und entrücken insofern ihren Gegenstand - namentlich die Poesie bzw. die Mythologie - aller Konturklarheit. Auf genau diese sprunghafte Weise verfährt Friedrich Schlegel bezeichnenderweise auch mit dem Epos, wenn er über dessen im Grunde aufgelöste Einheit festhält: „Das Epitheton ist eine kleine Episode, und die Episode ist ein grosses

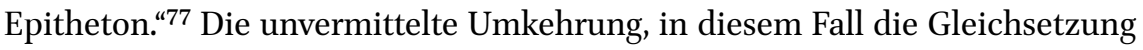
von Teil und Ganzem, unterläuft den absoluten Anspruch der These und setzt sie so einer skeptischen Reflexionsbewegung aus. In dieser extremen Redeform des unmittelbaren Kurzschlusses liegt das Potenzial der poetologischen Selbstverortung und -behauptung, welches die Autonomieprogramme der Romantik kennzeichnet: Was auf Festigkeit angelegt ist, wird noch im gleichen Moment aufgelöst und in bloßen Vermutungen scheint plötzlich Gewissheit auf - Erkenntnismöglichkeiten werden so zwar in Aussicht gestellt, stehen aber nie auf einem festen Grund. Insofern reagieren auch die Frühromantiker sensibel auf das Reflexivwerden der Zeit und machen es nutzbar für die Modalisierung ihrer poetologischen Programme und Verfahrensweisen. Aber Kontinuität und Nachvollziehbarkeit, ja eine klare Form, wie Goethe sie trotz aller Zugeständnisse an die Dynamiserung des Zeitregimes für unumgänglich hält, sind darin nicht aufzufinden.

Vor diesem Hintergrund wird deutlich, dass sich um 1800 neben der Destabilisierung der traditionellen Gattungspoetologie und Autonomisierung der Kunst auch ein damit verbundener Legitimationsverlust der bisherigen gattungstheoretischen Verfahrensweisen bemerkbar macht. Bei der Suche nach neuen, adäquaten Konzepten und Beschreibungsmöglichkeiten lässt sich insbesondere bei Goethe eine maßgebliche Orientierung an natürlichen Ordnungsmodellen beobachten, die auch den Blick auf innere, prozessuale Eigengesetzlichkeiten freigibt. Diese Fokusverschiebung weg von der äußeren, hin auf die innere Form verbindet sich weiter mit der Idee einer spezifisch zeitlichen Verfasstheit von literarischen Gattungen, die mit dem Bewusstsein für das Reflexivwerden der Zeit zusammenhängt. In der forcierten

75 Vgl. Matuschek: „Doch Homeride zu sein, auch nur als letzer, ist schön“. Zur Bedeutung der Mythologie bei Friedrich Schlegel. S. 118.

76 Vgl. S. 94 f. in diesem Buch.

77 KFSA I, 1. S. 124. 
gattungspoetologischen Diskussion über das Erzählen, das wie keine andere literarische Form auf zeitlicher Sukzession gründet, erlangen die Einsicht in den Führungswechsel der Zeithorizonte sowie die ästhetischen und medialen Probleme und Möglichkeiten, die sich daraus für die Dichtung ergeben, besondere Bedeutung und zwar sowohl für die romantische wie auch die klassizistische Theorie: Beide arbeiten sich ganz zentral am Problem der Zeit und ihrem Verhältnis zur Gegenwart ab, wenn sie auch zu unterschiedlichen Positionen und Konzeptionen finden. Daran, wie der Roman im Briefwechsel zwischen Schiller und Goethe aufgrund seiner ästhetischen Zugehörigkeit zur Moderne problematisiert und mit dem Dramatischen überschrieben wird, lässt sich nun bereits erahnen, dass auch die gegenübergestellte, komplementäre Konzeption des Epischen mehr einem kritischen Blick auf die Gegenwart und ihrem Verhältnis zu dieser geschuldet ist als einer blinden Antikenverherrlichung. ${ }^{78}$

\subsection{Von der Krise der Kunst und der Verzeitlichung der Zeit}

Die bisherigen Ausführungen haben bereits deutlich gemacht, dass es in der goethezeitlichen Auseinandersetzung um das Epische, das Dramatische und den Roman um weit mehr geht als die bloße Differenzierung und Feststellung von literarischen Erscheinungsformen. Wurde die Gattungsdebatte im oberen Abschnitt als kritische Gegenwartsanalyse gezeigt, in der die Veränderungen der Zeit thematisiert und als poetologische Eigenzeitlichkeiten reflektiert werden, soll im Folgenden darauf hingeführt werden, wie wurzelhaft der Eposdiskurs auch mit den grundlegenden Fragen zur Bedeutung der Kunst für die Kultur verbunden ist, die um 1800 virulent werden.

\subsubsection{Geltungsverlust der Kunst für die Kultur}

Dass der Kunst sowie ihren expliziten Programmen für die Kulturbildung und das kulturelle Selbstverständnis der Gesellschaft jeweils eine zentrale Rolle zukommt, scheint ein Gemeinplatz. Was diese Rolle beinhaltet und welche Positionierung der Kunst in der Kultur zugewiesen wird, ist aber grundsätzlich eine Verhandlungssache und steht immer dann wieder von neuem zur Debatte, wenn die hier erwarteten Leistungen, wie etwa eine kollektive Sinnstiftung, nicht mehr erbracht werden können. Im Zuge der intensiven Querelles-Debatten befindet sich das etablierte Kunstsystem spätestens ab

78 Vgl. Theisohn, Philipp: Totalität des Mangels. Carl Spitteler und die Geburt des modernen Epos aus der Anschauung. S. 3 . 
der Mitte des 18. Jahrhunderts in einer derartigen Krise. Angesichts der Ausbildung einer historisch-kritischen Kunsttheorie droht die Kunst in den Ausdifferenzierungs- und Ablöseprozessen von Aufklärung und Säkularisierung ihre Relevanz für die Kulturgemeinschaft zu verlieren. Nicht zuletzt können auf diesem Hintergrund auch die beschriebenen Modifizierungen, die der Kulturbegriff selbst zu dieser Zeit durchläuft, in Verbindung gebracht werden mit der Umstrukturierung des Wissenssystems und einer neuen Vorstellung eines gesamtzivilisatorischen Entwicklungsprozesses. ${ }^{79}$

Das Feststellen dieser Erschütterung und der Versuch, die weggefallene Verankerung der Kunst im gesamtgesellschaftlichen Kontext durch alternative, kunstinterne Kriterien zu ersetzen, zieht sich von hier als Problemdiskurs der Kunstautonomie durch die ganze Moderne und kann, wie die euphorischselbstbewussten Programme des Geniebegriffs und der Autonomieästhetik bezeugen, auch positiv als Befreiung von der regelhaften Nachahmungspoetik beschrieben werden. ${ }^{80}$ Gotthold Ephraim Lessings Abhandlung Laokoon oder Über die Grenzen der Malerei von 1766 kann diesbezüglich als Begründung einer autonomen Ästhetik gelten, die auf der jeweils spezifischen medialen und materiellen Beschaffenheit der Einzelkünste beruht. ${ }^{81}$ An ihn schließt Karl Philipp Moritz 1788 mit seiner Schrift Über die bildende Nachahmung des Schönen an, die Lessings Freisetzung der Künste aufnimmt und insofern zuspitzt, als sie das Kriterium der Schönheit als das eigentliche, oberste Ziel der bildenden Kunst einsetzt. ${ }^{82}$ Das Schöne ist bei Moritz im Gegensatz zum Nützlichen auf „keine Beziehung auf irgend etwas außer sich“" ${ }^{43}$ angewiesen, es bildet sich demnach aus dem eigenen Inneren heraus ${ }^{84}$ und ist damit ebenso frei von Ansprüchen der Moralität wie von einer eindeutigen Sinnstiftung oder Botschaft. Daraus zieht er nun allerdings die Konsequenz, dass das derartig autonome, zweckfreie Kunstwerk „ein schönes Ganzes“ sein soll, das den „Abdruck des höchsten Schönen im großen Ganzen der Natur" wiedergibt. ${ }^{85}$ Die Zwecklosigkeit der Kunst wird mit dieser Analogisierung von Kunst und Natur scheinbar mit der Bedingung der Ganzheit gerechtfertig, ${ }^{86}$ allerdings

79 Vgl. S. 21 ff. in diesem Buch.

8o Vgl. Luhmann, Niklas: Die Kunst der Gesellschaft. Frankfurt a. M.: Suhrkamp 2002. S. 256 f.

81 Vgl. Schneider: Die Laokoon-Debatte: Kunstreflexion und Medienkonkurrenz im 18. Jahrhundert. S. 68-85, hier S. 72.

82 Vgl. Moritz, Karl Philipp: Über die bildende Nachahmung des Schönen. In: Ders.: Werke, hrsg. v. Heide Hollmer und Albert Meyer, Bd. 2. Berlin: Aufbau 1985. S. 964 f.

83 Ebd. S. 967 .

84 Vgl. ebd. S. 961.

85 Ebd. S. 969 .

86 Vgl. Keller: Lebendiger Abglanz. Goethes Italien-Projekt als Kulturanalyse. S. 120. 
haben bereits die Ausführungen zu Goethes morphologischem Formdenken und seiner explorativen Methodologie gezeigt, dass diese Auffassung der Natur wie auch der Kunst als in sich geschlossenes Ganzes zeitgleich mit der Diskussion um das Epische problematisch werden.

Die radikalste Formulierung der Autonomieästhetik stammt von Hegel, dem 1835 der Abbruch der kulturellen Tradition, und damit der Verlust jeglicher kulturstiftender und -erhaltender Kräfte der Kunst, so total wie endgültig erscheint. Diesen Nullpunkt der Kultur versucht Hegel ins Positive umzudeuten, wenn er die kulturell entleerte Gegenwart als Ursprung einer neuen Kunst inszeniert, die zwar nicht mehr zur Kulturbildung taugt, aber durch ihre gewonnene Autonomie den modernen Künstler zur freien Verfügung und Kombination aller Formen und Inhalte ermächtigt. In seiner Geschichtsphilosophie stellt er die Befreiung der Kunst auf Kosten der kulturellen Tradition als untrennbar verbunden mit dem historischen Prozess, besonders der darin angelegten Selbstbewusstwerdung des Individuums, dar und insofern als folgerichtigen Entwicklungsschritt. ${ }^{87}$ Die Loslösung der Kunst aus ihren kulturellen Verpflichtungen ist demnach eine Errungenschaft des reflexiven Denkens: „Die Bildung der Reflexion, die Kritik und bei uns Deutschen die Freiheit des Denkens" ${ }^{48}$ hätten die gegenwärtige Freiheit der Kunst herbeigeführt. Dass die Bezüge zwischen dem bestehenden kulturellen Archiv und der aktuellen Kunstpraxis durch fortgeschrittene Reflexionstätigkeit erodiert werden bzw. willkürlich und artifiziell erscheinen, erkennen und elaborieren Heinz Brüggemann und Sabine Schneider als problematische Diffusionsdynamik der kulturellen Moderne. ${ }^{89}$ Inwiefern das Aufkommen des kritischen Denkens

87 Vgl. Schneider, Sabine: „Ein Unendliches in Bewegung“. Positionierung der Kunst in der Kultur. In: Ehrmann; Wolf (Hrsg.): Klassizismus in Aktion. Goethes Propyläen und das Weimarer Kunstprogramm. S. 47-65, hier S. 48 f.: „Der moderne Künstler kommt so in eine Situation, wo er sein Verhältnis zu den Formen und Inhalten (er-)klären muss - es gibt ja keine verbindliche Tradition mehr, die das übernehmen würde - er ist gezwungen eine Selbstbegründung anzustellen und einen reflexiven Gegenwartsstanpunkt zu konstruieren. Geschichtsbewusstsein und kritisches, theoretisches, reflexives Denken (über Kunst) sind verknüpft." Vgl. auch Brüggemann, Heinz: Modernität im Widerstreit. Zwischen Pluralismus und Homogenität. Eine Theorie-, Kultur- und Literaturgeschichte (18.-20. Jahrhundert). S. 82 f. und Luhmann: Die Kunst der Gesellschaft. S. 257.

88 Hegel, Georg Wilhelm Friedrich: Vorlesungen über die Ästhetik II. Frankfurt a. M.: Suhrkamp 1995. S. 235 .

89 Vgl. Brüggemann, Heinz:Text-Bühnen. Pluralität als Zeitdiagnose, ästhetisches Programm und Spielform im 2o. Jahrhundert. In: Ders.; Schneider (Hrsg.): Gleichzeitigkeit des Ungleichzeitigen. Formen und Funktionen von Pluralität in der ästhetischen Moderne. S. 233-26o und ders.: Modernität im Widerstreit. Zwischen Pluralismus und Homogenität. Eine Theorie-, Kultur- und Literaturgeschichte (18.-20. Jahrhundert). S. $82 \mathrm{f}$. 
jedoch nicht nur die Beziehung von Kunst und Kultur gefährdet, ${ }^{90}$ sondern überhaupt aufs engste mit einer umfassenden Krisenerfahrung verbunden ist, hat Jaspers bereits 1930 festgestellt und als spezifische Problemerscheinung des 19. Jahrhunderts ausgewiesen:

Der Verfall hat einen geistigen Grund. Autorität war die Form der Bindung im Vertrauen; sie gab Gesetz für Ungewissheit und verband den Einzelnen mit dem Seinsbewusstsein. Diese Form ist im 19. Jahrhundert im Feuer der Kritik endgültig zerschmolzen. [...] Nach der Entzauberung durch die Wissenschaft werden wir der Entgötterung der Welt darin eigentlich bewusst, dass kein Gesetz der Freiheit mehr als unerbittlich gekannt wird, an seiner Stelle nur Ordnung, Mitmachen, Nichtstören bleibt. Kein Wollen aber kann wahrhaftige Autorität wieder herstellen. Nur unfreie Gewaltsamkeit würde an ihre Stelle treten. Was sie ersetzen könnte, musste aus neuem Ursprung wirklich werden. Die Kritik bleibt nur mehr Bedingung dessen, was werden könnte, aber sie vermag nicht zu schaffen. ${ }^{91}$

Wie Reinhardt Koselleck in seiner wegweisenden Dissertation durch die Rückführung des epochalen Bruchs der politischen Ordnung - der Französischen Revolution - auf die moralische Kritik der europäischen Aufklärung dargelegt hat, setzt die zersetzende Dynamik von Kritik und Krise schon lange vor Hegels Dialektik ein. ${ }^{92}$ Gleichwohl stellt die Krise nach Koselleck die zentrale Antriebskraft eines epistemologischen Paradigmenwechsels dar ${ }^{93}$ und erscheint gerade mit Blick auf Hegels Denken durchaus als produktiver Motor der Moderne. Erst der Geltungsverlust der alten Ordnungssysteme forciert die erneute Suche nach adäquaten Lösungen, auf Krisen wird mit der Bildung neuer Paradigmen reagiert. Die fortschrittsgläubige Geschichts- und Kunstphilosophie kann insofern als Krisenbewältigungsstrategie aufgefasst werden, die paradoxerweise gerade darauf ausgelegt ist, selbst immer wieder in die Krise zu geraten. ${ }^{94}$ Genau darauf macht Eva Geulen in ihrer wegweisenden Hegel-Lektüre aufmerksam, wenn sie dessen Rede vom Ende der Kunst als rhetorische Figur aufzeigt, die nicht primär das Beschreiben eines tatsächlichen

90 Vgl. Brüggemann: Modernität im Widerstreit. Zwischen Pluralismus und Homogenität. Eine Theorie-, Kultur- und Literaturgeschichte (18.-20. Jahrhundert). S. 82: „Die moderne Welt ist konstituiert durch die Herrschaft des sich seiner selbst bewussten Gedanken.“

91 Jaspers, Karl: Die geistige Situation der Zeit, 7. Abdruck der im Sommer 1932 bearbeiteten 5. Auflage. Berlin: de Gruyter 1971. S. 75 .

92 Vgl. Koselleck, Reinhart: Kritik und Krise. Eine Studie zur Pathogenese der bürgerlichen Welt. Frankfurt a. M.: Suhrkamp 1973. S. 3 o f.

93 Vgl. Kuhn, Thomas S.: Die Struktur wissenschaftlicher Revolutionen. Frankfurt a. M.: Suhrkamp 2012. S. 89 .

94 Vgl. Koselleck: Kritik und Krise. Eine Studie zur Pathogenese der bürgerlichen Welt. S. $154-156$. 
Endpunkts der Kunst zum Ziel hat, sondern vielmehr eine narrative Technik darstellt, um den Diskurs über Kunst und ihre Verortung in der Gegenwart immer wieder von neuem zu initiieren: „Das ist die Ästhetik Hegels, deren berühmtes Ende der Kunst die Moderne widerrief, bevor sie noch begonnen hatte, und ineins damit dafür gesorgt hat, dass immer wieder auf das Ende der Kunst gesetzt wurde. ${ }^{“ 95}$ Am Ende des Endes der Kunst stehe dann eben kein Ende, sondern ein Anfang: die Entdeckung des Endes der Kunst als ein genuiner Diskurs der Moderne. ${ }^{96}$

Wie Sabine Schneider dargelegt hat, werden auch die Vertreter der Weimarer Klassik darauf aufmerksam, dass die Beziehung zwischen Kunst und Kultur prekär gewordenen ist, und verknüpfen ihrerseits die Diagnose eines Geltungsverlusts traditioneller Formen mit der gewandelten geschichtsphilosophischen Situation sowie der modernen Subjektivierung. ${ }^{97}$ Sowohl Goethes kulturanalytische Äußerungen rund um das Italien-Projekt als auch die bereits vorgestellten Passagen des Briefwechsels mit Schiller - hier sei noch einmal an die Wellengangs-Metapher erinnert - stellen die diagnostizierte Krise der Kunst als Verlust kultureller Verbindlichkeit in Zusammenhang mit den gesamtgesellschaftlichen Entwicklungsprozessen, allem voran einer problematischen Dynamisierung der Zeit. Es ist wie bereits angedeutet gerade die bisherige Zeitordnung, die von der Wechselwirkung von Kritik und Krise besonders stark betroffen ist - Zukunft und Vergangenheit werden gewalthaft auseinandergerissen, ${ }^{98}$ neue Zeitbegriffe sowie überhaupt ein neues Verständnis von Zeit als kulturelles und politisches Organisationsprinzip werden nötig. ${ }^{99}$ Darauf macht auch Heinz Brüggemann in seinen Untersuchungen zu einer Ästhetik der Moderne ${ }^{100}$ dezidiert aufmerksam und entfaltet für die von Emanzipation und Verzeitlichung der Kunst geprägte Umbruchsphase um

95 Geulen, Eva: Das Ende der Kunst. Lesarten eines Gerüchts nach Hegel. S. 14 f.

96 Vgl. ebd. S. $28 \mathrm{f}$.

97 Vgl. Schneider: „Ein Unendliches in Bewegung“. Positionierung der Kunst in der Kultur. S. $47-65$.

98 Vgl. Koselleck: Kritik und Krise. Eine Studie zur Pathogenese der bürgerlichen Welt. S. 7 .

99 Koselleck benennt 5 Kriterien der ,Verzeitlichung der Geschichte' in seiner Charakterisierung des 18. Jahrhunderts als Beginn der ,Neuen Zeit': Beschleunigung, Erschließung einer offenen Zukunft, veränderte Sprachverwendung der saecula/Jahrhunderte als eigenständige, bedeutungsvolle Einheiten, Gleichzeitigkeit historischregionaler Ungleichzeitigkeiten, Bedeutungszuwachs historischer Perspektivierung, vgl. Ders.: Das achtzehnte Jahrhundert als Beginn der Neuzeit. S. 269-282, hier S. 278 f.

100 Vgl. Brüggemann, Heinz: Zeitgeister und ihre Raum-Bilder im Bau der Moderne. Zur Konstellation von Stilpluralität und "Zeitgeist" in der ästhetischen Moderne. In: Gamper, Michael; Schnyder, Peter (Hrsg.): Kollektive Gespenster. Die Masse, der Zeitgeist und andere unfassbare Körper. Freiburg i. B.: Reihe Litterae 2006. S. 331-354. 
1800 das Bild einer vielstimmigen, heterogenen Moderne, in der historische Kunstformen wieder verfügbar werden und in ihrer Vielfalt die „freie Selbstbewegung des Künstlers" befördern.101

Den Nexus zwischen Zeitdiagnose und Kunstkritik bringt Carl Ludwig Fernow in seinen Überlegungen zum Status der bildenden Kunst um 1800 auf den Punkt, wenn er konstatiert, dass die „schönbildenden Künste [...] zu unserer Zeit [...] nicht mehr zur Kultur tauglich sind ${ }^{402}$. In ihrer Debatte über epische und dramatische Dichtung reflektieren Schiller und Goethe diesen Ausfall der Kunst in der Gegenwart als Anarchie und Diffusion der Gattungen. Die zeitgenössischen oder vielmehr zeitgemäßen Formen beurteilen sie aufgrund ihrer formalen Disparatheit als kindisch, barbarisch und abgeschmackt - in anderen Worten: als vergnügungsorientierte Privatsache, die jeglicher Funktionalität für die Kultur entbehrt. Dabei wäre es gemäß Schillers Programm der ästhetischen Erziehung gerade die hehre Aufgabe der Kunst, den „sinnlichen Menschen vernünftig zu machen" ${ }^{103}$, also zwischen den menschlichen Trieben zur naturhaften Sinnlichkeit auf der einen und zur rationalen Wahrhaftigkeit auf der anderen Seite zu vermitteln. ${ }^{104}$ Wenn Schiller nun aber an Goethe schreibt: „Ihnen wird man Ihre Wahrheit, Ihre tiefe Natur nie verzeyhen[sic], und mir, wenn ich von mir / reden darf, wird der starke Gegensatz meiner Natur gegen die Zeit und gegen die Masse, das Publicum [sic] nie zum Freund machen können" ${ }^{105}$, dann macht er damit auch darauf aufmerksam, dass die neuen literarischen Formen wie der Roman aufgrund ihrer einseitigen Ausrichtung auf kurzfristige Unterhaltung und Massentauglichkeit gerade jeglicher kulturstiftenden Leistungs- und Vermittlungsfähigkeit entbehren. ${ }^{106}$

101 Brüggemann: Modernität im Widerstreit. Zwischen Pluralismus und Homogenität. Eine Theorie-, Kultur- und Literaturgeschichte (18.-20. Jahrhundert). S. 84.

102 Fernow, Carl Ludwig: Über die Kunstplünderungen in Italien und Rom. In: Der neue Teutsche Merkur, 1790-1810, Bd. 3 (1796). S. 249-279, hier S. 275 f.; vgl. auch Keller, Claudia; Schneider, Sabine: Die Kunst in der Kultur. Die Auseinandersetzung der Weimarer Kunstfreunde mit einer problematischen Konstellation. In: Rosenbaum, Alexander; Rössler, Johannes et al. (Hrsg.): Johann Heinrich Meyer - Kunst und Wissen im klassischen Weimar. Göttingen: Wallstein 2013. S. 141-156, hier S. 146.

103 Schiller, Friedrich: Über die ästhetische Erziehung des Menschen in einer Reihe von Briefen. S. 641-645.

104 Vgl. ebd. S. 604-6o6.

105 Schiller an Goethe, 18.11.1796, BW. S. 308.

106 Die These des Gegenstandsverlusts als historische Problemstellung für die Kunstpolitik der Weimarer Klassik geht auf Ernst Osterkamp zurück, vgl. Osterkamp, Ernst: Aus dem Gesichtspunkt reiner Menschlichkeit. Goethes Preisaufgaben für bildende Künstler 1799-1805. In: Schulz, Sabine; Apel, Friedmar (Hrsg.): Goethe und die Kunst. Ostfildern: Hatje 1994. S. 310-322, vgl. auch Busch, Werner: Das sentimentalische Bild. Die Krise der Kunst im 18. Jahrhundert und die Geburt der Moderne. München: Beck 1993. Zur 
Die traditionellen Formen aber - zu denen das Epos gehört -, welchen man eine öffentliche Wirksamkeit und verbindliche ästhetische Vermittlung noch zugesteht, werden nun zunehmend unproduktiv. Das Verständnis für sie nimmt ab - sie verschwinden in der Zeit, zusammen mit den Vorstellungen einer verbindlichen Kultur und einer gesellschaftsrelevanten Kunst. In ihrer Auseinandersetzung über Autonomiegewinn und kulturellen Geltungsverlust der Gattungen thematisieren und problematisieren Schiller und Goethe also indirekt die Dialektik von Kritik und Krise, die sich als produktiver Antrieb der kulturellen Moderne erweisen wird.

Im Gegensatz zu Hegel lässt die Krisendiagnose bei Goethe und Schiller allerdings keinen Fortschrittsoptimismus verspüren, sondern weist besorgt auf die gefährdeten bzw. bereits verlorenen Bindungen zwischen den einzelnen Formen der Literatur und dem System der Kultur hin. Der im Zeichen einer ständigen, krisenhaften Erneuerung stehenden kulturellen Moderne begegnen die Kunstfreunde in ihren Gattungsgesprächen mit grosser Skepsis, erkennen sie darin doch die problematischen Zersetzungstendenzen von unkontrollierter Beschleunigung und Vervielfältigung, die Goethe schon in der Abhandlung zur Metamorphose der Pflanzen als gefährlich, weil gestaltauflösend, ausgewiesen hat. Damit beweisen sie einen hellsichtigeren Einblick in die komplexen Modernisierungsbewegungen und ihre Konsequenzen für Verbindung von Kunst und Kultur als die Beschleunigungseuphoriker der neuen Mythologie. Koselleck ordnet dann die Krisendiagnostik der Epochenschwelle auch schrafsinnig als Gegenkanon zu Hegels Fortschrittsrhetorik ein, weil sie den Blick eben auf die Schattenseiten dynamischer Linearität richtet bzw. darauf verweist, dass das Ordnungsmodell des Fortschritts bereits in seiner Entstehungsphase prekär ist. ${ }^{107}$

Anders auch als die zeitgenösssiche romantische Kunsttheorie, die die Loslösung der Kunst aus sozialen, politischen oder moralischen Kontexten und das gleichzeitige Verfügbarwerden von Inhalten und Formen positiv fasst, ${ }^{108}$ lenken Goethe und Schiller die Aufmerksamkeit auf die Entstehungskosten der autonomen Kunst. Die gravierenden Veränderungen im Kunstsystem und Funktionsverschiebungen beobachten sie nicht zuletzt deshalb mit Argwohn, weil sie die Schicksalszäsur von 1790 als Bruch in der Kulturgeschichte erleben,

Moderneauseinandersetzung in Schillers ästhetischen Programmen vgl.Noetzel, Wilfried: Friedrich Schillers Philosophie der Lebenskunst. Zur Ästhetischen Erziehung als einem Projekt der Moderne. London: Turnshare 2006.

107 Vgl. Koselleck: Kritik und Krise. Eine Studie zur Pathogenese der bürgerlichen Welt. S. 7 .

108 Vgl. Schneider: Das sentimentalische Spiel mit den Archiven des kulturellen Gedächtnisses. Schillers ludistische Ästhetik als Reflexion auf die Bedingungen künstlerischer Produktivität am Beginn der Moderne. S. 242-261, hier S. 248. 
der eine explizit neue Zeit der kulturellen Gefährdung einläutet. Im Disput um Epos und Roman wird diese eigene, dezidiert durch Akzeleration, Steigerung und Ausdifferenzierung gekennzeichnete Modernerfahrung artikuliert und auf die konkreten entleerenden Auswirkungen der Verzeitlichung nicht nur auf das System der Kunst, sondern auch auf dessen Beschreibung verwiesen, wodurch der Diskurs auf eine Beobachtungsebene zweiter Ordnung gehoben wird. ${ }^{109}$ Gleichzeitig kann gerade Goethes Einstellung zur Moderne, wie sie im Briefwechsel zum Ausdruck kommt, nicht auf eine pessimistische und konservative reduziert werden, fragt er doch immer wieder dezidiert nach Möglichkeiten des Anschließens der Kunst an die gegenwärtigen Bedingungen. Damit wirkt er bewusst einer einseitigen Beurteilung der Moderne als endgültigem Bruch der Kulturtradition entgegen und lenkt die Aufmerksamkeit vielmehr auf die mögliche Fortschreibung einer kontinuierlichen, kulturstiftenden Kunstentwicklung über den Bruch hinaus.

Dass diese Probleme am Gegenstand des Erzählens gerade besonders virulent werden, erstaunt nicht: Erzählen, als schriftliches oder mündliches Aneinanderreihen von kausal verknüpften Begebenheiten, benötigt Zeit - die Zeitgeschichte ${ }^{110}$ spult sich nun aber so schnell ab, dass die einzelnen Ereignisse und ihre Wechsel gar nicht mehr einholbar sind im zeitlich gedehnten Nacheinander des Erzählens. ${ }^{111}$ Daraus lässt sich eine grundsätzliche Inkompatibilität zwischen Modernität und dem Erzählen überhaupt - nicht nur dem Epos - ablesen, die an Schillers Romankritik besonders deutlich wird: Gegenwärtiges kann gar nicht mehr erzählt werden, und ein beschleunigtes Erzählen ist kein wirkliches, höheren künstlerischen bzw. kulturellen Ansprüchen genügendes Erzählen. Das erklärt aber gerade auch, wieso die Frage nach dem Erzählen für die Moderne so virulent und spezifisch das Epische so wichtig werden: Die typisch modernen Erzählformen - Roman, Novelle, Kurzprosa vermögen den Verlust des Epos als wahrhaftes, weil langsames und stilistisch anspruchsvolles Erzählen, nicht zu kompensieren. Sie sind stattdessen dezidiert darauf ausgerichtet, die neue, moderne Realität narrativ wiederzugeben formal sind sie auf Kurzfristigkeit, schnelle Sprach- und Ereignisabfolge sowie Diskontinuität ausgelegt, inhaltlich verhandeln sie Autonomie, Isolation und Entfremdung. Das sind nun gerade die zentralen Problemstellungen, die in der Debatte zwischen Musil, Döblin und Benjamin am Anfang des

109 Vgl. Luhmann: Die Kunst der Gesellschaft. S. 213 f.

110 Der Begriff wird bezeichnenderweise auch um 1800 aktuell, vgl. Koselleck, Reinhart; Gadamer, Hans-Georg (Hrsg.): Zeitschichten. Studien zur Historik. Frankfurt a. M.: Suhrkamp 200o. S. 25 o ff.

111 Vgl. Oesterle: „Es ist an der Zeit!“ Zur kulturellen Konstruktionsveränderung von Zeit gegen 180o. S. 91-121, hier S. $100 \mathrm{f}$. 
20. Jahrhunderts virulent werden ${ }^{112}$ und den Eposdiskurs der Epochenschwelle in eine geistige Linie mit der Krise des Erzählens in der klassischen Moderne stellen: Zum einen die Feststellung, dass die Autonomisierung der Kunst mit einem Vertrauensverlust in das Kunstsystem einhergeht, und zum anderen die Bemühung, die Leistungen und Funktionen, die eben die autonomen neuen Formen nicht mehr zu erbringen wissen, alternativen Verfahren zuzuweisen. Insofern geht das epische Erzählen, dessen kulturelle Leistungsfähigkeit an die spezifischen Zeitlichkeiten von Langsamkeit und Kontinuität gekoppelt ist, seiner Berechtigung durch die historischen Veränderungen nicht etwa verlustig, sondern ist gerade deshalb als integrativer Teil einer vielseitigen Moderne aufzufassen, der bis in die Gegenwart Relevanz hat.

\subsubsection{Die Ästhetische Eigenzeitlichkeit des Erzählens}

Von diesem Zusammenhang zwischen veränderter Zeiterfahrung und abgebrochener oder zumindest brüchig gewordener Verbindung zwischen Kultur und Kunst erzählt die Wellengang-Metapher: An der Epochenschwelle um 1800 ist die Zeit in Bewegung geraten und droht dabei ihre grundlegende Organisationsmacht ${ }^{113}$ einzubüßen. Koselleck hat diesen Wandel der Zeitstrukturen an den Ausbruch der Französischen Revolution von 1789 und eine damit einhergehende historische Beschleunigungserfahrung gebunden ${ }^{114}$ die Zeit der Revolution führt demnach unmittelbar zur Revolution der Zeit. Im deutschen Kulturraum beginnen sich ab 1792 neue Zeiterfahrungen zu manifestieren, ${ }^{115}$ deren Beschreibung und Problematisierung bezeichnender-

112 Vgl. S. 31 ff. in diesem Buch.

113 Zeit ist als kulturspezifische Konstruktion (anstatt als merkmalsvermitteltes Naturphänomen, z.B. Ablauf von Tages- und Jahreszeiten) stets abhängig von und nur gültig in einem Bezugssystem aus kulturellem Kontext, Technik der Zeitmessung und zeitordnungspolitischer Umsetzung. Zeitbegriffe sind deshalb immer Ordnungsbegriffe, Zeitvorstellungen immer Ordnungsprinzipien. Sie unterliegen deshalb staatlicher Aufsicht und dienen der Normierung, Harmonisierung und Lenkung individuellen sowie gesellschaftlichen Handelns, sie regeln das Speichern von Erfahrungen und Geschehnissen im je zeitordnungsabhängigen Erinnerungssystem der Geschichte. Als ordnungspolitische Kategorie betrifft die Zeitpolitik (Zeitgesetzgebung wie z.B. Kalender, Öffnungszeiten) alle anderen politischen und sozialen Bereiche, sie entscheidet mit über die Vergabe gesellschaftlicher Chancen und Öffentlichkeitsstrukturen, sie lenkt den Zugriff auf Erinnerungsspeicher und schließt bestimmte Positionen sowohl von öffentlicher Wirksamkeit wie auch vom Erinnerungssystem der Geschichte aus, vgl. Dücker, Burckhard: Zeit. In: Nünning, Ansgar (Hrsg.): Metzler Lexikon Literatur- und Kulturgeschichte. Ansätze - Personen - Grundbegriffe. S. 782 f.

114 Vgl. Koselleck: Vergangene Zukunft. Zur Semantik geschichtlicher Zeiten. S. 63.

115 Vgl. Becker: Zeit der Revolution! - Revolution der Zeit? Zeiterfahrungen in Deutschland in der Ära der Revolutionen 1787-1848/49. S. 37 ff. 
weise in die Zeit des forcierten Gattungsdiskurses fallen. Das konstatiert auch Oesterle, die den Kunstdiskurs in der ersten Hälfte der goer Jahre des 18. Jahrhunderts durch den Zusammenbruch der überkommenen Konstruktionen und den Verlust von Dauer geprägt sieht, während dann in der zweiten Hälfte unterschiedliche ästhetische Eigenzeiten, die allesamt am Problem einer "Gewährleistung von Dauer bei gleichzeitiger Inkonsistenz- und Veränderungsbeschleunigungserfahrung der Geschichte ${ }^{\star 116}$ operieren, generiert, ausprobiert und auch verworfen werden. Allerdings spricht sie den daran beteiligten Akteuren eine Einsicht in die Tatsache, dass diese Erfahrung von ständigen Wechseln und Veränderungen weder revolutionsspezifisch noch revolutionsverursacht sind, kategorisch ab. ${ }^{117}$ Dabei haben die obigen Ausführungen zu Goethes morphologischem und ästhetischen Formdenken gerade einen ganz anderen Schluss nahegelegt: den nämlich, dass dessen Einschätzung von Dynamik und Vielfalt sehr wohl über einen einseitigen Krisenund Katastrophenbefund hinausgeht und er im Begriff des Schwankens gerade den ständigen Wechsel sowohl als dauerhafte Gesetzhaftigkeit akzeptiert als auch vom Ereignis der Revolution loslöst.

Die komplexe Überschreibung von ästhetischer Temporalisierung, wertender Gattungshierarchie und moderner Kulturkritik, die sich im Disput über den Roman angebahnt hat, steht in radikalisierter Formulierung am Beginn des Aufsatzes Über epische und dramatische Dichtung: Der Hauptunterschied zwischen epischer und dramatischer Dichtung liegt für Schiller und Goethe darin, dass „der Epiker die Begebenheit als vollkommen vergangen vorträgt und der Dramatiker sie als vollkommen gegenwärtig darstellt". ${ }^{118}$ Vergangenheit und Gegenwart werden damit als grundsätzlich entgegengesetzte, gattungsdefinierende Zeitmomente markiert - Epos und Vergangenheit werden darüberhinaus im Zeichen der Vollkommenheit idealisiert, aber gleichwohl als abgeschlossen und unzugänglich inszeniert. Bei genauem Hinsehen erweist sich diese Absolutsetzung der vollkommenen Vergangenheit bzw. Gegenwart allerdings als Bemühen um eine klare, schematische Abgrenzung zwischen den Zeiten, die sich dezidiert gegen deren tatsächliches Reflexivwerden richtet. Die bisherige kulturelle Zeit-Konstruktion - als feste Ordnung von bekannter Vergangenheit und sich daraus erschließender Zukunft - ist ab der Mitte der 179oer Jahre mit einer vehementen geschichtlichen Beschleunigungserfahrung konfrontiert, die in bis zu diesem Zeitpunkt einzigartiger Verdichtung alle

116 Oesterle: „Es ist an der Zeit!“ Zur kulturellen Konstruktionsveränderung von Zeit gegen 180o. S. 91-121, hier S. 99.

117 Vgl. ebd.

118 Über epische und dramatische Dichtung, BW. S. 538. 
Bereiche und Ebenen der Kultur erfasst. Von der tiefen Verunsicherung und Skepsis gegenüber dieser historischen Prozessualität und Auflösung zeugt dann auch das dreidimensionale Geschichtsmodell von Vergangenheit, Gegenwart und Zukunft, das nun virulent wird.

Oesterle hat in ihrem Aufsatz zu Luhmanns Formulierung eines „Führungswechsels der Zeithorizonte“ - der im Wesentlichen eine Umorientierung weg von der Vergangenheit, hin auf die Zukunft beschreibt - aufgezeigt, wie dieser Vorgang gerade exemplarisch an der Bedeutungsgeschichte des Gegenwartsbegriffs nachverfolgt werden kann. ${ }^{119}$ Der bis in die Mitte des 18. Jahrhunderts rein räumlich besetzte Begriff der Gegenwart wird erst um eine genuin zeitliche Bedeutung erweitert, als um 179o das Fehlen eines Begriffs für das Jetzt, für zeitlich Koexistierendes, als Mangel deutlich wird. ${ }^{120}$ Die explizite Verwendung des Gegenwart-Begriffs als Zeitkategorie belegt nicht nur ein wachsendes Bewusstsein für die reflexive Verfasstheit der Zeitbestimmungen, ${ }^{121}$ sondern auch, wie unerläßlich überhaupt eine kritische Selbstreflexion geworden ist: ${ }^{122}$ Das Jetzt schiebt sich als zusätzliche, eigenständige historische Zeitdimension zwischen Zukunft und Vergangenheit und dynamisiert so das Zeitgefüge - da das Jetzt immer relativ, flüchtig ist, unterläuft die Zeitkategorie der Gegenwart die bisherige Vorstellung eines fixierten Zeitgefüges von tradierter Vergangenheit und vorbestimmter Zukunft.

Diese Art der Gegenwartssetzung, das hat Johannes F. Lehman eindrücklich aufgezeigt, bedarf allerdings stets einer Selbstpositionierung des Betrachters, der sich selbst als Teil einer wandelbaren Zeit versteht. ${ }^{123}$ Die nur temporär existierende Gegenwart hat immer auch einen Vergangenheits- und

119 Oesterle, Ingrid: Der ,Führungswechsel der Zeithorizonte in der deutschen Literatur. Korrespondenzen aus Paris, der Hauptstadt der Menschheitsgeschichte, und die Ausbildung der geschichtlichen Zeit ,Gegenwart'. In: Grathoff, Dirk (Hrsg.): Studien zur Ästhetik und Literaturgeschichte der Kunstperiode (= Gießener Arbeiten zur neueren deutschen Literatur und Literaturwissenschaft, Bd. 1). Frankfurt a. M.: Lang 1985. S. 11-76. Zur Geschichte des Gegenwartsbegriffs vgl. auch Geyer; Lehmann: Aktualität. Zur Geschichte literarischer Gegenwartsbezüge und zur Verzeitlichung der Gegenwart um 180o. S. $33-56$.

120 Vgl. Oesterle: Der ,Führungswechsel der Zeithorizonte' in der deutschen Literatur. Korrespondenzen aus Paris,der Hauptstadt der Menschheitsgeschichte, und die Ausbildung der geschichtlichen Zeit,Gegenwart'. S. 11-76, hier S. 17 f.

121 Vgl. dies.: „Es ist an der Zeit!“ Zur kulturellen Konstruktionsveränderung von Zeit gegen 180o. S. 91-121, hier S. 97. Bis 180o bezeichnet Gegenwart die Anwesenheit und Präsenz an einem Ort, ist also eine räumliche Kategorie.

122 Vgl. Geyer; Lehmann: Aktualität. Zur Geschichte literarischer Gegenwartsbezüge und zur Verzeitlichung der Gegenwart um 180o. S. 33-56, hier S. 33 .

123 Vgl. ebd. S. 37 sowie Lehmann, Johannes F.: Gegenwartsliteratur - Begriffsgeschichtliche Befunde zur Kopplung von „Gegenwart“ und „Literatur“. In: Geyer, Stefan; Lehmann, 
einen Zukunftsindex - Koselleck spricht sogar zugespitzt von „vergangenen Zukünften“. ${ }^{124}$ Nach Luhmann ist es gerade das Reflexivwerden der Zeiten, „in dem der Historismus als die Ermöglichung der Differenz gegenwärtiger Vergangenheit und vergangenen Gegenwarten [...] wurzelt “. ${ }^{125}$ Die Vergangenheit allerdings, als bisher unhinterfragter Hort der verbindlichen Geschichte, verliert dadurch ihre rückversichernde Relevanz für Gegenwart und Zukunft. Es lassen sich keine prognostischen Aussagen mehr machen von einer derartig beweglichen Position aus ${ }^{126}$ und die Vorstellung eines die Zukunft von der Vergangenheit aus verbürgenden Zeitkontinuums wird fragwürdig. Damit erweisen sich die epistemologischen Strukturen des Sammelns und Vergleichens, ${ }^{127}$ die sich der linearen Sukzzessivität entziehen, als ausschlaggebend - durch sie lässt sich nun überhaupt erst eine übergeordnete Struktur erkennen, die die Geschichte jenseits der einmaligen Einzelereignisse fassbar und dadurch auch sinnhaft macht. Für Koselleck ist es deshalb eine der wichtigsten Aufgaben der Geschichtswissenschaft, solche Muster der Verdichtung überhaupt erst sichtbar und dann verstehbar zu machen. ${ }^{128}$ Diesem Anspruch gerecht zu werden, wird allerdings mit zunehmender Diversifizierung, Pluralisierung und Überlagerung der Zeitverhältnisse immer schwieriger.

Die Entwicklung eines neuen Zeitregimes und eines damit einhergehenden Geschichtsbewusstseins reflektiert der Aufsatz Über epische und dramatische Dichtung äußerst kritisch: Die Relativität zwischen Vergangenheit und Zukunft, die der verzeitlichte Gegenwartsbegriff überhaupt erst zum Ausdruck bringt, wird mit der Konstruktion absoluter, vollkommener Zeiten konterkariert - dem unablässigen Wechsel und der Veränderung der Zeiten wird antithetisch die Idee einer fixierten, klar abgeschlossenen Zeit entgegengestellt. Das Darstellungsgesetz des ,vollkommen vergangenen' aktualisiert im Epos die griechische Antike als Sehnsuchtsort eines bruchlosen, unmittelbaren Verhältnisses zwischen Kunst und Natur sowie einer integralen, sozialen

Johannes F. (Hrsg.): Aktualität. Zur Geschichte literarischer Gegenwartsbezüge vom 17. bis zum 21. Jahrhundert. Hannover: Wehrhahn 2018. S. 37-6o.

124 Koselleck: Vergangene Zukunft. Zur Semantik geschichtlicher Zeiten. S. 17-37.

125 Luhmann, Niklas: Weltzeit und Systemgeschichte. In: Baumgartner, Hans Michael; Rüsen, Jörn (Hrsg.): Seminar: Geschichte und Theorie. Umriss einer Historik. Frankfurt a. M.: Suhrkamp 1976. S. 337-387, hier S. 354.

126 Vgl. Koselleck: Vergangene Zukunft. Zur Semantik geschichtlicher Zeiten. S. 54 und 6o ff. 127 Vgl. S. $101 \mathrm{ff}$. in diesem Buch.

128 Vgl. Koselleck: Vergangene Zukunft. Zur Semantik geschichtlicher Zeiten. S. 149; vgl. dazu auch Köhler, Christian: Zur historischen Zeit als Kategorie der Medienhistorik. In: Öhlschläger, Claudia; Capano, Lucia Perrone (Hrsg.): Figurationen des Temporalen. Poetische, philosophische und mediale Reflexionen über Zeit. Göttingen: V\&R unipress 2013. S. $45^{-63}$. 
Gemeinschaft, allerdings ist dieser ideale Kulturraum verloren in der Zeit. Damit scheint das Eposkonzept jeglichen Aktualitätsbezug auszuschließen und sich einer Anknüpfungsmöglichkeit an die Gegenwart kategorisch zu entziehen. Hier setzen offensichtlich die Deutungen des klassizistischen Epos als Ausdruck einer konservativen Restaurationsbemühung, als Abkehr der Kunst von der Gegenwart an und in diese Richtung geht auch die Interpretation Bachtins, der das epische Erzählen als ein Sprechen über eine für den Autor „unerreichbare Vergangenheit" auslegt. ${ }^{129}$

Die im Aufsatz von Schiller und Goethe vorgeschlagene Rekonzeptualisierung von Zeit und Zeitlichkeit ist aber bei genauerer Betrachtung eine viel komplexere - sie dient nicht nur als Beleg für die allgemeine fortschrittsorientierte Verzeitlichung um 180o, sondern verweist gerade auch auf die gegenläufige Tendenz hin zu pluralen Zeitvorstellungen. ${ }^{130}$ Vor allem die Ausführungen zum Begriff der Retardation und seiner prominenten Positionierung werden das deutlich machen. Oesterle benennt die Isolation von einzelnen Momenten bzw. eine "Momentarisierung der Zeit" als Konsequenz des „Enteilens der Zeit in eine unabsehbare Zukunft und des Wegbrechens der Vergangenheit“.131 Genau darauf, dass der Beschleunigung nur mit temporärem Festhalten von Momenten entgegengewirkt werden kann, macht Goethe sowohl mit seinem organischen Formbegriff der Verwandlung, der Idee der Prägnanz wie auch mit seiner Moderne-Metapher des Schiffbruchs aufmerksam. Das Ausschlaggebende an der epischen Zeitlichkeit ist dann auch ihre ambivalente Struktur, die zwischen der Rigidität einer vollkommenen, stillstehenden Zeit und der entfesselten Dynamik einer chaotischen Zeiten-Gemengelage als eine Lizenz zur freien, aber gemächlichen Bewegung zwischen den Zeiten und den Zeitkonstruktionen hin und her schwankt. Damit wird die Eigenzeit des Epos als eine dynamische entworfen, die auf dem an der Natur beobachteten Lebensprinzip der allmählichen Bewegung beruht. Das Epos wird so gleichzeitig als vergangen, gegenwärtig und zukünftig, als zeitlich abgeschlossen und anschlussfähig konzipiert. Insofern scheint Goethe Wolfs These von der Genese des Epos über die Zeit hinweg

129 Bachtin, Michail M.: Epos und Roman. Zur Methodologie der Romanforschung. In: Kowalski, Edward; Wegner, Michael (Hrsg.): Untersuchungen zur Poetik und Theorie des Romans, aus dem Russischen von Michael Dewey. Berlin, Weimar: Aufbau 1986. S. 465506, hier S. 476 .

130 Vgl. Brüggemann: Text-Bühnen. Pluralität als Zeitdiagnose, ästhetisches Programm und Spielform im 20. Jahrhundert. S. 233-26o.

131 Oesterle: „Es ist an der Zeit!“ Zur kulturellen Konstruktionsveränderung von Zeit gegen 180o. S. 91-121, hier S. 8. 
durchaus eine positive Seite abzugewinnen, ermöglicht sie doch, das Epische in und für alle Zeiten produktiv zu machen. ${ }^{132}$

Die Reflexion über das Epische als vollkommen Vergangenes erweist sich dadurch als äußerst scharfsinnige poetologische und ästhetische Reaktion auf die Erfahrungen von Beschleunigung und Diskontinuität der Moderne. Es wird die Kehrseite linear ausgerichteter Zeit sichtbar gemacht, die sich immer nur auf ein flüchtiges, unmittelbares Jetzt beschränkt und dadurch den Sinn für und den Zugriff auf überzeitliche Phänomene von Dauer - sprich die traditionelle Kulturgeschichte - verliert. Das erfordert einerseits ein geschärftes Bewusstsein für Phänomene des Kurzfristigen, Temporären ${ }^{133}$ und lenkt andererseits die Aufmerksamkeit bewusst auf das Beharren und Ausdehnen von Zeit sowie auf die besondere Lizenz bestimmter kultureller Produkte wie dem Epischen, sich der allgemeinen Verzeitlichung zu entziehen. Gerade in diesem Ausharren erscheint nun überhaupt die Möglichkeit, an die kulturell wertvolle Kunst der Vergangenheit anzuschließen. Insofern bildet die rückwärtsgerichtete Zeitstruktur des Epos, „das Gegenwärtige zum Vergangenen“"134 zu machen, formspezifisch eine kritische Reflexion über die Gegenwart ab, aber auch über die allgemeine Hinwendung zur Gegenwart als einzigem, flüchtigen Moment von Wirklichkeit. ${ }^{135}$ Durch das ihm eingeschriebene Zeitlichkeitsparadox wird das Epos auf das Bewahren des kulturhistorischen Kontinuums ausgerichtet, das durch die Bruch-Erfahrung der Moderne überhaupt erst als sentimentalisches Bedürfnis erkennbar wird und vom Roman gerade nicht abgedeckt wird. Anstatt die dialektischen Oppositionen von Vergangenheit und Gegenwart gegeneinander auszuspielen, können sie in dieser Vorstellung füreinander nutzbar gemacht und das Alte in etwas Neues verwandelt werden, ohne seine

132 Vgl. Buschmeier, Matthias: Epos, Philologie, Roman. Wolf, Friedrich Schlegel und ihre Bedeutung für Goethes Wanderjahre. In: Goethe Jahrbuch 125 (2008). S. 64-79, hier S. 76.

133 Für die klassische Moderne um 1900 und durch das 20. Jahrhundert hindurch können komplementär die populären Kurzformen als exponierte Schauplätze (Experimentierräume) eines narrativen Bewusstwerdens und Ausstellens von dargestellter Kürze geltend gemacht werden, Augenblick und Momentaufnahme sind hier inspiriert-künstlerische Schöpfungsmomente im Zeichen des Plötzlichen. Sie enthalten heterogene Konzepte ästhetischer Eigenzeit und intensivieren die Spannung eines paradoxen Zeitbewusstseins, vgl. dazu Öhlschläger, Claudia: Augenblick und lange Dauer. In: Dies.; Perrone Capano, Lucia (Hrsg.): Figurationen des Temporalen. Poetische, philosophische und mediale Reflexionen über Zeit. S. 93-106.

134 Friedrich Schiller: Über die tragische Kunst. In: Ders.: Werke und Briefe in zwölf Bänden, hrsg. v. Otto Dahn u.a., Bd. 8. Deutscher Klassiker Verlag 1992. S. 270.

135 Vgl. Lehmann: Ist die Romantik modern oder vormodern? Folgerungen. S. 149-157, hier S. 153 . 
eigene Signatur zu verlieren. ${ }^{136}$ Goethe scheint das Anknüpfen der modernen Kunstbedingungen an ein vergangenes, episches Zeitalter und an alles, was der sehnsüchtige Rückblick darauf hineinzulesen vermag, also durchaus prekär, aber im entscheidenden Unterschied etwa zu Bachtin nicht unmöglich. ${ }^{137}$

Im Anschluss an diese Ausführungen scheint sich die These zu verdichten, dass das Epische um 1800 zum ausgewiesenen Reflexionsmedium der historischen Erfahrung eines unwiderruflichen Zeitenbruchs wird. Goethe und Schiller entwerfen die Poetologie des epischen Erzählens als ein bewusstes, integratives Gegenmodell zu den romantisch-autonomen Kunstformen und zeigen deren Entstehungskosten auf - Kulturverlust, Traditionsabbruch, Trivialisierung. Die Loslösung der Kunst aus einer gesellschaftsrelevanten Funktion ist zwar der produktive Motor für die autonomen modernen Programme wie dem Roman. Diese Befreiung aus den alten, rigiden Ordnungssystemen erzeugt aber auch eine Leerstelle, die in der fortschreitenden Moderne immer schwieriger zu füllenist. Im Gegensatz zu Schlegels neuer Mythologie soll das Epische, wie es im Briefwechsel der Weimarer Kunstfreunde konstituiert wird, die abgebrochene Kulturtradition nicht restlos ersetzen, sondern einen möglichen Anschluss daran vorstellen und zwar ohne über die Krisenerfahrung hinwegzutäuschen. Die epische Alternative stützt sich dabei äußerlich auf längst Vergangenes, Unzeitgemäßes - eine anspruchsvolle, hochpoetische Sprache, ausführliche Beschreibungen und ein langsames Erzähltempo - betreibt aber gerade dadurch auch eine gezielte Vergegenwärtigung. Modern zu sein bedeutet nämlich nicht, das unendliche Fortschreiten und die Beschleunigung der Zeit anzuerkennen und anzunehmen, sondern eine bestimmte Haltung gegenüber dieser Dynamisierung einzunehmen. Wenn das Epische also auf Entschleunigung ausgerichtet und damit die Hoffnung auf einen kontinuierlichen Fortgang der Kulturgeschichte verbunden wird, ist das nicht gezwungenermaßen konservativ, sondern vielmehr Ausdruck eines sensiblen Bewusstseins für die Krise der Kunst und einer skeptischen Haltung gegenüber der Akzelerationstendenz der Moderne.

${ }_{13} 6$ Vgl. Görner, Rüdiger: Ästhetik der Wiederholung. Versuch eines literarischen Formprinzips. Göttingen: Wallstein 2015. S. 19.

137 Die systematische Zuweisung von Zeiten bzw. Zeitlichkeiten und Gattungen resp. literarischer Form entspricht der allgemeinen Historisierungstendenz des 19. Jahrhunderts. Hegel wird die literarischen Gattungen dann endgültig in ein telelogisches Weltbild überführen und damit das Ende des Epos begründen. Durch die Zuweisung von historischen Epochen bzw. Stufen der menschlichen Bewusstseinsentwicklung und Gattungen - spezifisch die Bindung des Epos an einen vor-modernen Kulturzustand wird das Epos in der Moderne unmöglich, oder vielmehr scheint das, epische Zeitalter' in einer unerreichbaren Vergangenheit zu liegen. 


\subsubsection{Die Lizenzen des Epischen}

Mit der poetologischen Konstruktion des Epischen als vollkommen vergangenes werfen Goethe und Schiller also einen skeptischen Blick auf die neue, reflexive Geschichtszeitkategorie der Gegenwart und beweisen damit ein sensibles Bewusstsein für den Zeit-Regime-Wechsel der Moderne. Die einseitige Ausrichtung auf den Zeithorizont der Zukunft sowie die damit einhergehende Entkoppelung von Vergangenheit und Zukunft stehen für sie in unmittelbarem Zusammenhang mit dem diagnostizierten Kulturzerfall - im Roman finden diese problematischen Zeitveränderungen ihre poetologische Entsprechung. Mit der Ausrichtung auf die Vergangenheit und den damit verbundenen Vorstellungen von Dauer und Kontinuität wird das Epische zum ästhetischen und formalen Gegenprogramm und bleibt gleichzeitig auf die moderne Gegenwart bezogen. Der Anschluss an das antike Epos, der Zugriff auf die ihm eingeschriebene Vergangenheit und vor allem auf die darin eingeschlossenen Vorstellungen von einer intakten Kulturgemeinschaft und unverfälschten Kunst werden im Aufsatz von Goethe und Schiller nämlich als von vorneherein problematische Aufgaben des modernen Epikers dargestellt. Dieser ist wie alle Dichter dem allgemeinen Gesetz der Dichtkunst verpflichtet, „alles sinnlich gegenwärtig“ zu machen. Er steht vor der apriori unlösbar scheinenden Aufgabe, „das Geschehene zu vergegenwärtigen“, ohne „dass der Character des Vergangenseyns [sic] [...] verwischt werden darf“. ${ }^{138}$ Er soll also ein Kunstwerk dichten, dass gleichzeitig dem Anspruch der Zeitgenossenschaft genügt und doch frei ist vom Dekadenzmerkmal, das dem Gegenwärtigen zumindest in Bezug auf die Kunst zu diesem Zeitpunkt angelastet wird. Die Erwartungen an die unterschiedlichen Darstellungsformen des Epischen und des Dramatischen werden also an die Zeitbegriffe von Vergangenheit und Gegenwart gekoppelt und gleichzeitig wird eine übergeordnete Zeitgenossenschaft der Kunst gefordert. In diesem vermeintlich krassen Widerspruch zeigt sich, dass die Forderungen nach Überzeitlichkeit und Normativität auf der einen und Historizität, Individualität und Autonomie auf der anderen Seite ineinandergreifende, komplementäre Aspekte der Kunstbetrachtung der Epochenschwelle sind. Für diese unterschiedlichen, sich zuweilen konkurrenzierenden Vorstellungen von Zeitzuständen und -abläufen beweist Goethe schon ganz zu Beginn der Diskussion um das Epische ein ausgeprägtes Gespür, wenn er auf ihr jeweils genuines Darstellungspotenzial hinweist:

138 Schiller an Goethe, 26.12.1797, BW. S. 542. 
Da es [das epische Gedicht] in der größten Ruhe und Behaglichkeit angehört werden soll [...]. Eine Haupteigenschafft [sic] des epischen Gedichts ist dass es immer vor und zurück geht, daher sind alle retardirende [sic] Motive episch. Es dürfen aber keine eigentliche Hindernisse seyn welche eigentlich ins Drama gehören. Sollte dieses Erforderniss des Retardirens, [...] wirklich wesentlich und nicht zu erlassen seyn, so würden alle Plane die grade hin nach dem Ende zu schreiten völlig zu verwerfen oder als eine subordinirte [sic] historische Gattung anzusehen seyn [sic]. [Hervorhebung M.E.] $]^{139}$

Der Begriff der Retardation wird später im Aufsatz noch vom Begriff der Retrogradation abgegrenzt, aber diese feine Unterscheidung ist an dieser Stelle noch nicht gegeben. Hier wird mit retardierend einerseits ein kontemplativer Bewusstseinszustand beschrieben und dem Epos zugewiesen, der eine deutliche Absetzung zur neugier- und spannungserzeugenden Romansituation darstellt, und andererseits wird das Verzögern der Handlung durch Vor- und Rückgriffe in der chronologischen Ordnung als entscheidende innere Präfiguration des Epischen beschrieben. Schiller bestätigt die Kontemplation als zentrale epische Eigenschaft, die sich explizit gegen Ungeduld und Eile richtet:

er [der epische Dichter] schildert uns bloss das ruhige Daseyn und Wirken der Dinge nach ihren Naturen, sein Zweck liegt schon in jedem Punkt seiner Bewegung, darum eilen wir nicht ungeduldig zu einem Ziele sondern verweilen uns mit Liebe bei jedem Schritte. / Er erhält uns die höchste Freiheit des Gemüths, und da er uns in einen so großen Vortheil setzt, so macht er dadurch sich selbst das Geschäft desto schwerer, denn wir machen nun alle Anforderungen an ihn, die in der Integrität und in der allseitigen vereinigten Thätigkeit [sic] unserer Kräfte gegründet sind. [...] Ihre Idee von dem retardierenden Gange des epischen Gedichts leuchtet mir ganz ein. [Hervorhebungen M.E.] ${ }^{140}$

Schiller ist mit dem Retardieren als widerstrebender Gangart des Epischen insofern einverstanden, differenziert diese dann aber weiter aus, indem er die Retardation als ein bewusstes Moment des Verharrens mit einem spezifisch ästhetischen Potenzial beschreibt und es mit einer größeren geistigen Bewegungsfreiheit in Verbindung bringt. Damit stellt er eine Verbindung zu seinem eigenen, in den Briefen über die ästhetische Erziehung formulierten Begriff der Schönheit als Freiheit in der Erscheinung her ${ }^{141}$ - die im Epos maximal erhaltene geistige Freiheit setzt auch die äußere Gestalt frei und gereicht ihr zu einer überragenden Schönheit. Dieser Konnex von Verlangsamung, Verharren einerseits und Beweglichkeit, Freiheit andererseits zu

139 Goethe an Schiller, 19.4.1797, BW. S. 375 f.

140 Schiller an Goethe, 21.4.1797, BW. S. 377.

141 Vgl. Schiller: Kallias oder über die Schönheit. S. 400 und 411. 
einer eigenen, uneindeutigen Ästhetik zeigt an, dass es sich bei der Retardation weniger um ein Gesetz als vielmehr um eine ästhetische Lizenz des Epischen handelt. Darin wird nämlich gerade Schillers Idee eines idealen „ästhetischen Zustands“ aktualisiert, in dem der Spieltrieb die sinnliche Seite bzw. den "Sinntrieb“ und die vernünftige Seite bzw. den „Formtrieb“ miteinander vermittelt und so zu größtmöglicher Freiheit und Schönheit führt. ${ }^{142}$ Diese dem Epischen zugestandene erhöhte Bewegungsfreiheit ist nicht ohne Konsequenzen: Je mehr Beweglichkeit und Mannigfaltigkeit zugelassen werden, desto schwieriger wird die klar umrissene Gestaltung eines zusammenhängenden Ganzen und desto gefährdeter das traditionelle Gattungsmerkmal der epischen Einheit. Mit einem Blick auf Wolf wird dadurch aber gerade auch die hermetische Abgeschlossenheit der vollkommenen Vergangenheit relativiert. Die Auflösung der Autorpersönlichkeit Homer und seines Werks in ein über die Zeit entstandenes und aus verschiedenen Federn stammendes Konvolut zieht fast automatisch auch die Aufhebung vermeintlich unüberwindbarer Gattungskonventionen - namentlich der räumlichen Totalität und zeitlichen Abgeschlossenheit - nach sich, die hier ihrerseits produktiv in den Dienst einer modernen Erneuerung des Epos genommen wird.

Wenn Schiller im Folgenden das Epische aufgrund seiner formalen Flexibilität als die größere künstlerische Herausforderung beschreibt als das Dramatische, zeigt sich daran erneut, wie die Vorstellung des ästhetischen Zustands als Gemütsfreiheit und das Epische als Form, die diesen zu befördern vermag, aufs engste miteinander verbunden sind. Während der epische Dichter die „höchste Freiheit des Gemüths“ aufrecht erhält, „raubt“ sie der tragische Dichter. Er setzt sich selbst in Vorteil, „indem er unsre Thätigkeit [sic] nach einer Seite richtet und concentriert". ${ }^{143}$ Diese auf einseitige Linearität und Fokussierung abzielende Dramen-Konzeption aktualisiert die beschleunigte, treibende Zeitlichkeit des Romans und ist insofern sehr viel enger bzw. einseitiger gefasst als das Epische. Die innere Beweglichkeit des Epischen scheint den Gattungstheoretikern zwar das ausschlaggebende Hauptkriterium für die Form zu sein, taugt aber nicht zum eigentlichen Gattungsgesetz, wie Goethes weitere Bemühungen zeigen:

142 Schiller: Über die ästhetische Erziehung des Menschen in einer Reihe von Briefen. S. 622645; vgl. auch Oschmann: Zwischen Theorie und Performanz. Schillers Begriff der „Form“. S. 202.

143 Schiller an Goethe, 21.4.1797, BW. S. 377. 
Ich suchte das Gesetz der Retardation unter ein höheres unterzuordnen, und da scheint es unter dem zu stehen welches gebietet: dass man von einem guten Gedicht den Ausgang wissen könne, ja wissen müsse und dass eigentlich das Wie blos [sic] das Interesse machen dürfe. Dadurch erhält die Neugierde gar keinen Antheil an einem solchen Werke und sein Zweck kann, wie Sie sagen, in jedem Puncte [sic] seiner Bewegung liegen. ${ }^{144}$

Als Beweis für diese Argumentation verweist Goethe auf die Odyssee, die zwar bis ins kleinste Detail retardierend sei, durch antizipierende Vordeutungen und Weissagungen aber einen Ausgleich zur dermaßen verzögerten Handlung leiste. ${ }^{145}$ Hier wird erneut deutlich, wie das Epische wesentlich auf eine entschleunigte, vor- und zurückschwankende Erzähl-Bewegung sowie einen dadurch erzeugten Entspannungszustand ausgerichtet wird - und dies im bewusst scharfen Kontrast zu fortschreitender Linearität und drängender Neugier, die sich Drama und Roman teilen. Darüber hinaus wird nun aber auch einsehbar, inwiefern die strukturelle Disposition des Epischen auf engste mit den explorativen Prämissen der Morphologie sowie der produktiven Dynamik des Schwankens verbunden ist.

Inwiefern diese Konstellation mit einem grundsätzlichen Unsicherheitszustand einhergeht, der das klassizistisch normative Gattungsdenken herausfordert, vermögen etwa Humboldts diesbezügliche Harmonisierungsbemühungen veranschaulichen. Dieser sieht den größten Unterschied zwischen den Gattungen gleichwohl darin, dass „die Tragödie auf einen Punkt versammelt, was der epische Dichter auf eine unendliche Fläche ausdehnt“. ${ }^{146}$ Das Epische definiert er weiter über eine „nie stillstehende[...] Bewegung und ununterbrochene[...] Stetigkeit“"147, die eine Wirkung der „verweilenden[...] und ruhigen[...] Muße"148 entfaltet. Damit übernimmt er die Konnotation einer gleichzeitig langsamen und dynamischen Zeithaftigkeit des Epischen mit einem kontemplativen Gemütszustand. An die paradoxe Konstellation von fixiert-vollkommener Vergangenheit und dynamischer Retardation bei Goethe und Schiller versucht Humboldt seinerseits mit dem Begriff der Stetigkeit anzuschließen:

Dem epischen Dichter wird die Beobachtung einer vollkommenen Stetigkeit auf eine doppelte Weise durch den Begriff der Handlung und den der Erzählung zur Pflicht. [...] Die Handlung muss also ununterbrochen fortgehen; kein Umstand

\footnotetext{
144 Goethe an Schiller, 22.4.1797, BW. S. 378.

145 Vgl. ebd.

146 Humboldt: Ueber Göthes Herrmann und Dorothea (1799). S. 116.

147 Ebd. S. 40.

148 Ebd. S. 119 .
} 
darf absichtlich hingestellt scheinen; unabhängig von dem Zweck, zu dem er gebraucht ist, muss er schon für sich selbst als eine nothwendige Folge aus dem Vorigen herfliessen; der Zusammenhang des Plans muss so fest und so innig seyn, dass der Leser selbst ihn nicht anders hätte entwickeln, so übereinstimmend mit den physischen und moralischen Gesetzen der Natur, dass die Begebenheit in der That nicht anders hätte fortlaufen können; nur die erste Anlage, auf die sich das Uebrige gründet, ist der Willkühr [sic] des Dichters unterworfen, alles Folgende bestimmt sich lediglich von selbst durch einander. Diess [sic] ist die sinnliche objective Stetigkeit [...] [Hervorhebungen M.E.]. ${ }^{149}$

Humboldt erhebt hier die Stetigkeit zwar zum zentralen poetologischen Prinzip, aber eine klare Begriffsdefinition macht ihm sichtlich Mühe. Während in Goethes und Schillers retardierendem Gang deutlich ein entschleunigendes und insofern auf sinnliche Breite ausgerichtetes Erzählen zu erkennen ist, scheint Humboldts Begriff der Stetigkeit eher eine disparate Häufung von sehr unterschiedlichen Prinzipien und Forderungen der Eindeutigkeit, die das Entfalten einer sinnlichen Breite im Sinne von Mannigfaltigkeit gerade verhindert. In der ,ununterbrochen fortgehenden' Handlung wird just die lineare Abrichtung aufgerufen, der die Retardation potenziell entgegengestellt ist. Humboldts Hauptanliegen scheint es zu sein, die ,unendliche Fläche‘ des Epos zumindest durch eine klare zeitliche Ordnung zu begrenzen, die räumliche Entgrenzung im Sinne der Prägnanz also wenigstens temporal unter Kontrolle zu bringen. Obwohl der Bezug zwischen Zeitlichkeitsmoment und Handlungsstruktur in beiden Gattungskonzeptionen von zentraler Bedeutung ist und insofern die allgemeine Aufmerksamkeitsverschiebung auf temporale Indikatoren veranschaulicht, beschreibt Schiller diesen Zusammenhang sehr viel klarer und differenzierter als Humboldt:

Beide der Epiker und der Dramatiker stellen uns eine Handlung dar, nur dass diese bei dem Letztern der Zweck, bei Ersterem bloßes Mittel zu einem absolutern aesthetischen [sic] Zwecke ist. / Aus diesem Grundsatz kann ich mir vollständig erklären, warum der tragische Dichter rascher und direkter fortschreiten muss, warum der epische bei einem zögernden Gange seine Rechnung besser findet. Es folgt auch, wie mir däucht, daraus, dass der epische sich solcher Stoffe wohl thut [sic] zu enthalten, die den Affekt sey [sic] es der Neugierde oder der Theilnahme [sic] schon für sich selbst stark erregen, wobey also die Handlung zu sehr als Zweck interessiert, um sich in den Grenzen eines bloßen Mittels zu halten [Hervorhebungen M.E.].150

149 Ebd. S. 147 f.

$15^{\circ}$ Schiller an Goethe, $25 \cdot 4 \cdot 1797$, BW. S. $381 \mathrm{f}$. 
Diese Dialektik von Zweck und Mittel knüpft an Kant an und reflektiert nicht nur die allgemeine Autonomisierung der Kunst, sondern liefert darüber hinaus auch eine neue, spezifisch ästhetische Selbstbegründung des Epischen jenseits eines gesellschaftlichen Auftrags. Schiller erklärt eine zielgerichtete, chronologische Handlungsstruktur für das Epos als unwichtig oder zumindest vernachlässigbar, denn im Gegensatz zum Drama, dessen Zielsetzung die Unterhaltung durch einen spannenden Handlungsverlauf ist, verfolgt das Epische einen ,absoluten ästhetischen Zweck', dem die Handlung gerade nur zum ,bloßes Mittel' gereicht. Während Schiller hier das Epische über die Lizenz des verzögernden Vor- und Zurückgreifens in der Erzähl-Chronologie im Kern mit der Idee der geistigen Freiheit und insofern mit dem Ideal des ästhetischen Zustands verbindet, versucht Humboldts ,fester und inniger Plan', demzufolge die Begebenheiten in einem notwendigen und unhintergehbaren Abfolgeverhältnis stehen, derartige Ermächtigungen gerade zu unterbinden. Gleichmäßigkeit ist deshalb auch das auschlaggebende Prinzip seines Zeitlichkeitsbegriffs, worin eine Veränderung der Geschwindigkeit, wie sie dem Begriff der Verzögerung positiv eingeschrieben ist, nicht abgebildet werden kann:

um die subjective [Stetigkeit] in dem Gemüthe des Lesers hervorzubringen, [...], muss der epische Dichter noch mehr thun [sic]. Ueberall nemlich [sic], wo er eine Mannigfaltigkeit von Bestimmungen in den Charakteren, Gesinnungen, Empfindungen anwendet, muss er sie gerade eben so durch unendlich kleine allmählige Abstufungen von einander trennen, allen grellen Contrast [sic] vermeiden und in ihrer Verschiedenheit selbst immer nur den Reichthum [sic] und den Umfang der Gattung darstellen, zu der sie alle gemeinschaftlich gehören. Denn darin besteht die wahre Stetigkeit einer Reihe von Gliedern, dass durch die Verschiedenheit der einzelnen nur die Einheit noch klarer wird, die sie alle in eine zusammenhängende Kette verbindet. [Hervorhebungen M.E.] ${ }^{151}$

Die Stetigkeit wird hier zur beschwörenden Formel, die jegliche Anachronie und Heterogenität anprangert, kontrolliert und schließlich auflöst. Weder Goethes Idee einer zwar langsam-entspannten aber spielerisch-schwankenden Dynamik, die hin und her geht im Zeitgefüge der Erzählung, noch Schillers Verbindung von Sinnlichkeit und Reflexion im Zeichen epischer Freiheit lässt sich bei Humboldt wiederfinden. Vielmehr fixiert er den Stetigkeitsbegriff auf einen ununterbrochenen, linearen Fortschritt und transkribiert ihn damit zu einem rigiden Gesetz, wogegen die Retardation bei Goethe und Schiller gerade als eine Lizenz zur freien Bewegung in der Zeitordnung aufgezeigt werden konnte. Schiller selbst verweist darauf, wie zentral die konzessive Anlage des Retardationsbegriffs ist: „Auch glaube ich, es giebt [sic] zweierlei Arten zu

151 Humboldt: Ueber Göthes Herrmann und Dorothea (1799). S. 148. 
retardieren“, präzisiert er in einem Brief an Goethe, „die eine liegt in der Art des Wegs, die andre in der Art des Gehens, und diese däucht mir kann auch bei dem geradesten Weg [...] sehr gut statt finden“. ${ }^{152}$ Damit wird ein stetiger, linearer Fortgang, wie ihn Humboldt imaginiert, zwar durchaus als valide Möglichkeit aufgezeigt, epische Retardation zu erzeugen, aber eben nicht als die einzige.

An den im Grunde positiv auf Freiheit und Beweglichkeit ausgerichteten Retardationsbegriff der Weimarer Brieffreunde reicht der Stetigkeitsbegriff, den die Brüder Schlegel in ihrer Epostheorie installieren, dann interessanterweise bedeutender näher heran. Den „Begriff des Epos“ fasst August Wilhelm Schlegel gleich zu Beginn seiner diesbezüglichen Vorlesung als „eine ruhige Darstellung des Fortschreitenden “153 zusammen und überführt ihn damit in eine paradoxe Dynamik von Ruhe und Bewegung. Der epische Handlungsfortgang

braucht aber nicht immer mit der Zeitfolge fortzugehen, vielmehr liebt das Epos den episodischen Gang, dass nämlich eine frühere Begebenheit, da, wo es eben nötig ist, sie dem Geiste näherzurücken, eingeschaltet wird. Es kann hierbei die Ordnung der Zeit gerade umkehren, indem es von jedem Nächsten wiederum Veranlassung nimmt, etwas Früheres zu berühren. Diese Methode ist ihm eben deswegen besonders eigen, weil es wie oben gezeigt worden, die Stetigkeit liebt, und also nicht durch einen Sprung plötzlich zu dem entferntesten Umstande übergeht, um von diesem zu dem gegenwärtigen Punkte zurückzukehren, sondern allmählich zu jenem rückwärtsgeleitet wird. [Hervorhebungen M.E.] ${ }^{154}$

Die Gangart des Epischen charakterisiert Schlegel als ein langsames, stetiges Fortschreiten und begründet gleichwohl damit die besondere Lizenz epischer Darstellung, sich außerhalb der chronologischen Reihenfolge, also entgegen eines linear ausgerichteten Fortschritts zu bewegen. Ohne sie als solches zu bezeichnen, macht Schlegel die ästhetische Zeitlichkeits-konstellation des Epos als spannungsvolles Wechselspiel von Beharrlichkeit und Dynamik transparent. In seiner Rezension zu Goethes Hermann und Dorothea beschreibt er das Epos als „zugleich sanfte Anregung und Beruhigung“, man bemerke „kein Hinstreben zu einem Hauptziel [...], jedes, wodurch das Folgende vorbereitet wird, scheint doch nur um seiner selbst willen da zu stehn: ganz das verweilende Fortschreiten, die sinnlich belebende Umständlichkeit, die

\footnotetext{
$15^{2}$ Schiller an Goethe, 25.4.1797, BW. S. 381.

153 Schlegel, August Wilhelm: Vom Epos (1801). In: A.W. Schlegels Vorlesungen über schöne Literatur und Kunst, hrsg. v. Bernhard Seuffert, Bd. 1. Heilbronn: Heinniger 1884. S. $35^{8-}$ 370, hier S. 358 .

154 Ebd. S. 364.
} 
besonnene Anordnung, die leichte Folge, die lose Verknüpfung“. ${ }^{155}$ Die im Begriff des Fortschreitenden inhärente Gerichtetheit wird durch belebende Umständlichkeit wieder zurückgenommen und zur reinen Bewegungsmetapher der Entschleunigung aufgelöst. Diese Beurteilung übernimmt August Schlegel fast wortwörtlich von seinem Bruder Friedrich, der über das „hellenische Epos“ befindet, dass sein „stetiger Strom in jedem Punkt seines Laufs zugleich Anspannung und Befriedigung enthält“, es deshalb „nicht anstrengend und ermüdend“ sei, weil „seine sanfte Anregung“ „keine durchgängig bestimmte Richtung hat" ${ }^{156}$ So verdichtet er die Vorstellung epischer anfangs- und endloser Unendlichkeit zu einer Allgegenwart oder Gleichzeitigkeit und Gleichwertigkeit aller Teile.

\subsubsection{Retardation}

Am Gegenstand des Epos erlangen die Entdeckung eines reflexiven Zeitregimes - mit sich überlagernden Zeithorizonten zum einen und das Aufmerksamwerden auf innere Zeitlichkeiten als das formbestimmende Kriterium zum anderen - kaum zu überschätzende Bedeutung. Die bisherigen Ausführungen haben aber auch gezeigt, dass in der zeitlichen Verfasstheit der Dichtung keine normative Regelhaftigkeit aufzuspüren ist und dass darüber hinaus die neuen Zeit- und Geschwindigkeitsbegriffe im ästhetischen Diskurs weder klare Bedeutungen haben noch einer eindeutigen Verwendung folgen. Vielmehr scheinen sich die räumlichen und kompositorischen Konturen der epischen Form geradezu aufzulösen, wenn der Blick auf ihre Grenzen gerichtet wird.

Einigkeit herrscht alleine darüber, dass die Kohäsionskräfte des chronologischen Erzählens im Epos potenziell weniger zwingend oder sogar aufgelöst sind: „Die Zeitverhältnisse der Wirklichkeit werden aufgehoben“, schreibt August Schlegel dazu und formuliert damit für das Epos eine ästhetische Eigenzeit, die sowohl Elemente des Verharrens wie auch des Beschleunigens ineinander verschränkt: „[...] und Alles fügt sich in eine nach den Gesetzen schöner Anschauung geordnete dichterische Zeitfolge, wo das Dauerende [...] nur einen Moment der Darstellung einnimmt, und das noch so schnell Vorübergleitende bis zur vollendeten Entfaltung des in ihm sich drängenden Lebens festgehalten wird. “ ${ }^{157}$ Diese Entdeckung und Ausstellung von epischer Anachronie als positive Gattungseigenheit - gattungshistorisch und poetologisch - geht einher mit dem Brüchigwerden der Vorstellung vom

155 Ders.: Goethes Hermann und Dorothea. S. 183-221, hier S. 192.

156 KFSA I, 3. S. 98.

157 Schlegel: Goethes Hermann und Dorothea. S. 183-221, hier S. 19 o. 
Epos als totalitärer Einheit: Veränderungen der Zeit können überhaupt nur in Relation zum Raum wahrgenommen und dargestellt werden. Dessen werden die Diskursteilnehmer durchaus gewahr, am deutlichsten wird wiederum Schlegel in seiner Rezension, in der er "den wohlberechneten Bau des Ganzen“ als Prämisse des Epos mit Verweisen auf antike Werke dekonstruiert, die diesem Anspruch bereits nicht genügt hatten. Dafür erkennt Schlegel in Odyssee und Ilias "Maß, Verhältniss und Ordnung noch in den kleinsten Theilen [sic]“, wo sie auf das ganze Werk bezogen fehlen. ${ }^{158}$ Die epische Einheit ist bei Schlegel auf die Phantasie bezogen, also keine Forderung, die sich auf den logisch-rationalen Zusammmenhang richtet, sondern auf die sinnlich-ästhetische Wahrnehmung. Die Einheit des Epos sei deshalb „nichts weiter als Umriss, sichtbare Begränzung [sic]. Daher lässt sie sich denn auch nicht absolut bestimmen; sie kann vergrößert und erweitert werden, bis die Masse der Anschauungen die sinnliche Auffassungskraft übersteigt“. ${ }^{159}$ Diese Beschreibung einer eigentlichen Charakteristik des Unbestimmten wiederholt Schlegel pointiert, wenn er dem Epos grundsätzlich jegliche Handlungseinheit abspricht. Anstatt ein großes Ganzes sei die Erzählung im Epos vielmehr eine

Mehrheit, weil jede Begebenheit aus Teilen besteht, die ebenfalls noch Begebenheiten sind; und weil sich aus Teilbegebenheiten immer noch größere zusammensetzen lassen. Die Begrenzung des Epos ist folglich sehr unbestimmt: die Erzählung kann fortgesetzte werden, solange der stetige Fortschritt nicht unterbrochen wird und der Umfang des Gedichtes die Fassungskraft der Hörer nicht übersteigt. ${ }^{160}$

Im Gegensatz zu Goethe und Schiller bedeutet für Schlegel die Verzeitlichung des Einheitsbegriffs, wie sie in der Vorstellung des stetigen Fortschritts aktualisierte wird, die bewusste Aufgabe einer Einheit auf formaler Ebene. Zwar scheint in den Forderungen nach Überschaubarkeit und Fassbarkeit vordergründig noch die Idee einer irgendwie abgeschlossenen Ganzheit auf, tatsächlich überführt Schlegel die Form des Epischen aber vorsätzlich in eine paradox anmutende Bestimmtheit durch Unendlichkeit und Grenzenlosigkeit: „Nirgends ein Stillstand des Gesanges; aber auch nirgends ein unzeitiges Forteilen, sondern das schönste Gleichgewicht und Maß der stetigen und unermüdlichen Bewegung." ${ }^{161}$ Darüber hinaus erklärt er die epische Einheit, wie sie seit der aristotelischen Poetik als das räumliche Ordnungsprinzip

158 Ebd. S. 185 .

159 Schlegel: Goethes Hermann und Dorothea. S. 183-221, hier S. 187.

16o Schlegel: Vom Epos (1801). S. 358-370, hier S. 363 .

161 Ders.: Goethes Hermann und Dorothea. S. 183-221, hier S. 19 o. 
der Gattung gedacht wird, ${ }^{162}$ als beliebig teilbar: „kleine Stücke der Ilias und Odyssee enthalten [...] [die epische Einheit] noch in sich; Episoden von wenigen Zeilen können für sich als ein vollständiges Epos betrachtet werden [...], diese Leichtigkeit der Theilung und Vereinigung [ist] vielmehr eine natürliche Eigenheit der Gattung.“"163 Friedrich Schlegel begründet die „eigentümliche Einheit“ des Epos in der „episodische[n] Gränzenlosigkeit [sic] [...], welche sich in den hellenischen Beispielen [...] auch auf den kleinsten nur noch gegliederten Teil desselben erstreckt, und die merkwürdige Eigentümlichkeit der epischen Bilder und Gleichnisse begründet" ${ }^{164}$ Die Einheit der homerischen Epen - und damit überhaupt des Epischen - resultiert also nicht aus einem die Einzelteile übergreifenden Handlungsschema, sondern aus dem Zusammentreten einzelner, in sich vollendeter Teile. Schlegel schließt insofern an Wolfs Dekonstruktion an, als er das Ganze des Epos als eine beliebige Zusammenstellung, also das Ergebnis redaktioneller Arbeit ausweist. Allerdings zielt er damit nicht auf philologische Ermächtigung, sondern vielmehr gerade auf die Befreiung der Poesie von der Philologie, wenn er die

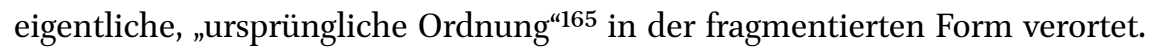
Die berühmte Metapher, die Schlegel dafür findet, ist „ein poetischer Polyp, wo jedes kleinere oder grössere Glied [...] für sich eignes Leben, ja auch ebensoviel Harmonie als das Ganze hat". ${ }^{166}$ Mit dem Rekurs auf die Entdeckung der Reproduktionsfähigkeit abgeteilter Körperteile steht der Polyp bei Schlegel als Bild für den inneren, organischen Zusammenhang der homerischen Epen trotz oder gerade wegen der Eigenständigkeit ihrer einzelnen Teile. ${ }^{167}$ Insofern nutzt Schlegel in seiner Charaktersierung des Epischen die aus der Biologie zunehmend in die Ästhetik eingewanderte Vorstellung eines organischen Bildungstriebs ${ }^{168}$ um auf die generative und produktive Potenz der einzelnen Teile, mehr noch auf die Umkehrbarkeit von Teil und Ganzem hinzuweisen.

Wenn jedes Glied selbständig und in sich geschlossen ist, nimmt sich die epische Komposition als eine lose, willkürliche Verkettung von einzelnen

162 Vgl. Buschmeier: Poesie und Philologie in der Goethe-Zeit. Studien zum Verhältnis der Literatur mit ihrer Wissenschaft (= Studien zur deutschen Literatur, Bd. 185). Tübingen: Niemeyer 2008. S. 350 f.

163 Schlegel: Goethes Hermann und Dorothea. S. 183-221, hier S. 187.

164 KFSA I, 1. S. 466.

165 Ebd. S. 518.

166 Ebd. S. 113 .

167 Vgl. Buschmeier: Epos, Philologie, Roman. Wolf, Friedrich Schlegel und ihre Bedeutung für Goethes Wanderjahre. S. 69 .

168 Vgl. Schneider, Sabine: Die schwierige Sprache des Schönen. Moritz' und Schillers Semiotik der Sinnlichkeit (= Epistemata. Reihe Literaturwissenschaft, Bd. 231). Würzburg: Königshausen \& Neumann 1998. S. 253 f. 
Totalitäten aus. Dadurch bewahrt sie sich eine größtmögliche Freiheit in der Verknüpfung und gleichzeitig eine - wenn auch nur partielle - Ganzheit. In dieser Spannung zwischen epischer Fragmentierung und Totalitätsanspruch wiederholt sich das bereits im Zeitlichkeitskonzept der Darstellung aufgespürte Schwanken bzw. zeigt sich die Tendenz zur Auflösung, die Idee des Zugleichs und des Ineineinander aller Teile ${ }^{169}$ als Konsequenz der Freilegung der epischen Lizenz zur freien Bewegung zwischen den Zeiten. Das traditionelle Gattungsmerkmal der epischen Einheit wird in die kleinere Einheit, in die Episode verlagert. Diese wird insofern entschieden ermächtigt, dass der Totalitätsanspruch auf dieser Darstellungsebene noch aufrecht erhalten werden kann. Es ergibt sich aber wiederum das Bild einer in sich paradoxen Konstruktion: In der fragmentarischen Ganzheit des Epos spiegelt sich der ambivalente Anspruch von gleichzeitiger Abgeschlossenheit und Anschlussfähigkeit. Dazu noch einmal Friedrich Schlegel, in für ihn typisch paradoxer Manier:

Diese reine dichterische Erzählung, welche keinen bestimmten Zweck hat, sondern nur nach Fülle und sinnlicher Harmonie strebt, kennt ihrem Wesen nach weder Anfang noch Ende. So lange nur der Stoff gleichartig bleibt, und die Umrisse sich runden lassen, können die kleinen Massen in immer größere zusammenwachsen. Gebt dem epischen Dichter Raum und Zeit: er wird nicht eher enden, als bis er seinen Stoff erschöpft, und eine vollständige Ansicht der ganzen ihn umgebenden Welt vollendet hat, wie sie die homerische Poesie gewährt. ${ }^{170}$

Dagegen nimmt nun Goethe, der in anderen Belangen aus Schlegels Eposkonzept ebenso Gewinn zieht wie aus Wolfs Thesen, ${ }^{171}$ dezidiert Stellung, erscheint ihm die unerbittliche Fragmentierung der epischen Totalität doch völlig unangebracht:

Es ist sonderbar wie er [Schlegel], als ein guter Kopf, auf dem rechten Wege ist und sich ihn doch gleich wieder selbst verrennt. Weil das epische Gedicht nicht die dramatische Einheit haben kann, weil man eine solche absolute Einheit in der Ilias und Odyssee nicht gerade nachweisen kann, vielmehr nach der neuern Idee sie noch für zerstückelter / angiebt [sic] als sie sind; so soll das epische Gedicht keine Einheit haben, noch fordern, das heißt, nach meiner Vorstellung: es soll aufhören ein Gedicht zu seyn [sic]. Und das sollen reine Begriffe

169 Vgl. Wohlleben: Die Sonne Homers. Zehn Kapitel deutscher Homer-Begeisterung. Von Winckelmann bis Schliemann. S. 6o.

170 KFSA I, 1. S. 124.

171 Vgl. Buschmeier: Epos, Philologie, Roman. Wolf, Friedrich Schlegel und ihre Bedeutung für Goethes Wanderjahre. S. 77 . 
seyn [sic], denen doch selbst die Erfahrung, wenn man genau aufmerkt, widerspricht. Denn die Ilias und Odyssee, und wenn sie durch die Hände von tausend Dichtern und Redacteurs [sic] gegangen wären, zeigen die gewaltsame Tendenz der poetischen und critischen [sic] Natur nach Einheit. Und am Ende ist diese neue Schlegelsche Ausführung doch nur zu Gunsten der Wolfischen Meinung, die eines solchen Beystandes [sic] gar nicht einmal bedarf. Denn daraus dass jene großen Gedichte erst nach und nach entstanden sind, und zu keiner vollständigen und vollkommenen Einheit haben gebracht werden können, (obgleich beyde vielleicht weit vollkommner organisirt [sic] sind als man denkt) folgt noch nicht: dass ein solches Gedicht auf keine Weise vollständig, vollkommen und Eins werden könne noch solle. ${ }^{172}$

Abgesehen davon, dass Goethe hier wohl am Einheitsbegriff festhält, macht er an dieser Stelle aber auch ganz entscheidende Zugeständnisse gegenüber dem traditionellen Anspruch einer klar umrissenen Einheit, wie er in der PropyläenEinleitung noch formuliert wurde. Angesicht der sich verdichtenden Hinweise darauf, dass es sich bei der epischen Einheit um die bloße Konstruktion einer retrospektiven Auslegungspraxis handelt, lässt sich die klassizistische Vorstellung einer abgeschlossenen Ganzheit nicht mehr aufrechterhalten. Im Gegensatz zu Schlegel ist diese Einsicht bei Goethe jedoch mit einem tiefen Unbehagen verbunden und auch Schiller versucht, dem Mangel einer übergreifenden Einheit durch die Autonomsetzung der Einzelepisoden entgegenzuwirken: „Es wird mir aus allem, was Sie sagen, immer klarer, dass die Selbstständigkeit seiner Theile [sic] einen Hauptcharakter des epischen Gedichtes ausmacht“173, schreibt er im April 1797 an Goethe und entwirft für das Epos aufgrund dieser Erkenntnis das Kohärenzmodell der Substanz:

Dem Epiker möchte ich eine Exposition gar nicht einmal zugeben; wenigsten nicht in dem Sinne, wie die des Dramatikers ist. Da er uns nicht so auf das Ende zutreibt, wie dieser, so rücken Anfang und Ende in ihrer Dignität und Bedeutung weit näher an einander, und nicht, weil sie zu etwas führt, sondern weil sie selber etwas ist, muss die Exposition uns interessieren. Ich glaube, dass man dem dramatischen Dichter hierin / weit mehr nachsehen muss; eben weil er seinen Zweck in die Folge und an das Ende setzt, so darf man ihm erlauben, den Anfang mehr als Mittel zu behandeln. Er steht unter der Categorie der Causalitaet [sic], der Epiker unter der Substantialität; dort kann und darf alles etwas als Ursache von was anderm daseyn [sic] hier muss alles sich selbst um seiner selbst willen geltend machen. ${ }^{174}$

172 Goethe an Schiller, 28.4.1797, BW. S. 387.

173 Schiller an Goethe, 21.4.1797, BW. S. 377.

174 Schiller an Goethe, 25.4.1797, BW. S. 384 . 
Die Verknüpfung der Episoden geschieht dementsprechend nicht durch die Logik der Sukzession, wie im Drama oder im Roman- die immer eine zeitliche Ordnung aktualisiert -, sondern durch das Prinzip der Substanz, also durch die Notwendigkeit oder Relevanz für das Ganze. Damit wird nicht zuletzt Lessings kategorische Verpflichtung der Dichtung auf das Gesetz der Sukzession für das Epos relativiert, wenn nicht sogar umgekehrt. ${ }^{175}$ Schiller stützt seine Überlegungen zur inneren Organisationsstruktur des Epischen auf Friedrich Schlegel, der das epische Erzählen seinerseits von jeglicher sukzessiven Organisationsstruktur entbindet. Zentral dafür ist Schlegels Begriff der Handlung - als Gegenbegriff zur Begebenheit - worunter er alles, was die „Wirkung einer freien Willensäusserung ${ }^{\prime 176}$ ist, versteht und die als solche nur als kausales Ereignis aufgefasst werden kann. In seiner Geschichte der Poesie der Griechen und Römer spricht er dem Epos die Darstellung von Handlung ganz grundsätzlich ab: „Das epische Gedicht stellt aber keineswegs eine einzige vollständige poetische Handlung, sondern eine unbestimmte Masse von Begebenheiten dar. ${ }^{4177}$

Derart zufällig bzw. substanziell angeordnete Episoden - wie sie zueinander stehen, wird durch die Darstellung nicht vorgegeben - ermöglichen dem Verstand eine eigene, freie hermeneutische Bewegung, fordern ihn aber dadurch auch gerade stärker heraus. Schlegel bindet das Epos deshalb an die vereinende Kraft der Stetigkeit: „Der Gang des Epos besteht in immer von neuem angeknüpfte parzialen Verwicklungen und Auflösungen so dass Spannung und Befriedigung über das ganze gleichmässig verteilt ist. ${ }^{\text {"178 }}$ Bezeichnenderweise referenziert Schlegel hier mit den Begriffen der Verwicklung und der Lösung fast wörtlich auf die Tragödienterminologie der aristotelischen Poetik und vermischt das Epische insofern gerade mit dem vermeintlich antithetischen Dramatischen. ${ }^{179}$ Aus der späteren Romanpoetik werden diese dramatischen Elemente zugunsten einer programmatischen Langeweile dann auch wieder kategorisch ausgeschlossen. ${ }^{180}$ Entscheidend an Schlegels Bekenntnis zu

175 Vgl. Buschmeier: Epos, Philologie, Roman. Wolf, Friedrich Schlegel und ihre Bedeutung für Goethes Wanderjahre. S. 74 .

176 KFSA, I, 1. S. 473 .

177 Ebd. S. 124.

178 Schlegel: Vom Epos (1801). S. 358-370, hier S. 363 .

179 Vgl. Aristoteles: Poetik. S. 57.

180 Theodor Fontane über seinen Roman Stechlin in einem Brief vom Mai/Juni 1897 an Adolf Hoffmann: „Zum Schluss stirbt ein Alter und zwei Junge heiraten sich; - das ist so ziemlich alles, was auf 5oo Seiten geschieht." Zitiert nach: Fontane, Theodeor: Der Stechlin. Sämtliche Romane, Erzählungen, Gedichte, Nachgelassenes, hrsg. v. Walter Keitel und Helmuth Nürnberger, Bd. 5. München: Hanser 1994. S. 420. ,Langeweile“ war schon für Stifters Romane (bes. Nachsommer und Witiko) ausschlaggeben, vgl. Wildbolz, Rudolf: 
einem sich in die räumliche Unendlichkeit ausbreitenden Epischen ist die darin verankerte Objektivität: „Bei dieser Gleichartigkeit aller Teile kann es keinen ausgezeichneten Anfang und Schluss haben, und es ist daher weder eine Tugend noch ein Fehler, sondern eine unvermeidliche Eigentümlichkeit der Gattung, das es in der Mitte anfängt und gewissermassen auch in der Mitte schließt." ${ }^{181}$ Schlegel verknüpft die Vorstellung von gleichrangig nebeneinanderstehenden epischen Teilen mit der Unterordnung subjektivierender Prinzipien gegenüber dem Objektiven - „das Epos ist Darstellung des rein Objektiven“182 - und führt dies wiederum auf die spezifische Zeithaftigkeit des Epos zurück: „Die epische Ruhe ist eben die Absonderung des rein Objektiven, wodurch sich diese Gattung über die gewöhnliche Wirklichkeit zum idealischen erhebt. ${ }^{\text {“83 }}$ Der Zustand der Kontemplation sowie eine entsprechend ruhige Darstellung sind bei Schlegel direkt verantwortlich für die tiefere, von störenden, ,subjektiven' Regungen bereinigte Einsicht, die das Epos von anderen Gattungen wie dem Drama positiv abhebt. ${ }^{184}$ Diese positive Emphase des Objektiven zu einem Zeitpunkt erhöhter Reflexivität und damit verbundener Fokussierung des Subjektiven lässt vermuten, dass es bei der epischen Erhebung über die gewöhnliche Wirklichkeit nicht um eine Transzendierung des Epos geht, sondern um die Zuständigkeit, allgemeine, verbindliche und dauerhafte Wissensbestände zu transportieren. Mit diesem eigentümlichen Beharren auf Objektivität wird nicht zuletzt auch Blanckenburgs Romankonzeption der inneren Geschichte ${ }^{185}$ problematisiert und wieder in den Blick genommen, was diese auszublenden sucht: das große Ganze des Weltzusammenhangs und die Verortung des Einzelnen darin.

Auf die entscheidende Doppelfunktion, die der Ruhe als Gestaltungsprämisse und Beförderin einer umfassenden, allgemeinen Erkenntnis zukommt, war bereits Goethe aufmerksam geworden: Die „größte[...] Ruhe und Behaglichkeit" der epischen Rezeptionssituation, heißt es dazu im Briefwechsel, lade den Verstand mehr als andere Dichtungen dazu ein, Forderungen zu machen. ${ }^{186}$ An diese Verbindung von wünschenswerten Effekten der Distanzierung und Objektivierung mit einer entschleunigten Darstellung schließt Schlegel sein

Adalbert Stifter: Langeweile und Faszination (= Sprache und Literatur 97). Stuttgart: Kohlhammer 1976. S. $141 \mathrm{f}$.

181 Schlegel: Vom Epos (1801). S. 358-370, hier S. 364.

182 Ebd. S. 358 .

183 Ebd.

184 Vgl. Buschmeier: Epos, Philologie, Roman. Wolf, Friedrich Schlegel und ihre Bedeutung für Goethes Wanderjahre. S. 75 .

185 Vgl. S. 27 f. in diesem Buch.

186 Goethe an Schiller, 19.4.1797, BW. S. 375 . 
Eposkonzept an. Gleichzeitig weist er aber die Idee einer epischen Einheit aufgrund der fehlenden linearen Zeitabfolge entschieden zurück: „Die rein dichterische Erzählung [...] kennt ihrem Wesen nach weder Anfang noch Ende $^{“ 187}$, sie wird deshalb immer „zwischen ungeendet und endlos in der Mitte schweben"188, wie es bei August Wilhelm Schlegel dann heißt.

Es bleibt an dieser Stelle festzuhalten, dass die an der Epochenschwelle virulent werdende Vorstellung von epischem Erzählen weder dem normativen Begriff, wie er von der traditionellen Gattungspoetologie installiert wurde, noch dem darin transportierten Anspruch auf Einheit gerecht wird. Nach wie vor steht die Frage nach formaler Einheitlichkeit zwar im Zentrum der Auseinandersetzung, diese richtet sich aber nun entweder auf neue Wege, eine poetische Einheit zu gestalten oder auf die ästhetischen Potenziale, die gerade aus der Aufgabe der Einheitsvorstellung entstehen. Dem Faktor der Zeit kommt dabei diskursübergreifend eine kaum zu überschätzende Bedeutung zu, sofern ihm eine eigenständige, produktive und vor allem gestaltbildende Macht zugewiesen wird. So unterschiedlich die Zeitlichkeitsbegriffe und ihre ästhetischen Leistungspotenziale auch reflektiert werden - Schlegel gibt die Kategorie der Ganzheit zugunsten einer unendlichen Stetigkeit komplett auf, während Goethe und Schiller im Begriff der Retardation eine alternative, auf Kontinuität zielende Vorstellung von Ganzheit zu begründen suchen. Lässt sich doch die durchgängige Verschiebung von einer linear gedachten Zeitordnung des epischen Erzählens, hin zu einer mehr räumlichen Zeitordnung der Simultanität beobachten, die auf die mögliche Gleichzeitigkeit aller Zeitkategorien im Epos führt. ${ }^{189}$ Dem Epos wird insofern eine ambivalente Mittelstellung zwischen den Zeithorizonten von Vergangenheit und Gegenwart zugewiesen, die es gerade dazu ermächtig, zwischen diesen zu vermitteln.

Die oft betonte Diskrepanz zwischen romantischer und klassizistischer Programmatik erscheint mit Blick auf diese besondere Lizenz des Epischen mehr als sich gegenseitig befruchtendes Wechselverhältnis, das von einem produktiven Gedankenaustausch profitiert. Goethe und Schiller sind durchaus bemüht, die von Wolf und Schlegel in ihren progressiven Eposkonzepten aufgedeckte Flexibilität und Fragmentarizität der epischen Form zu konterkarieren: Dem entgrenzenden Potenzial zur Unendlichkeit, das sowohl der retrogradierenden - also zurückschreitenden - Zeitlichkeit wie auch den anarchistischen Tendenzen der Substanzialität inne liegt, setzten sie

187 KFSA I, 1. S. 124.

188 Schlegel: Vom Epos (1801). S. 358-370, hier S. 364.

189 Vgl. Buschmeier: Epos, Philologie, Roman. Wolf, Friedrich Schlegel und ihre Bedeutung für Goethes Wanderjahre. S. 74 . 
einerseits die Verortung in einer abgeschlossenen Vergangenheit und andererseits ein Einheitskonzept ,im Kleinen' entgegen. Vor allem Goethe, und das ist für die vorliegende Untersuchung durchaus bedeutungsvoll, zieht aus den Programmen der formalen Auflösung auch Gewinn, obwohl er sich bisweilen radikal gegen diese ausspricht, und zeigt insofern in Bezug auf das Epische ein bedeutend freieres Formdenken als Humboldt, aber auch als Schiller. So lernt er nämlich von Schlegel und Wolf, dass gerade die Form des Fragments zum synthetisierenden Anschluss und insofern zur Herstellung einer, wenn auch nur momentanen, Einheit beiträgt. ${ }^{190}$ Das ist die Idee der Prägnanz, die sich sowohl im morphologischen Formbegriff wie auch im kulturpolitischen Programm der Kontinuität trotz Traditionsbruch widerspiegelt und die Goethe für sein ganz eigenes Erneuerungsprojekt des Epischen produktiv macht.

\subsection{Medienpoetologische Reflexionen}

Wie die vorhergehenden Ausführungen gezeigt haben, rekurrieren die in der Eposdebatte der Epochenschwelle diskutierten Gattungseigenschaften nach wie vor auf das seit der Antike tradierte Merkmal der Totalität und die damit verbundenen Vorstellungen von epischer Breite und Objektivität. ${ }^{191}$ Die Gattungstradition wird also fortgesetzt und gleichzeitig entscheidend modifiziert - unter dem Zeitdruck der Moderne werden die traditionellen Kategorien insofern erneuert, als sie mit ihren jeweiligen Gegenpolen in ein Spannungsverhältnis gebracht werden: Unter den Zeitlichkeitsbegriffen der Retardation und der Stetigkeit sowie auch den Organisationsprinzipien der Substanzialität und Objektivität wird die epische Darstellung als eine ambivalente, zwischen Form und Formlosigkeit hin- und herschwankende Doppelstruktur erfasst. Dieser Ablösung äußerlich wahrnehmbarer, normativer Kategorien stehen Goethe und Schiller bedeutend skeptischer gegenüber als die Frühromantiker, wie ihre nicht nachlassende Suche nach höheren Gesetzen $^{192}$ und reinen Begriffen ${ }^{193}$ bereits deutlich gemacht hat. Dass das Epische aber auch für die Brieffreunde, insbesondere Goethe, gerade aufgrund seiner prekär gewordenen Form und entsprechend komplexen Merkmalssemantik nicht nur problematisch, sondern eben gleichzeitig auch produktiv

190 Vgl. ebd. S. 78.

191 Vgl. von Essen, Gesa: Epos. In: Lamping, Dieter (Hrsg.): Handbuch der literarischen Gattungen. Stuttgart: Kröner 2009. S. 204-220.

192 Vgl. Goethe an Schiller, 22.4.1797, BW. S. 378 und Schiller an Goethe, 25.4.1797, BW. S. 381.

193 Vgl. Goethe an Schiller, 28.4.1797, BW. S. 387 . 
wird, soll im Folgenden entlang der produktions- und rezeptionsästhetischen Überlegungen der Gattungsbedatte weiterverfolgt werden. Dabei soll deutlich werden, wie der Eposdiskurs das Auseinanderbrechen des Zusammenhangs von Wissen und Erzählen um 1800 als medialen Wechsel von Mündlichkeit und Schriftlichkeit reflektiert bzw. problematisiert und in der Poetologie des Epischen ein Kommunikationsmodell vorgestellt wird, das trotz Zugeständnissen an diesen Wechsel noch eine gelingende Vermittlung kollektiver, verbindlicher Erfahrung in Aussicht stellt.

\subsubsection{Vermittlung zwischen individueller Subjektivität und kollektiver Objektivität}

In dem von Goethe verfassten Aufsatz wird auf knapp vier Seiten ein hoch komplexes poetologisches Gebilde entworfen, in dem die zentralen Gattungsunterschiede jeweils bewusst auf den Dichter und sein Publikum zurückgeführt werden:

Wollte man das Detail der Gesetze wornach beyde [der Epiker und der Dramatiker] zu handeln haben aus der Natur des Menschen herleiten, so müsste man sich einen Rhapsoden und einen Mimen, beyde als Dichter, jenen mit seinen ruhig horchenden, diesen mit seinen ungeduldig schauenden und hörenden Kreise umgeben, immer vor Augen haben und es würde nicht schwer fallen zu entwickeln was einer jeden von diesen beyden Dichtarten am meisten frommt [sic], welche Gegenstände jede vorzüglich wählen, welcher Motive sie sich vorzüglich bedienen wird, [...]. [Hervorhebungen M.E.] ${ }^{194}$

Das ist in erster Linie die Formulierung einer Rezeptionsästhetik. Die Art und Weise der geistigen Aufnahme und Verarbeitung geben hier die "Gesetzte“ der literarischen Formen vor. Die Medialität bzw. die Vermittlungskraft wird zum ausschlaggebenden Kriterium der Gattungsdifferenzierung und zwar als komplexe Verschränkung von Produktions- und Rezeptionsseite. Dabei deutet sich bereits an dieser Stelle eine sehr subtile zeit- und medienkritische Differenzierung von erwünschten epischen - ruhig horchend - und potenziell gefährlichen, dramatischen - ungeduldig hörend - Konstellationen an, die wiederum nahelegt, dass im Dramatischen der zeitgenössische Roman als triviale Unterhaltungsliteratur aktualisiert wird. Die Konzipierung eines ungeduldigen Hörers enthält allerdings angesichts der Französischen Revolution und der sich überschlagenden Gewaltexzesse auch eine politische Brisanz - wird hier doch grundsätzlich übereiltes Handeln getadelt und als sicherer Weg in die Katastrophe dargestellt. In der medienpoetologischen

194 Über epische und dramatische Dichtung, BW. S. 538. 
Konstellation des Epischen werden die Gattungsmerkmale als spezifische Dispositionen der Produktionsseite aufgezeigt, die effektiv auf die Rezeptionsseite übertragen werden:

\begin{abstract}
Die Behandlung im ganzen betreffend, wird der Rhapsode, der das vollkommen vergangne vorträgt, als ein weiser Mann erscheinen, der in ruhiger Besonnenheit das Geschehene übersieht, sein Vortrag wird dahin zwecken die Zuhörer $\mathrm{zu}$ beruhigen damit sie ihm gern und lange zuhören, er wird das Interesse egal vertheilen [sic], weil er nicht im Stande ist einen allzulebhaften Eindruck geschwind zu balanciren [sic], er wird nach Belieben rückwärts und vorwärts greifen und wandeln, man wird ihm überall folgen, denn er hat es nur mit der Einbildungskrafft [sic] zu thun, die sich ihre Bilder selbst hervorbringt, und der es auf einen gewissen Grad gleichgültig ist was für welche sie aufruft. [Hervorhebungen M.E.] ${ }^{195}$
\end{abstract}

Das hier porträtierte Dichterideal des Rhapsoden verdichtet in sich die als ambivalent aufgezeigte Zeitlichkeits- und Organisationsstruktur des Epos: Der kontemplative Geisteszustand des Dichters verleiht ihm eine Übersicht über das Geschehen, welches er als abgeschlossenes, in der Vergangenheit liegendes erzählt. Diese entspannte und distanzierte Erzählerposition befördert die Gleichgültigkeit und insofern die narrative Bewegungsfreiheit des Epikers, die ihn nicht nur zum Wissenden macht, sondern auch zur Vermittlung von Wissen ermächtigt. Auch für August Wilhelm Schlegel ist die Vorstellung eines gleichwohl allwissenden, wie auch unbeteiligten Erzählers von zentraler Bedeutung für das Epos:

Die Darstellung des Epos soll eine ruhige sein. Dazu gehört nicht nur, dass der Dichter keine Teilnahme an den Begebenheiten äußere, wodurch er ohnehin nur eine den Eindruck schwächende Störung verursacht, und die Aufmerksamkeit von dem Gegenstande ab auf sich, von dem Objektiven auf das Subjektive gelenkt wird; sondern er muss eine solche Herrschaft über den Stoff ausüben, als wenn ihm die einzelnen Teile desselben wirklich gleich gültig wären. ${ }^{196}$

Damit macht er die vom Epiker zu leistende Beruhigungsleistung nicht wie Goethe und Schiller in erster Linie von dessen Geisteshaltung abhängig, sondern macht vielmehr die absolute Beherrschung des Stoffs zur Voraussetzung für die gleichgültige Geisteshaltung des Erzählers und insofern zum Apriori der formalen Darstellung.

An die Verortung einer gattungsbestimmende Beruhigungsleistung im Epos bzw. im homerischen Epos, schließt sich auch Humboldt an. Sie steht für ihn

195 Ebd. S. 540.

196 Schlegel: Vom Epos (1801). S. 358-370, hier S. $35^{6}$. 
allerdings in unmittelbarem Zusammenhang mit dem ästhetischen Ideal der Totalität, das er nur in der uneinholbaren Kunst der vergangenen Antike aufzuspüren vermag:

Daher die beruhigende Wirkung, die jedes rein gestimmte Gemüth [sic] bei der Lesung der Alten erfährt; daher, dass sie auch den leidenschaftlichsten Zustand heftiger Aufwallung oder erliegender Verzweiflung allemal zur Ruhe herab und zum Muthe [sic] hinaufstimmen. Denn diese Kraft einhauchende Ruhe fehlt niemals, sobald nur der Mensch sein Verhältniss zu der Welt und dem Schicksale ganz übersieht. 197

Die kontemplative Wirkung des Epos ist deshalb ausschließlich von der Rezeption seiner originalen, antiken Ausprägungen zu erwarten und liegt für Humboldt grundsätzlich jenseits der medialen Möglichkeiten und Fähigkeiten der neuen Dichter. Stand der vormoderne Dichter noch in einem moralisch-religiösen Auftragsverhältnis mit seinem Publikum, haben die autonomieästhetischen Konzept der Moderne den Dichter von einer wie auch immer gearteten Zweckgebundenheit seiner Dichtung ja gerade befreit und ihn insofern in ein Verhältnis zur Rezeptionsseite gestellt, das dem antiken konträr entgegensteht. Diese modernen Begriffe von der autonomen Kunst und dem autonomen Künstler greifen auch Goethe und Schiller in ihrer Charakterisierung des Dramatikers, seiner Kompetenzen und der Wirkung, die er auf sein Publikum hat, besonders prominent auf, um ihn dem Epiker gegenüberzustellen:

Der Mime [...] stellt sich als ein bestimmtes Individuum dar, er will dass man an ihm und seiner nächsten Umgebung außchliesslich Theil [sic] nehme, dass man die Leiden seiner Seele und seines Körpers mitfühle, seine Verlegenheiten theile und sich selbst über ihm vergesse. [...] Der Zuschauende [sic] Hörer muss von rechts wegen in einer steten sinnlichen Anstrengung bleiben, er darf sich nicht zum Nachdenken erheben, er muss leidenschafftlich [sic] folgen, seine Phantasie ist ganz zum Schweigen gebracht, man darf keine Ansprüche an sie machen und selbst was erzählt wird muss gleichsam darstellend vor die Augen gebracht werden. ${ }^{198}$

Sowohl auf der Produktions- wie auf der Rezeptionsseite wird hier die Individualisierung des Subjekts umgesetzt - der Künstler erscheint als mündiges Individuum, dessen subjektive Einzelperspektive auf den Rezipienten, der ebenfalls als ein Einzelner erscheint, übertragen wird. Dem Dramatiker kommt demnach die Verhandlung bzw. unmittelbare Darstellung

197 Humboldt: Ueber Göthes Herrmann und Dorothea (1799). S. 23.

198 Über epische und dramatische Dichtung, BW. S. 540 f. 
von individueller und subjektiver Erfahrung zu. Damit wird ihm die wichtige modernespezifische Funktion angetragen, die Wirklichkeit als individuelle und subjektive Konstruktion aufzuzeigen, die er spätestens ab Mitte des 18. Jahrhunderts mit dem Romancier teilt. ${ }^{199}$ Die Vermittlung einer persönlichen Perspektive, der Leiden und Leidenschaften eines Einzelnen, kann hier allerdings nur gelingen, wenn die Reflexionstätigkeit der Rezeptionsseite ausgeschaltet ist. Der Dramatiker wird als freier aber isolierter Künstler beschrieben, der zuschauende Hörer als doppelt unfreier Getriebener - von der eigenen unterhaltungssüchtigen Ungeduld und gleichzeitig von der drängenden, besitzergreifenden Darstellung des Dramatikers. Die programmmäßige Überforderung des Rezipienten erscheint als Grundvoraussetzung für das Erzeugen eines tiefgehenden, subjektiven Eindrucks. Diese die Subjektautonomie sowohl formal wie inhaltlich herausstellende Dramenkonzeption verweist wiederum darauf, dass die Freiheit und Autonomie des Künstlers nur um den Preis eines kulturellen Geltungsverlusts zu haben sind, der sich hier einerseits als Isolation des Produzenten und andererseits als Entmündigung des Rezipienten zeigt: „der tragische Dichter [raubt uns] unsre Gemüthsfreiheit, und indem er unsre Thätigkeit [sic] nach einer einzigen Seite richtet und concentriert [sic], so vereinfacht er sich sein Geschäft um vieles, und setzt sich in Vortheil [sic], indem er uns in Nachtheil [sic] setzt.“200 In dieser Charakterisierung eines Übergriffs wiederholen sich die negativen, problematischen Effekte und Konsequenzen einer sich der dekadenten, beschleunigten Gegenwart verschreibenden Kunst, wie sie am Roman aufgezeigt wurde, und werden in die Produktions-Rezeption-Konstellation des Dramatischen überführt: Die unmittelbare, identifikatorische Beziehung zwischen Mime und Zuhörer, die zwar „viel lebhaftere Wirkungen“201 ermöglicht, zwingt den Rezipienten zu einem unproduktiven, blossen Hören und Schauen, deren Kontrolle er vollständig an den Produzenten abgibt. Die Vermittlungsleistung des so gefassten Dramatischen ist demnach auf eine private Einzelperspektive und eine linear abgerichtete, drängende Gegenwärtigkeit ausgerichtet. Das Verhältnis zwischen Produzent und Rezipient wird als eine erschwerte Kommunikationssituation zwischen isolierten Individuen inszeniert, die nur durch die völlige Vereinnahmung des Zuschauers gelingen kann.

199 Vgl. S. 27 f. in diesem Buch.

200 Schiller an Goethe, 21.4.1797, BW. S. 377.

201 Über epische und dramatische Dichtung, BW. S. 541. Wörtliche Wiederholung aus Schillers Brief vom 21.4.1797. 
Diese pejorative Konnotation des Dramatischen mit einer rigiden Beschränkung des Zuschauers erzeugt auch in den anderen Auseinandersetzungen über das Epos eine Folie, auf der sich das Epische als freie und freiheitsfördernde Gattung abhebt. So schreibt August Schlegel über Hermann und Dorothea, dass die „Anlage des Ganzen durchaus episch“ sei, weil darin „keine künstlichen Verwicklungen, keine gehäuften Schwierigkeiten, keine plötzlich eintretenden Zwischenfälle, keine auf einen Punkt hindrängende Spannung" seien und das Gemüt "nie in dem Grade mit fortgerissen wird, dass es die Freiheit der Betrachtung verlöre“. ${ }^{202}$ Bis zu einem gewissen Grad widerspricht sich Schlegel damit nun gerade selbst, hatte er doch der Gattung in seiner Epostheorie durchaus „Verwicklung und Auflösung“ zugestanden, die „Spannung und Befriedigung über das ganze gleichmäßig“ verteilen würden. ${ }^{203}$ Diese dramatische, mit dem Dekadenzmerkmal der Gegenwärtigkeit versehene Dichtung hat die kulturstiftende, gesellschaftsrelevante, verbindliche Kraft der traditionellen Formen am Beginn der Moderne eingebüßt. Wie in der Auseinandersetzung über den Roman sichtbar wurde, ist sie gleichwohl als Beschreibungsbemühung aufzufassen wie auch als Symptom der kulturellen Krise, in der sich Kunst und Gesellschaft unversöhnlich gegenüberstehen. Das Epische aber ist in Abgrenzung zum Dramatischen, welches das Leben eines Einzelnen zu Unterhaltungszwecken in den Vordergrund rückt und dadurch den auf Privates reduzierten Roman aktualisiert, „nicht ein sinnlicher Reiz für die Neugier, sondern eine Aufforderung zur Theilnahme, an die Menschheit gerichtet“. ${ }^{204}$ Das Epos soll also, um eben episch zu sein, eine gesellschaftliche Verbindlichkeit herstellen, eine allgemeine Gültigkeit haben. Durch die Kontrastierung zum Dramatischen wird in der Eposkonzeption auf diese kulturelle Leerstelle der Moderne verwiesen und dezidiert auf die Entstehungskosten einer autonomen Kunst aufmerksam gemacht. Geichzeitig wird damit aber auch eine Alternative angeboten, die genauso der problematischen Moderneerfahrung geschuldet ist, jedoch einen anderen Umgang mit dieser vorstellt.

\subsubsection{Restitution der Sinnlichkeit im Epischen}

Für das Gelingen der epischen Vermittlungsleistung sind gerade die medienpoetologischen Voraussetzungen ausschlaggebend. Das Epos wird in Goethes Aufsatz als ausgedehnter mündlicher Vortrag des Rhapsoden vor einer geduldig horchenden und deutlich als Kollektiv markierten Zuhörerschaft

\footnotetext{
202 Schlegel: Goethes Hermann und Dorothea. S. 183-221, hier S. 208.

203 Vgl. S. 16o in diesem Buch.

204 Schlegel: Goethes Hermann und Dorothea. S. 183-221, hier S. 207.
} 
inszeniert: Ist zunächst für beide Gattungen von einem vernehmenden Kreis die Rede, wird dieser in der Charakterisierung des Epischen dann zu einem Zuhörer-Kollektiv, im Dramatischen dagegen zu einem einzelnen HörerIndividuum. Das epische Erzählen wird damit, wie schon bei Herder und Wolf, auf seinen Ursprung in der oralen Tradition zurückgeführt, ${ }^{205}$ allerdings nicht so explizit auf den Gesang. Auch für Schlegel steht die ruhige Darstellung des Fortschreitenden in direktem Zusammenhang mit einer explizit mündlichen Medialität:

Bei allem Beschreiben ist die Arbeit für den, welcher redet, gering, für den Zuhörer aber sehr groß. Wird hingegen etwas in seiner Fortschreitung aufgefasst, so hebt und trägt die dem Gegenstände entsprechende Bewegung der Worte den empfangenden Geist, und an dieser, als Grundlage der gesamten Darstellung, entwickelt sich vom Simultanen, so viel als nötig ist, mit Leichtigkeit zu anschaulichen Bildern. ${ }^{206}$

Schlegel betont hier zunächst die unhintergehbare Sukzessivität jeglicher sprachlich verfassten Kunst sowie ihrer Rezeption und begründet damit auch für das epische Erzählen eine Darstellung des dynamischen Nacheinanders. Darüber hinaus verbindet er aber die medialen Voraussetzungen der Poesie im Allgemeinen mit den spezifischen Eigenheiten der Oralität im Gegensatz zur Literarizität. Mit der Forderung nach einer den Gegenständen entsprechenden Bewegung und der Charakterisierung einer spezifisch oralen Rezeptionssituation - der Epiker ist ein Sprechender, sein Gegenüber ein Zuhörer - beschränkt er die Zeichenabfolge im Epos auf eine der mündlichen Sprache gemäße Erzählgeschwindigkeit, die den ästhetischen Eindruck von Simultanität ermöglicht.

Besonders bemerkenswert scheint hier, dass er dabei die Aufmerksamkeit gezielt auf eine dem Hörer abgeforderte Leistung lenkt: Richtiges Zuhören Goethe und Schiller markieren eine ähnliche Differenz zwischen Hören und Horchen - ist Gedächtnisarbeit. Über diese heraufbeschworene Medialität von Sprechen und Zuhören wird das Epos bei Schlegel nicht zuletzt auch auf Sinnlichkeit ausgerichtet. „Die Begrenzung des Epos ist folglich sehr unbestimmt: die Erzählung kann fortgesetzt werden, solange der stetige Fortschritt nicht unterbrochen wird und der Umfang des Gedichtes nicht die Fassungskraft der Hörer übersteigt. “207 Das Fassungsvermögen der Einbildungskraft des Zuhörers gibt demnach die Begrenzung des Epos an. Die Herausforderung einer hier explizit

205 Vgl. S. 16 f. und 47 f. in diesem Buch.

206 Schlegel: Vom Epos (1801). S. 358-370, hier S. 359.

207 Ebd. S. 363. 
auralen ${ }^{208}$ Rezeption ist ungemein größer als die einer lesenden - das Gehörte muss ad hoc synthetisiert werden. Mit dem Arbeitsbegriff auf der Rezeptionsseite wird aber auch klar, dass das Epos auf ein entsprechend leistungsfähiges Publikum angewiesen ist, um diese Leistung als intellektuelles Werkzeug zu erbringen. Die epische Arbeit ist insofern eine wechselwirkende Kooperation zwischen Produzent, Text und Rezipient und entsprechend komplex. Dabei hebt Schlegel die Anregung zu einer sinnlichen Tätigkeit bedeutend stärker hervor als die zu einer rationalen und restituiert damit im Epos eine Sinnlichkeit, die in den übrigen Beiträgen zwar implizit mitschwingt, aber nicht derart explizit zur Sprache kommt.

Ein Blick auf die medienpoetologische Bestimmung bei Goethe und Schiller wird jedoch deutlich machen, dass die Emphase des sinnlichen Aspekts der auralen Rezeption als eigenständige Erkenntnisform durchaus wesentlich ist für alle Eposkonzepte der Epochenschwelle. Sie begründet nämlich eine weitere Entgegensetzung zum Roman, der, wie sich noch zeigen wird, keinerlei Anlage zu einer sinnlichen Tätigkeit, geschweige denn Erkenntnis bietet. Und gleichwohl rückt das Epos damit in Nähe der Novelle, die, wie Biere aufgezeigt hat, als ein "die Sinne herausforderndes Ereignis“209 ebenfalls einen Kontrast bildet zum Roman in der Tradition Blankenburgs, der sich vornehmlich als auf Moralität ausgerichtetes, "gutes Erzählen“210 ausnimmt. Im entscheidenden Unterschied zum Epos wird die Novelle aber gerade nicht auf einen eindeutig erschließbaren Sinn oder eine klare Bedeutung ausgelegt, sondern vielmehr auf Rätselhaftigkeit, wodurch ihr jegliche belehrenden oder sinnstiftenden Funktionen abgesprochen werden. ${ }^{211}$ Im Schwanken zwischen Sinnlichkeit und Vernunft oder vielmehr im doppelten Anspruch an das epische Erzählen, gleichwohl auf die unmittelbare sinnliche Wahrnehmung wie auch auf die rationale Reflexion zu wirken, werden Gleichzeitigkeit und Beweglichkeit auch auf der Ebene der Rezeption als die ausschlaggebenden, inneren Merkmale der Form aktualisiert. Darüberhinaus tritt mit der stärkeren Ausrichtung auf die sinnliche Vermittlungsleistung der Ästhetik im Sinn von aisthesis die tradierte Verbindung von Epos und Mythos in den Hintergrund und macht Platz für die moderne Vorstellung einer zwar verbindlichen,

208 Der Begriff der Auralität stammt aus der Filmwissenschaft und bezeichnet Wirkungsweisen, bei denen auf den Gehörsinn gerichtete, auditive Elemente im Zusammenspiel mit visuellen Elementen eine rezeptionsleitende Rolle übernehmen. Gemäß Goyet wird der Begriff mittlerweile auch in anderen Bereichen angewendet, vgl. Goyet: Über die Bedingungen der Möglichkeit eines ,Neugründungsepos'. S. 31-54, hier S. 37.

209 Biere: Das andere Erzählen. Zur Poetik der Novelle 180o/19oo. S. 194.

210 Ebd. S. 193.

211 Vgl. ebd. S. 122 und S. 197. 
aber immanenten Einrichtung der Welt. Insofern konstituiert sich der übergeordnete Weltzusammenhang, der das moderne Epische vermitteln soll, unter dem Aspekt der Gleichzeitigkeit von Sinnlichkeit und Rationalität nicht länger als ein transzendent-mythologischer, sondern vielmehr als ein realistisch-historischer.

Durch die Revitalisierung der lebendigen Sprache und das Beharren auf einer oralen, öffentlichkeitsherstellenden Rezeptionssituation erlangt das Epische die ihm schon seit jeher eingeschriebene kulturelle Kraft zur gesellschaftlichen Verbindlichkeit zurück, die die populären, zeitgemäßen Gattungen des Dramas und des Romans nicht herzustellen vermögen. Es wird aber auch entschieden neu ausgerichtet: Die zu leistende epische Arbeit bezieht sich im Epos der Sattelzeit dezidiert auf die Erscheinungen und Ereignisse der reale Erfahrungswelt ${ }^{212}$ und nicht mehr auf deren metaphysische Übersteigerung. Über den epischen Erzähler heißt es im Aufsatz Über epische und dramatische Dichtung wohl, dass „der Rhapsode [...] als ein höheres Wesen in seinem Gedicht nicht selbst erscheinen [sollte], er läse hinter einem Vorhange am allerbesten, so dass man von aller Persönlichkeit abstrahirte [sic] und nur die Stimme der Musen im Allgemeinen zu hören glaubte“.. ${ }^{213}$ Wenn Schiller und Goethe den epischen Erzähler hier als ein höheres Wesen bezeichnen, hat das aber nichts mit der Apotheose zu tun, wie sie etwa in der Homerrezeption des frühen 18. Jahrhunderts hatte beobachtet werden können. ${ }^{214}$ Vielmehr zielt diese Erzählerfiktion auf die diagnostizierte Krise der Kunst, wird darin doch die Idealvorstellung eines echten Künstlers artikuliert, der sich im Gegensatz zum Dilettanten von den problematischen Tendenzen des Zeitalters zu abstrahieren und ganz in den Dienst einer kulturstiftenden Kunst zu stellen vermag. Die Vorstellung vom Epos als poetischer Kulturbegründung, wie sie Winckelmanns Antikenbild zugrunde liegt, ${ }^{215}$ bleibt also auch für den Gattungsdiskurs der Epochenschwelle relevant, erfährt allerdings insofern eine entscheidene Modifizierung, als sie sich nicht mehr ausschließlich auf die idealisierte Antike richtet, sondern vielmehr auf die problematische Gegenwart.

Die Dichterfreunde entwerfen in dieser wohl meistzitierten Stelle zum klassizistischen Epos eine eigentümliche, komplexe und paradoxe Erzählerposition - während zuvor noch eindeutig von einem vortragenden

212 Vgl. Buschmeier: Poesie und Philologie in der Goethe-Zeit. Studien zum Verhältnis der Literatur mit ihrer Wissenschaft. S. 394.

213 Über epische und dramatische Dichtung, BW. S. 540.

214 Vgl. S. 44 in diesem Buch.

215 Vgl. S. 42 ff. in diesem Buch. 
Rhapsoden die Rede war, wird er nun als Lesender inszeniert, dessen Stimme zwar hörbar ist, aber nicht als seine eigene wahrgenommen wird. Einleitend handelt es sich noch um eine Regelformulierung für den Dichter, deren Status durch den Konjunktiv sogleich als unsicher markiert, durch die Verdoppelung aber wiederum bekräftigt wird. Dann kippt das Bild auf die Rezeptionsseite und macht hier Empfehlungen an den Zuhörer, die allerdings wiederum eine prekäre ,als ob'-Situation erzeugen. Diese Medienästhetik ist eine hochstilisierte und vor allem auch problematische Konstruktion, die wie bei Schlegel im Kern auf Oralität rekurriert. Allerdings gehört das öffentliche, mündliche Vorlesen im Zuge des oben beschriebenen medialen Wandels ${ }^{216}$ zu diesem Zeitpunkt bereits der Vergangenheit an und die stille Lektüre hat sich durch eine verstärkte Literarisierung als weitverbreitete Norm durchgesetzt ${ }^{217}$ - lautes Vorlesen findet, wenn überhaupt, nur noch im trauten Heim der bürgerlichen Kleinfamilie statt. Die Vorstellung eines Erzählers hinter dem Vorhang, der in der Öffentlichkeit spricht oder vorliest, scheint zunächst auf die fahrenden Sänger der griechischen Antike zu rekurrieren und erinnert darüber hinaus an Goethes begeisterte Beschreibung der lebendigen, interagierenden Kulturgemeinschaft Italiens. ${ }^{218}$ Damit verdeutlicht sich die grundlegende, kulturpolitische Ausrichtung des Epischen und es wird gleichwohl eine Kommunikationssituation entworfen, die unzeitgemäß, konservativ und vor allem, wie Lubkoll festhält, ${ }^{219}$ hoch artifiziell ist - sie beschwört eine idealisierte mündliche Tradition herauf, die es so nie gegeben hat und projiziert sie in eine konstruierte Vergangenheitsvorstellung hinein. Auch wenn sich die grecozentrische Antikenbegeisterung um 1800 auf einem einmaligen Höhepunkt befindet, muss dieser Rhapsode hinter dem Vorhang also eher seltsam anmuten.

Dass es in dieser Konstruktion dann auch gar nicht um das verzweifelte Konservieren einer verlorenen Mündlichkeit geht, sondern darin vielmehr ein Steuerungsversuch zu einer idealen, epischen Lektüre unternommen wird, hat Christians überzeugend nachgewiesen. Das dramatische „Hören“ auf den "Mimen“ erkennt er als dem Epischen entgegengestellte Romanlektüre, die das zeitgenössische stille Lesen als gefährlich problematisiert. ${ }^{220}$ In der

\footnotetext{
216 Vgl. S. 89 in diesem Buch.

217 Vgl. Lubkoll: Fingierte Mündlichkeit - inszenierte Interaktion. Die Novelle als Erzählmodell. S. $385 \mathrm{ff}$.

218 Vgl. S. 85 f. in diesem Buch.

219 Vgl. Lubkoll: Fingierte Mündlichkeit - inszenierte Interaktion. Die Novelle als Erzählmodell. S. 387 .

220 Christians: Der Traum vom Epos. Romankritik und politische Poetik in Deutschland (1750-200o). S. $132 \mathrm{f}$.
} 
Rekonstruktion einer oralen Produktions- und auralen Rezeptionssituation geht es also nur vordergründig um echte Mündlichkeit, tatsächlich wird eine medienästhetische Hierarchisierung von unterschiedlichen Leseverhalten betrieben, von denen das ideale auf einer zitierten Mündlichkeit beruht und als episch bezeichnet wird. Goethe und Schiller werden hier schon früh auf die Probleme der innerlichen Versprachlichung aufmerksam, die sich beim stummen Lesen von schriftlichen, prosaischen Texten neu ergeben ${ }^{221}$ - eine zum Schluss hindrängende, beschleunigte Lektüre und die daraus resultierenden Effekte von Überforderung und einer stillgestellten Einbildungskraft. Anhand der Gegenüberstellung von epischer und dramatischer Medialität verweisen sie auf die problematischen Konsequenzen einer privatisierten, stillen Lektüre - deren prototypische Gattung natürlich wiederum der Roman ist: die Loslösung der Kunst aus der Kultur und die Isolation des Individuums in einer kulturell entleerten Moderne.

Genau die gleiche Problematik illustriert auch Schlegel, wenn er eine abnehmende Toleranz gegenüber Wiederholungen konstatiert, die früher „vor dem Ohr des sinnlichen Hörers, das sie tönend füllten, leichter vorüberwallen: dem heutigen Leser (der nur allzu selten der Poesie Stimme zu geben oder sie auch nur zu hören versteht) möchten sie einförmig und ein unwillkommener Aufenthalt dünken“.222 Den so beklagten Verlust von Sinn - als auf Wiederholung angewiesene Erkenntnis - und Sinnlichkeit in der modernen Gegenwartskunst bezieht er ebenfalls auf einen lesenden, unterhaltungsorientierten Rezipienten. Bei Schlegel scheint aber das Zuhören eher die Qualität einer Herausforderung zu haben oder eine verlorene Gedächtniskompetenz zu sein und den Rezipienten also potenziell in die Pflicht zu nehmen, während bei Schiller und Goethe das Zuhören einer Freisetzung der Einbildungskraft gleichkommt, die den Rezipienten entlastet. Diese beiden Perspektiven schließen sich gegenseitig bei weitem nicht aus, vielmehr machen sie gerade in Kombination die gegenseitige Bemächtigung von Text und Rezipient sichtbar, die das Epos sowohl in der Antike wie auch in der Moderne konstituiert. Das medienästhetisch ausschlaggebende Merkmal des Epos ist eben, dass es die produktive und rezeptive Seite in ein integrales Verhältnis setzt, die epische Bewegungsfreiheit ist zugleich Privileg und Verpflichtung, die zu leistende Vermittlungsarbeit ist als eine gemeinschaftliche zu erbringen.

221 Ähnlich argumentiert Lubkoll in Bezug auf die Novelle: Deren gattungskonstitutive ,inszenierte Mündlichkeit' halte das mündliche Erzählen wach, sie tradiere es im Medium der Literatur, sie transformiere es aber auch und verleihe ihm neue Funktion, vgl. Lubkoll: Fingierte Mündlichkeit - inszenierte Interaktion. Die Novelle als Erzählmodell. S. 388.

Schlegel: Goethes Hermann und Dorothea. S. 183-221, hier S. 210. 
In der epischen Lektüreempfehlung wird der Leser vom internalisierten stillen Lesen abgelenkt und der zwar anwesende, aber unsichtbare Rhapsode wird in den Leser hineinprojiziert - dadurch liest der ,lesende Zuhörer' sich selbst vor bzw. horcht seiner eigenen inneren Stimme als die der ,Musen im Allgemeinen'. Den Versprachlichungsprozess als inneres Sprechen und Hören vorzustellen, erzeugt die positiv bewerteten Effekte von Entschleunigung, Objektivierung und Versinnlichung. Damit ist wiederum die Lizenz zur Bewegungsfreiheit - rationaler und sinnlicher - verbunden. Ausschlaggebend für eine solche in den Rezipienten hinein geschriebene, vorgestellte Mündlichkeit ist die Konzeption des Rhapsoden als Erzählerfigur, die jeglicher Subjektivität entbehrt. Schlegels epischer Dichter gibt „eine Darstellung der Außenwelt, wie sie aus einem durch keine teilnehmende Regung gestörten Geiste hervorgehen würde, und erhebt uns zu gleicher Besonnenheit der Betrachtung“'.23 Die Konjunktivformulierung lässt vermuten, dass Schlegel sich der Schwierigkeit oder vielmehr der Unmöglichkeit einer derartigen Erzählerposition wohl bewusst ist - eine narrative Darstellung kommt um Gewichtung und Hierarchisierung nie ganz herum. Die vom Epiker geforderte Gleichgültigkeit soll vielmehr dessen Individualität verwischen. Auch bei Goethe erscheint der Rhapsode als „höheres Wesen“ selbst nicht in seinem Gedicht, als körperlose Stimme ist er von aller Persönlichkeit abstrahiert. ${ }^{24}$ Diese Unbestimmtheit und Objektivität der Erzählinstanz macht überhaupt erst möglich, dass der Leser sich bei seiner zwar stillen, aber imaginiert lauten Lektüre an ihre Stelle setzen kann. Der Leser wird so selbst zum produktiven Künstler, er wiederholt und verinnerlicht im Lesen den kreativen, sinnlichen Schöpfungsprozess und erlangt so eine Kontrolle über den Text sowie die eigene Rezeption, die ihm im Dramatischen - und eben auch im Roman - vollständig verwehrt bleibt.

Unter diesen Voraussetzungen lässt sich für die Medialität des Epos eine Dynamik des spannungsvollen, unabgeschlossenen Hin- und Herschwankens zwischen Produktion und Rezeption beobachten. Die Trennung zwischen produktiver und rezeptiver Aneignung ist im Epischen aufgelöst bzw. obsolet, beides ereignet sich gleichzeitig im Akt des Lesens. Diese doppelte Bewegung ist konstitutiv für das Epos, darin liegt nämlich nicht nur die Bemächtigung des Lesers über den Text, sondern gerade auch die Umkehrung: Diese Art des Selbst-Vortrags in der Rolle des Rhapsoden setzt Wissen voraus, einerseits über den Text - denn für die geforderte objektive, gleichgültige Erzählhaltung muss eine gewisse Kenntnis oder Übersicht vorherrschen - und andererseits

223 Schlegel: Vom Epos (1801). S. 358-370, hier S. $35^{8}$.

224 Buschmeier: Poesie und Philologie in der Goethe-Zeit: Studien zum Verhältnis der Literatur mit ihrer Wissenschaft. S. 396. 
aber vor allem auch ein allgemeines, verbindliches Hintergrundwissen, das eine Kontextualisierung ermöglicht. ${ }^{225}$ Insofern setzt sich die bereits beobachtete Programmatik des bewussten Anschließens an die traditionelle Gattungsmerkmal - hier der mündlichen und öffentlichen Rezeption - und einer gleichzeitigen, spezifisch auf die Erfahrung der Moderne verweisenden Modifizierung dieser Merkmale - die Verlagerung in einen allein und stumm lesenden Rezipienten - auch auf der medienästhetischen Ebene der Eposdebatte fort. Der mediale Paradigmenwechsel der Moderne wird darin allerdings einer kritischen Neubewertung unterzogen und mit der Installation einer sinnlichen, auf die selbsttätige Einbildungskraft zurückgreifenden Erkenntnis konfrontiert.

\subsubsection{Reintegration der Kunst in die Kultur durch das Epische}

Dem epischen Erzählen, wie es im übergreifenden Gattungsdiskurs der Epochenschwelle konstituiert wird, muss auch in medienpoetologischer Hinsicht eine eindeutige formale Bestimmung im Sinne traditioneller Gattungstheorie abgesprochen werden. Während die Dramenkonzeption auch medienästhetisch mehr oder weniger eng gefasst ist, wird das Epische sowohl bei Goethe und Schiller als auch bei Schlegel durchwegs auf eine paradoxe Überblendung von Produktions- und Rezepetionsseite, Oralität und Literarizität ausgerichtet. In dieser zutiefst unklassizistischen Verschränkung von scheinbar disparaten Materialien liegt allerdings zum einen die Errungenschaft eines in die Gesellschaft (re)integrierten Künstlers begründet, der auch nach der Auflösung des traditionellen Auftragsverhältnis noch in einem produktiv-vermittelnden Austausch mit seiner Leserschaft steht. Zum anderen entsteht die entsprechend positive Konzeption eines Lesers, der Interesse an einer lebendig-poetischen Kunst hat, die zur eigenen, geistigen Tätigkeit einlädt und nicht primär auf Unterhaltung abzielt, im Gegensatz zu den modernen „Menschen[, die] jede interessante Situation gleich in Kupfer gestochen sehen [wollen], damit nur ja ihrer Imagination keine Thätigkeit [sic] / übrig bleibe so soll alles sinnlich wahr vollkommen gegenwärtig dramatisch seyn [sic] und das dramatische selbst soll sich dem wirklich wahren völlig an die Seite

225 Goyet sagt, dass der Aspekt des Hörens, also das Aufnehmen des Gesagten, früher stärker gewichtet wurde als die mündliche Produktion. In der Forschung herrscht darüber keine Einigkeit, gesichert ist aber, dass vor dem Kollektiv vorgetragen wurde. Das hat Konsequenzen für einen Text. Er muss die Anwesenden mit einbeziehen, ihre Erwartungen erfüllen - er verändert sich von Vortrag zu Vortrag - das Publikum gestaltet den Text mit, vgl. Goyet: Über die Bedingungen der Möglichkeit eines ,Neugründungsepos. S. 31-54. 
stellen“.226 Im Epischen wird so die aufgebrochene Verbindung zwischen Kunst und Kultur, über die Wissen überliefert und verbindliche Vorstellungen von Geschichte und Kultur, von politischer und sozialer Zugehörigkeit vermittelt werden können, wiederhergestellt oder zumindest in Aussicht gestellt. Es ist diese integrative, rückversichernde und identitätsstiftende Funktion des Epischen, die am Beginn des 20. Jahrhunderts so vehement zurückgefordert wird für die Gegenwartsliteratur und sie ist auch das primäre Anliegen der romantischen Kunst, wie deren Charakterisierung durch Schlegel aufzeigt:

\begin{abstract}
Nur sie [die romantische Kunst] kann gleich dem Epos ein Spiegel der ganzen umgebenden Welt, ein Bild des Zeitalters werden. Und doch kann auch sie am meisten zwischen dem Dargestellten und dem Darstellenden, frei von allem realen und idealen Interesse auf den Flügeln der poetischen Reflexion in der Mitte schweben, diese Reflexion immer wieder potenzieren und wie in einer endlosen Reihe von Spiegeln vervielfachen. Sie ist der höchsten und der allseitigsten Bildung fähig; nicht bloß von innen heraus, sondern auch von außen hinein; indem sie jedem, was ein Ganzes in ihren Produkten sein soll, alle Teile ähnlich organisiert, wodurch ihr die Aussicht auf eine grenzenlos wachsende Klassizität eröffnet wird.227
\end{abstract}

In der medialen Kipp-Konstellation kann die Vermittlungsleistung einer versichernden, kulturstiftenden Kunst vom geneigten, gern und lang zuhörenden` Leser selbst erbracht werden, indem er den stillen Leseakt als ruhigen Vortrag vor sich selbst imaginiert: Episches Lesen ist Kulturpraxis.. ${ }^{28}$ Damit wird das Bild einer idealen Leserschaft, einer durch die kulturstiftende Kunst im Leseakt verbundenen, utopischen Gemeinschaft vorgestellt: Die Kulturnation. Diese Idee einer kulturell hergestellten Kollektiv-Identität entspricht dem Identitätsentwurf des Bildungsbürgertums, das sich zu diesem Zeitpunkt aber gerade erst von der aristokratischen Obrigkeit abzugrenzen und zu formieren beginnt. ${ }^{229}$ Das Epos-Projekt ist also wesentlich an der Herstellung und Vermittlung von gesellschaftlichen Idealvorstellungen beteiligt, und zwar bevor diese realhistorisch evident werden.

226 Goethe an Schiller, 23.12.1797, BW. S. 535 f.

227 KFSA I, 2. S. $182 \mathrm{f}$.

228 Ähnlich beschreibt Biere die medienästhetische Vortragssituation der ,Unterhaltungen deutscher Ausgewanderter, vgl. Biere: Das andere Erzählen. Zur Poetik der Novelle 1800/190o. S. $65^{-197 .}$

229 Vgl. S. 15 in diesem Buch. Auch Lubkoll stellt eine Verbindung her zwischen der fingierten Mündlchkeit - allerdings der Novelle - und dem Bildungsprogramm der ,ästhetischen Eziehung, vgl. Lubkoll: Fingierte Mündlichkeit - inszenierte Interaktion. Die Novelle als Erzählmodell. S. 391. 
Im Epos scheint es daher gar nicht unbedingt um das Konservieren von alten, gefestigten Strukturen - gesellschaftlichen oder ästhetischen - zu gehen, sondern vielmehr um das Potenzial, neue zu generieren, die mit den bestehenden bzw. sich ablösenden Konzepten aber noch in Beziehung stehen und insofern eine breite, kontinuierliche Entwicklung erfahrbar machen. Während das alte Epos tatsächliche Volksdichtung war ${ }^{230}$ - es wurde an öffentlichen Plätzen vorgetragen und vereinte so die verschiedenen Stände in einer gemeinsamen Rezeption zu einem Kollektiv-, findet in der neuzeitlichen Eposdebatte eine entscheidende Beschränkung bzw. eine Differenzierung und Hierarchisierung in ein ,episches' und ein ,dramatisches' Publikum statt. Das Epische rekurriert zwar auf die mit der mündlichen Medialität verbundene Herstellung von Öffentlichkeit und Kollektivität - die zitierte bzw. fingierte ${ }^{231}$ Oralität steht dafür ein, dass die kollektiv erbrachte, epische Arbeit zur Lösung der gegenwärtigen Krise der Kunst taugt, hier kann noch oder wieder ein gesellschaftlicher Gesamtzusammenhang hergestellt werden. Daran kann aber, wie die vorhergegangenen Bemerkungen zur Entwicklung des Kulturbegriffs $^{232}$ gezeigt haben, in frühmodernen Zeiten nicht mehr die ganze Menschheit bzw. das ganze Volk teilnehmen, sondern nur eine bestimmte Gruppe, die bestimmte Anlagen mitbringt - das ist mit Schiller gesprochen nicht das "gemeine[...] Volk der Beurtheiler [sic] “233, sondern die als kunstaffin imaginierte Bürgerlichkeit. Mit dieser Wendung auf einen realistischobjektiven Weltbezug wird das Epische noch einmal zum Medium einer intakten Kulturgesellschaft und insofern zur Hoffnung, die kulturkritische Gegenwartsdiagnose ins Positive zu wenden.

Das epische Schwanken, das sich bis hierhin als die ganze Konzeption vielfältig durchdringende, ambivalente Grundbewegung gezeigt hat, lässt sich in Bezug auf seine soziale Funktion als Denkweise oder vielmehr als empfohlene Leseweise verstehen, die das kollektive, interagierende Gemeinschaftsbewusstsein als natürliche Grundlage der Gesellschaft aufrechterhält, trotz der (historischen) Einsicht in dessen Erosionserscheinungen und Verdrängung

230 In einer echten Mündlichkeitssituation ist es so, dass alle den Text kennen, ihn auswendig können, so sehr vertraut mit dem Text sind, dass jede Leerstelle aufgefüllt werden kann, überall ein- oder abgesetzt werden kann: Ein Rezipient, der im Geiste immer über den ganzen Text verfügt. Die Rezipienten Moderne sind das nicht gewohnt durch ihr linear ausgerichtets Aufnehmen, oder eben auch nicht dazu geneigt - der Zusammnehang einer langen Erzählung wird aus den Augen verloren.

231 Im Anschluss an den Begriff, wie ihn Lubkoll benutzt, vgl. Lubkoll: Fingierte Mündlichkeit inszenierte Interaktion. Die Novelle als Erzählmodell. S. 381-402.

232 Vgl. S. 81 f. in diesem Buch.

233 Schiller an Goethe, 2.7.1796, BW. S. 209. 
durch ein nach Innen gekehrtes, isoliertes Subjekt. ${ }^{234}$ In dieser Zurichtungsbemühung zeigt sich deutlich, dass dem Epos eine soziale Tragweite zukommt, die nicht auf die Vermittlung von Komplexen wie Volk oder Nation reduziert werden kann, sondern ein genuin kulturell begründetes Gemeinschaftsmodell entwirft, das dem Modell der individualisierten und rationalisierten Gesellschaft entgegensteht. Darin wird eine komplexe Verschränkung von Privatem und Öffentlichem, von subjektiver Erfahrung und historischer Dimension, von innerer Geschichte und Weltgeschichte mit einem Glücksversprechen verbunden: Im Epos scheint aufgrund seiner besonderen formalen und medialen Ausrichtung auf Entschleunigung und Sinnlichkeit die narrative Vermittlung einer rücksichernden Erfahrung von Ganzheit, Begreifbarkeit und Stabilität möglich, die in der kontingenten, beschleunigten Gegenwart bzw. den zeitgemäßen Dichtungsformen nicht mehr realisierbar ist. Mit Rückblick auf Goethes Kulturprogramm sowie seinen morphologischen Formbegriff und den darin sichtbar gemachten Zeitreflexionen ${ }^{235}$ darf wohl davon ausgegangen werden, dass es ihm auch im gemeinsam mit Schiller entworfenen Eposkonzept ganz bewusst darum ging, das Vergangene mit dem Gegenwärtigen zu vermitteln, also einerseits daran zu erinnern, was dem Gegenwartsbewusstsein entgeht, und andererseits aber auch auf eine zukünftige Entzifferung hinzuführen. Durch die spezifische Lizenz, zwischen den Zeiten zu vermitteln, sind im Epischen gleichzeitig bewahrende Erinnerung, trauernde Verabschiedung und utopisches Offenhalten enthalten. ${ }^{236}$

Genau das vermögen die zeitsensitiven Konzepte der modernebegeisterten Romantiker eben nicht zu leisten - und in der obigen Schlegel-Stelle zeigt sich das deutlich -, sind sie doch mehrheitlich in eine Richtung ausgerichtet: in die Zukunft. Auch dort, wo für epische Stetigkeit und Gleichmäßigkeit plädiert

234 Vgl. Willems, Gottfried: „Ihr habt jetzt eigentlich keine Norm, die müsst ihr euch selbst geben“. Zur Geschichte der Kanonisierung Goethes als „klassischer deutscher Nationalautor". S. 103-134. Eine neue Sicht der Gesellschaft und des Individuums, bzw. geradezu deren Entdeckung durch die Aufklärung, definiert er als Kristallationspunkt des spezifischen Antiken- und Gattungsdiskurses der Sattelzeit. Bezüglich des Individuums begreife die Aufklärungen den Einzelnen zunächst als Subjekt der Erfahrung, dann als Ich, das sich seiner selbst, der eigenen Existenz vergewissern will (in inneren und äußeren Erlebnissen). Daraus folgt auch eine nach innen gerichtete, subjektiv-erlebnishafte Dichtung, die mit dem antiken, sich auf Regeln und Gesetze berufenden Kunstverstand in Konflikt gerät, vgl. ebd. S. 112 f.

235 Vgl. Kap. 3: Erschütterung der Wissenssysteme und methodische Neuansätze.

236 Böhme argumentiert ebenfalls für ein bewusst auf Erinnerung angelegtes Zeitbewusstsein Goethes, allerding in anderem Zusammenhang, vgl. Böhme, Hartmut: Lebendige Natur. Wissenschaftskritik, Naturforschung und allegorische Hermetik bei Goethe. In: Ders. (Hrsg.): Natur und Subjekt. Frankfurt a. M.: Suhrkamp 1988. S. 145-178, hier S. $15^{1}$ f. 
wird, bleibt das Zeitmoment linear nach vorne ausgerichtet. Das kommt einer Verdrängungskultur gleich, deren Glück sich gezwungenermaßen stets in die Unendlichkeit von Raum und Zeit davonstiehlt. Bei Goethe dagegen eröffnet sich die Vorstellung eines glücklichen Zustands in der Zukunft aber gerade dank der verankernden Kraft des vergegenwärtigenden Erinnerns ${ }^{237}$ und er richtet das Epos als schwankende Erinnerungsspur damit bewusst gegen die verdrängenden, vergessenden und zensurierenden zeitgenössischen Tendenzen aus. Darauf, dass für Goethe die Rückwendung in die Antike auf den Boden der Gegenwart führt und damit Wege in die Moderne öffnet, hat auch schon Willems aufmerksam gemacht: Es sei gerade das Ringen um Modernität, was für Goethe die Antike so interessant mache ${ }^{238}$ - mit einer konservativer Haltung, die sich auf das antike Erbe als einen Hort absoluter Normen verpflichtet fühlt, hat das aber, wie wir gesehen haben, nichts zu tun.

Nicht zuletzt ist darin auch eine politische Dimension aufzuspüren. Goethes Bemerkung über Hermann und Dorothea, dass er darin "was das Material betrifft, den Deutschen einmal ihren Willen gethan [sic] habe und [sie] [nun] äusserst zufrieden“239 seien, kann in diesem Zusammenhang durchaus als Hinweise darauf gelesen werden, dass es bei dem darin entworfenen Gesellschaftsbild des Bildungsbürgertums um eine gezielte Vorverständigung aufgrund fehlender gesellschaftlich-kultureller Rückbindung geht. Das kommt dem Anfüllen einer gegenwärtigen Leerstelle im Sozialgefüge gleich, ${ }^{240}$ das sich gleichzeitig auf das alte, bekannte Gemeinschaftsmodell bezieht und die neue, auf dem Individuum gründende Gesellschaftsform integriert. ${ }^{241}$ Ein nationales Sendungsbewusstsein, wie es die spätere Kanonisierung ihrem Nationaldichter

237 Vgl. Böhme: Lebendige Natur. Wissenschaftskritik, Naturforschung und allegorische Hermetik bei Goethe. S. $145^{-178}$, hier S. $15^{2}$.

238 Vgl. Willems: „Ihr habt jetzt eigentlich keine Norm, die müsst ihr euch selbst geben“. Zur Geschichte der Kanonisierung Goethes als „klassischer deutscher Nationalautor“. S. 103134, hier S. 128.

239 Goethe an Schiller, 3.1.1798, BW. S. 55०.

240 Harth bestätig das: Nicht selten werden die Voraussetzungen für das Neue lange vor dem Umbruch des gesellschaftlichen Systems auf kultureller Ebene geschaffen, vgl. Harth, Dietrich: Zerrissenheit. Der deutsche Idealismus und die Suche nach kultureller Identität. In: Assmann, Jan; Hölscher, Tonio (Hrsg.): Kultur und Gedächtnis. Frankfurt a. M.: Suhrkamp 1988. S. 220-240, hier S. 222. Und auch Benedict Anderson schreibt: „In der Tat sind alle Gemeinschaften, die größer sind als die dörfliche mit ihren Face-to-faceKontakten, vorgestellte Gemeinschaften." Vgl. Anderson, Benedict R. O'G: Die Erfindung der Nation. Zur Karriere eines folgenreichen Konzepts, aus dem Engl. von Benedikt Burkard. Frankfurt a. M.: Campus-Verlag 1993. S. 15.

241 So argumentiert auch Lubkoll. Inwiefern literarische Formen um 1800 als Experimentierraum für soziale und ästhetische Ordnungen fungieren, zeigt sie eindrücklich an Kleist Novellenpoetik, vgl. Lubkoll: Soziale Experimente und ästhetische Ordnung. In: 
anlastet, lässt sich aber durch die hier dargestellten soziokulturellen Funktionen, die dem Epischen eingeschrieben werden, nicht ausmachen - der Bürger bleibt auch hier, wie an anderen Stellen in Goethes Werk, ${ }^{242}$ immer ein Weltbürger im Sinne des Kosmopolitischen. ${ }^{243} \mathrm{Im}$ medienpoetologischen Gesellschaftsentwurf des Eposkonzepts wird die zwar produktive, aber eben auch gefährliche - politisch nämlich durchaus höchst brisante (Stichwort: Französische Revolution) - Lizenz zur freien Bewegung der stillen Lektüre mit einer Reduktion kontrastiert: Das epische Erzählen entfaltet seine kulturstiftende Kraft in der Moderne nicht mehr im öffentlichen Plenum der Gesamtbevölkerung, sondern in den Individuen, die zur entsprechenden Rezeption in der Lage sind - den gebildeten, geduldigen Bürgern. Es kann um 1800 aber auch die Forderung nach einer allumfassenden, kulturstiftenden Kunst schlicht nicht mehr aufrechterhalten werden, diese integrative Qualität wird nun spezifisch ins Epische gerettet:

Es gibt leidenschaftliche, rhetorische und mimische Erzählungen, die epische hingegen ist unparteiisch, und von keinen Äußerungen der Teilnahme unterbrochen; sie sucht durch Anschaulichkeit, aber nicht durch Verstärkung und Übertreibung zu wirken, und endlich nimmt sie zwar die Reden der handelnden Personen in sich auf, aber nicht so, dass der Erzähler sich ganz in diese versetzt und sich selbst darüber verlöre, sondern er bildet sie zur Gleichartigkeit mit den übrigen Teilen der Erzählung um. ${ }^{244}$

Im Epos soll nicht über die verunsichernden Erfahrungen von unübersichtlicher Pluralität, fragmentierter Vereinzelung und chaotischer Beschleunigung hinweggetäuscht werden. Es versucht ihnen vielmehr beizukommen, indem es sie gleichzeitig ausstellt und mit ihren Gegenpolen aus einer früheren Zeit in eine schwankende Wechselbeziehung setzt. So scheint im Epos die Hoffnung auf, durch die modernespezifische Erneuerung der alten, kulturstiftenden Formen - der gesellschaftlichen und der ästhetischen - die gegenwärtige Krise lösen zu können und zugleich wird die Prekarität dieses Unternehmens zum Ausdruck gebracht. Auf der Ebene des Gesellschaftsentwurfs werden

Dies.; Oesterle (Hrsg.): Gewagte Experimente und kühne Konstellationen. Kleists Werk zwischen Klassizismus und Romantik. S. 120.

242 In den Xenien von Goethe und Schiller. S. 69. „Deutscher Nationalcharakter: Zur Nation euch zu bilden, ihr hoffet es, Deutsche, vergebens; Bildet, ihr könnt es, dafür freier zu Menschen euch aus“, zitiert nach Schiller: Sämtliche Werke, Bd. 1. S. 267.

243 Willems: „Ihr habt jetzt eigentlich keine Norm, die müsst ihr euch selbst geben“. Zur Geschichte der Kanonisierung Goethes als „klassischer deutscher Nationalautor“. S. 103134, hier S. 129.

244 Schlegel: Vom Epos (1801). S. 358-370, hier S. 361. 
unterschiedliche, gleichzeitig wirksame soziale Ordnungssysteme - das individuelle und das kollektive - überblendet und in eine unauflösliche Ambiguität geführt, die die darin angelegte Idee des Bürgertums als erstaunlich (welt-)offen ausweisen. Vom hegelschen Epos als Darstellung der „totalen Welt einer Nation“245 ist das Epische der Epochenschwelle damit weit entfernt. In diesem werden gerade die Spannung zwischen Ideal und Realität, Normativität und Historizität sichtbar gemacht bzw. als unabgeschlossener kultureller Verhandlungsprozess aufgezeigt, der sich bevorzugt im epischen Erzählen abspielt.

\footnotetext{
245 Hegel, Georg Wilhelm Friedrich: Vorlesungen über die Ästhetik III. S. 33 O.
} 